\title{
Expeditious Access to Spiro-fused 2,5-Cyclohexadienones via Thio(seleno)cyanative ipso-Cyclization
}

Chada Raji Reddy, ${ }^{*, a, b}$ Uprety Ajaykumar $^{\text {a,b }}$ and Dattahari H. Kolgave ${ }^{a, b}$

${ }^{\mathrm{a}}$ Department of Organic Synthesis \& Process Chemistry

CSIR-Indian Institute of Chemical Technology (CSIR-IICT), Hyderabad 500007, India

${ }^{\mathrm{b}}$ Academy of Scientific and Innovative Research (AcSIR), Ghaziabad 201002, India

E-mail: rajireddy@iict.res.in

Table of Contents

\begin{tabular}{|l|l|}
\hline 2. Structures of propiolamides and propiolates. & $\mathrm{S}_{2}$ \\
\hline 3. Control Experiment - procedure & $\mathrm{S}_{3}$ \\
\hline $\begin{array}{l}\text { 3. }{ }^{1} \mathrm{H} \text { NMR, }{ }^{13} \mathrm{C} \text { NMR and }{ }^{19} \mathrm{~F} \text { NMR spectral copies of all new } \\
\text { compounds }\end{array}$ & $\mathrm{S}_{4}-\mathrm{S}_{90}$ \\
\hline
\end{tabular}


Structures of Starting materials: $N$-Propiolamides and $N$-propiolates<smiles>COc1ccc(N([14CH3])C(=O)C#Cc2ccccc2)cc1</smiles><smiles>[R]c1ccc(C#CC(=O)N(C)c2ccc(OC)cc2)cc1</smiles>

1b, $\mathrm{R}=\mathrm{Me}$

1c, $\mathrm{R}=\mathrm{OMe}$

1d, $R=F$

$1 \mathrm{e}, \mathrm{R}=\mathrm{Cl}$

1f, $\mathrm{R}=\mathrm{NO}_{2}$

$1 \mathrm{~g}, \mathrm{R}=\mathrm{CN}$

1h, $\mathrm{R}=\mathrm{COCH}_{3}$<smiles>COc1ccc(N(C)C(=O)C#Cc2cc(C)cc(C)c2)cc1</smiles><smiles>COc1ccc(N(C)C(=O)C#Cc2cccc(C(F)(F)F)c2)cc1</smiles><smiles>COc1ccc(N(C)C(=O)C#Cc2cccc3ccccc23)cc1</smiles><smiles>COc1ccc(N(C)C(=O)C#Cc2cccs2)cc1</smiles><smiles>[R]C#CC(=O)N(C)c1ccc(OC)cc1</smiles>

1n, $R=E t$<smiles>COc1ccc(N(CC(=O)c2ccccc2)C(=O)C#Cc2ccccc2)cc1</smiles><smiles>COc1ccc(N(Cc2ccccc2I)C(=O)C#Cc2ccccc2)cc1</smiles><smiles>COc1ccc(N(C)C(=O)C#Cc2ccccc2)c(C)c1</smiles>

$1 \mathrm{r}$<smiles></smiles>

1s<smiles>COc1ccc(OC(=O)C#Cc2cc(C)cc(C)c2)cc1</smiles>

$5 d$<smiles>COc1ccc(OC(=O)C#Cc2cccc3ccccc23)cc1</smiles>

$5 e$<smiles>COc1ccc(N(C)C(=O)C#Cc2ccccc2)cc1F</smiles>

1t<smiles>[R]c1ccc(C#CC(=O)Oc2ccc(OC)cc2)cc1</smiles>

5a, $\mathrm{R}=\mathrm{H}$

5b, $\mathrm{R}=\mathrm{Cl}$

5c, $\mathrm{R}=\mathrm{COCH}_{3}$ 


\section{Control Experiment with 2,2,6,6-tetramethylpiperidin-1-yl)oxidanyl (TEMPO):}
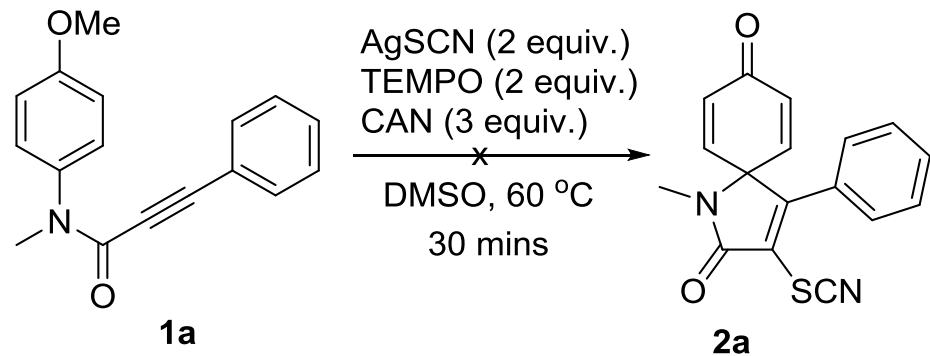

$N$-(4-Methoxyaryl)-propiolamide $1 \mathbf{a}(50 \mathrm{mg}, 0.19 \mathrm{mmol})$, Silver thiocyanate $(64 \mathrm{mg}, 0.38$ mmol), 2,2,6,6-tetramethylpiperidin-1-yl)oxidanyl (TEMPO) (59 mg, $0.38 \mathrm{mmol})$ and Ceric Ammonium Nitrate $(308 \mathrm{mg}, 0.57 \mathrm{mmol}$ ) were taken in a reaction vial and $3 \mathrm{~mL}$ of DMSO was added. The reaction mixture was stirred at $60{ }^{\circ} \mathrm{C}$ (oil bath temperature) for 30 minutes and the progress of the reaction as monitored by TLC was found to be inhibited. 


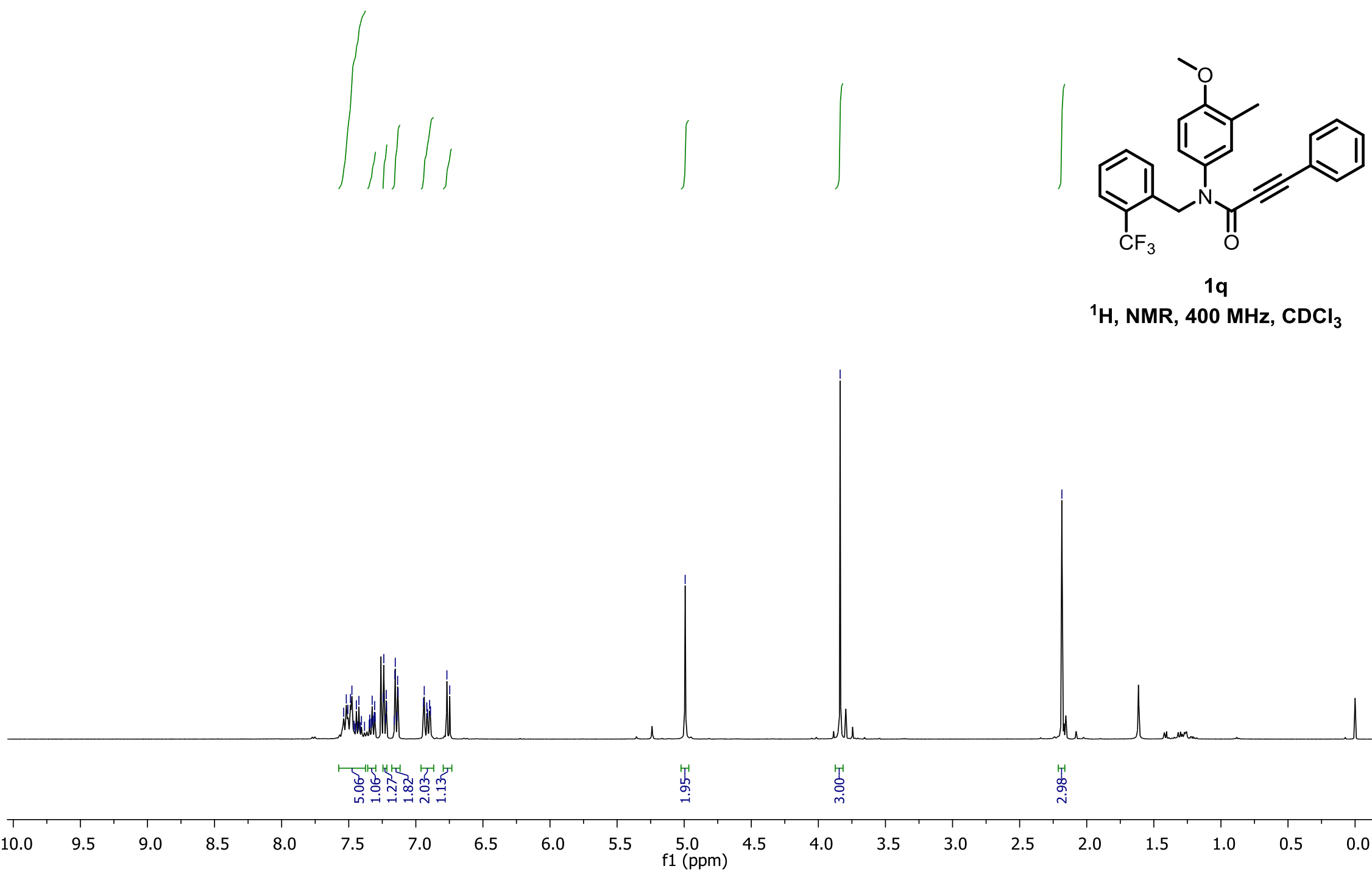




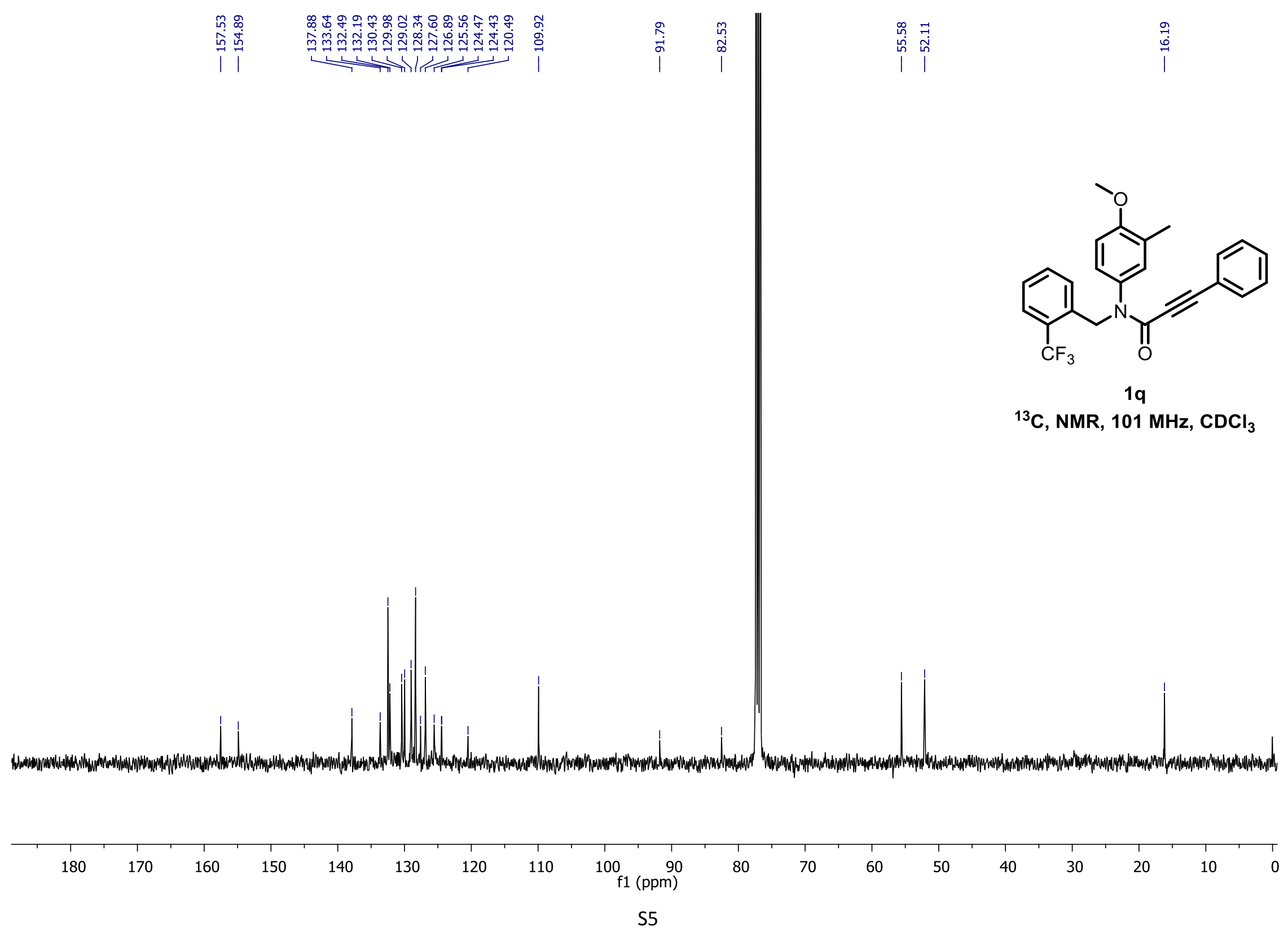




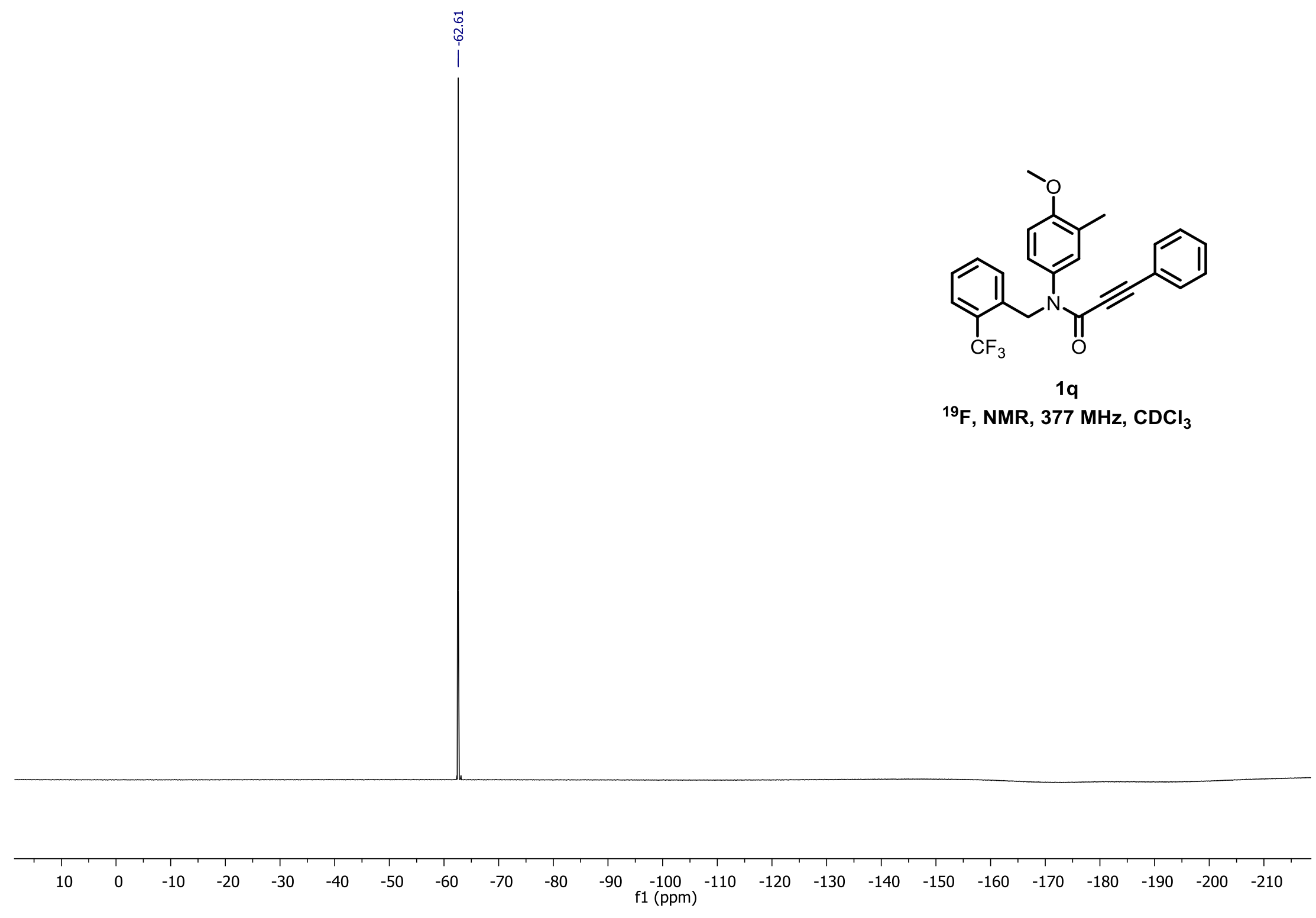




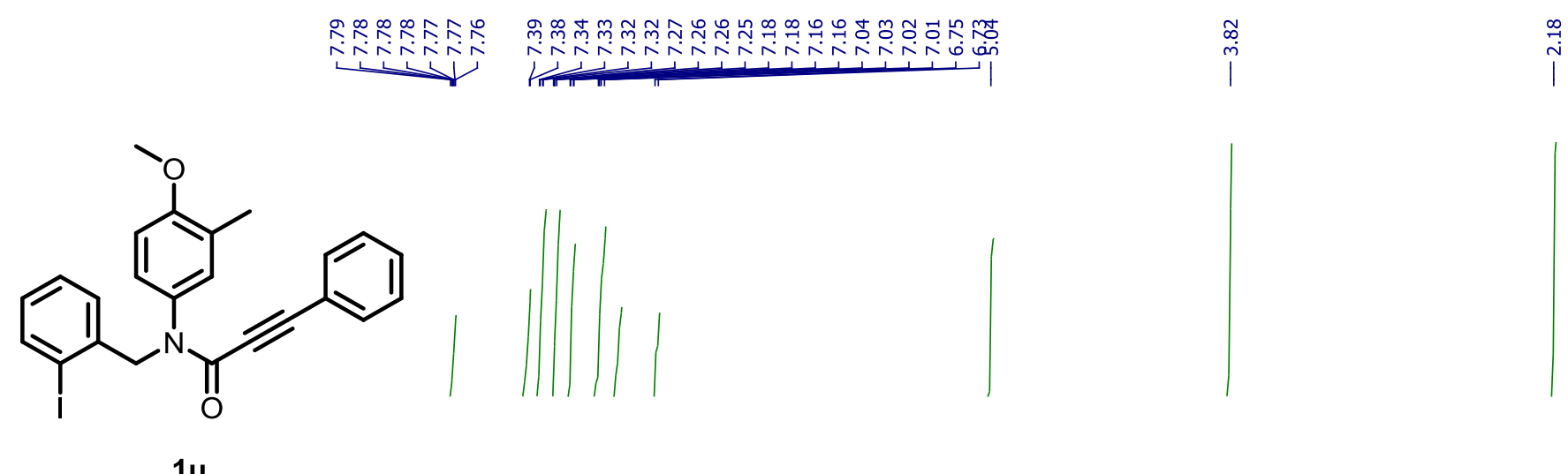

${ }^{1} \mathrm{H}, \mathrm{NMR}, 500 \mathrm{MHz}, \mathrm{CDCl}_{3}$

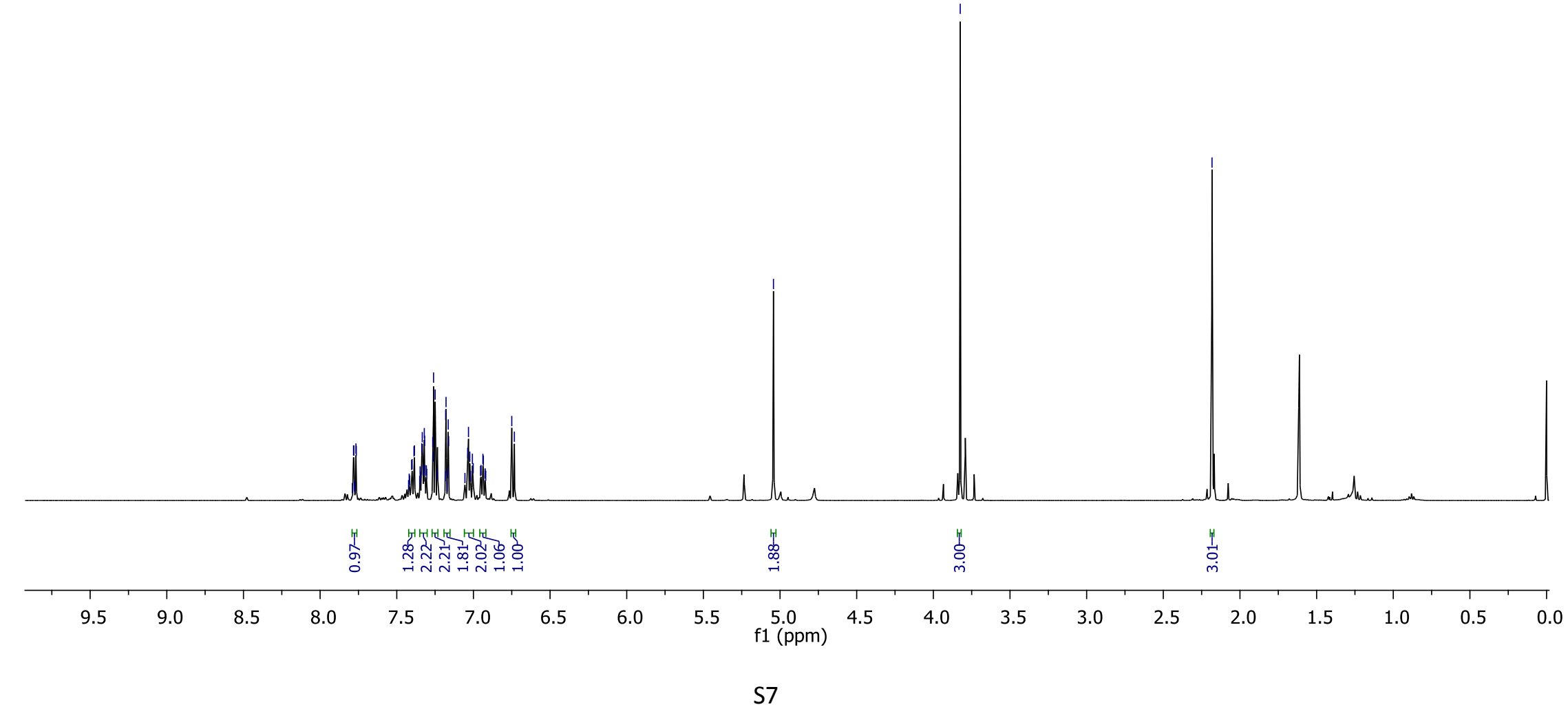




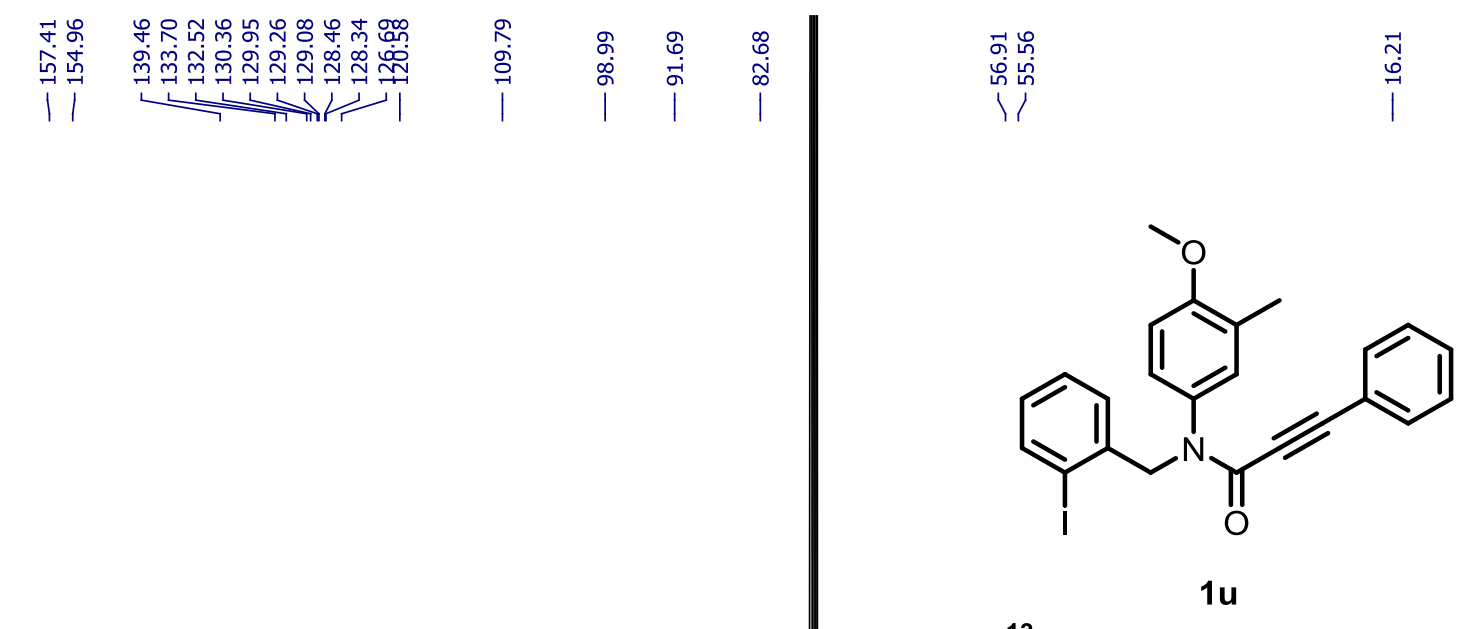

${ }^{13} \mathrm{C}, \mathrm{NMR}, 101 \mathrm{MHz}, \mathrm{CDCl}_{3}$

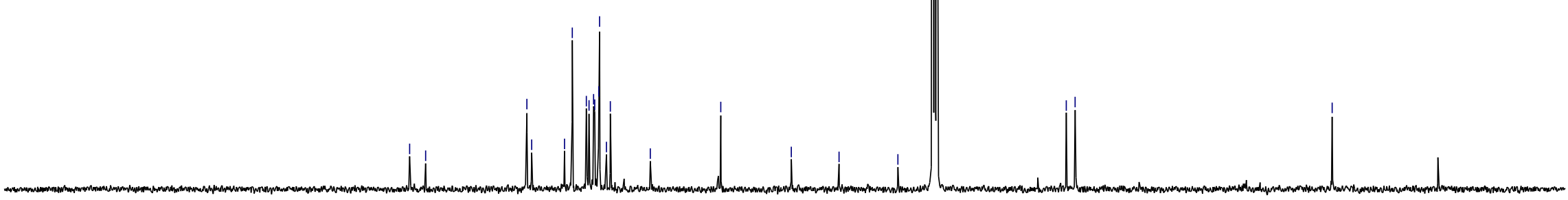

$\begin{array}{lllllllllll}210 & 200 & 190 & 180 & 170 & 160 & 150 & 140 & 130 & 120 & 110\end{array}$ 


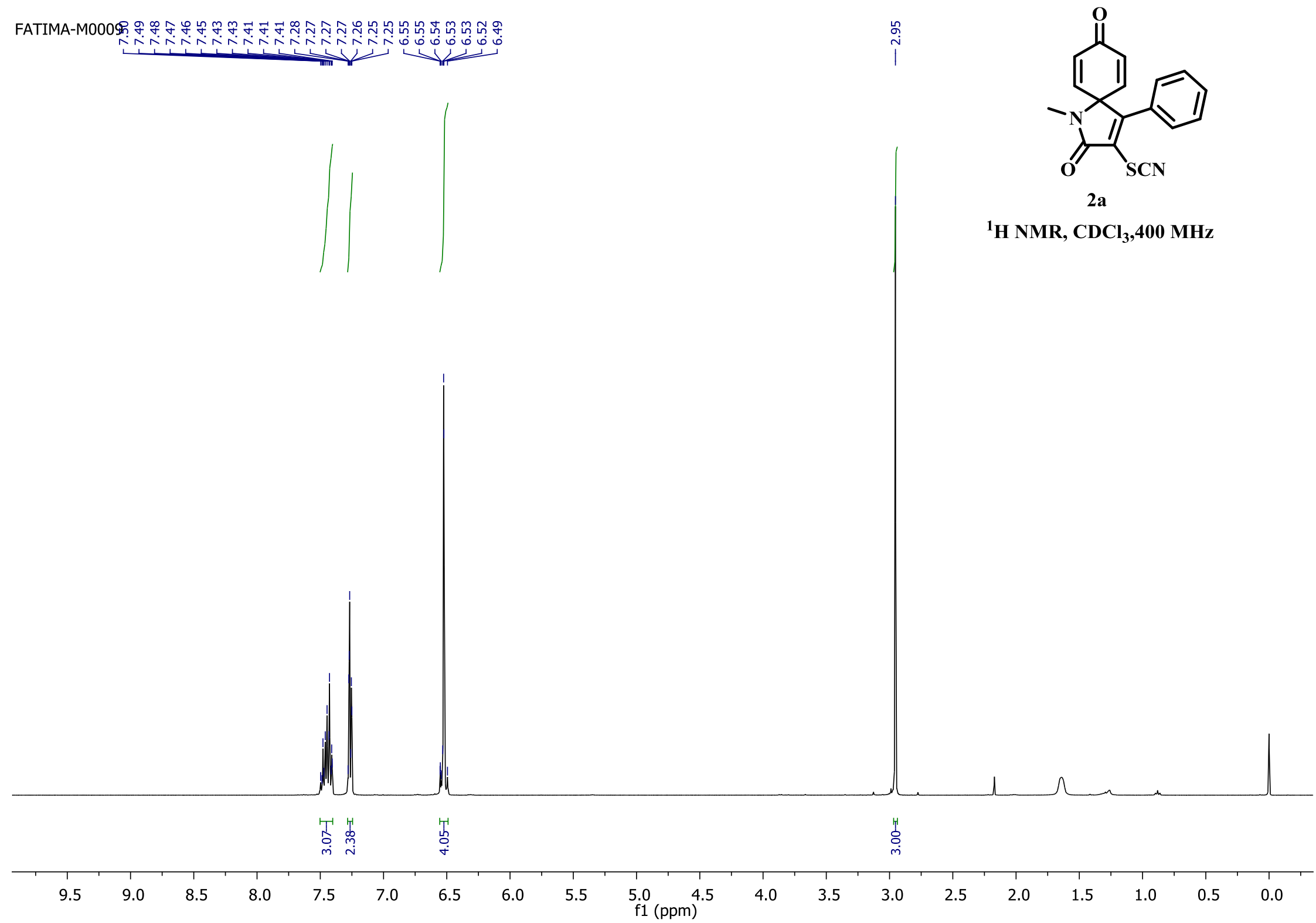




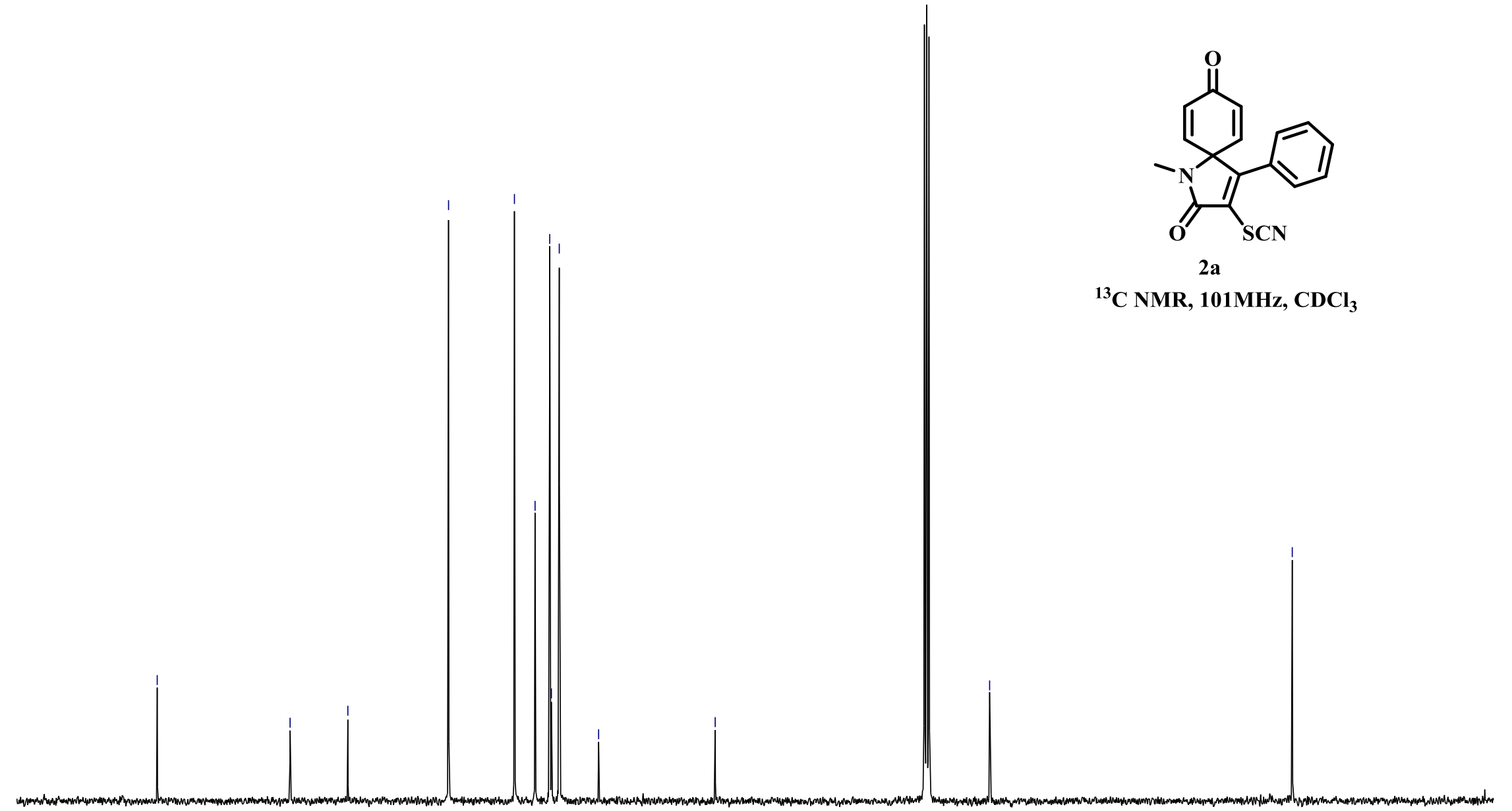




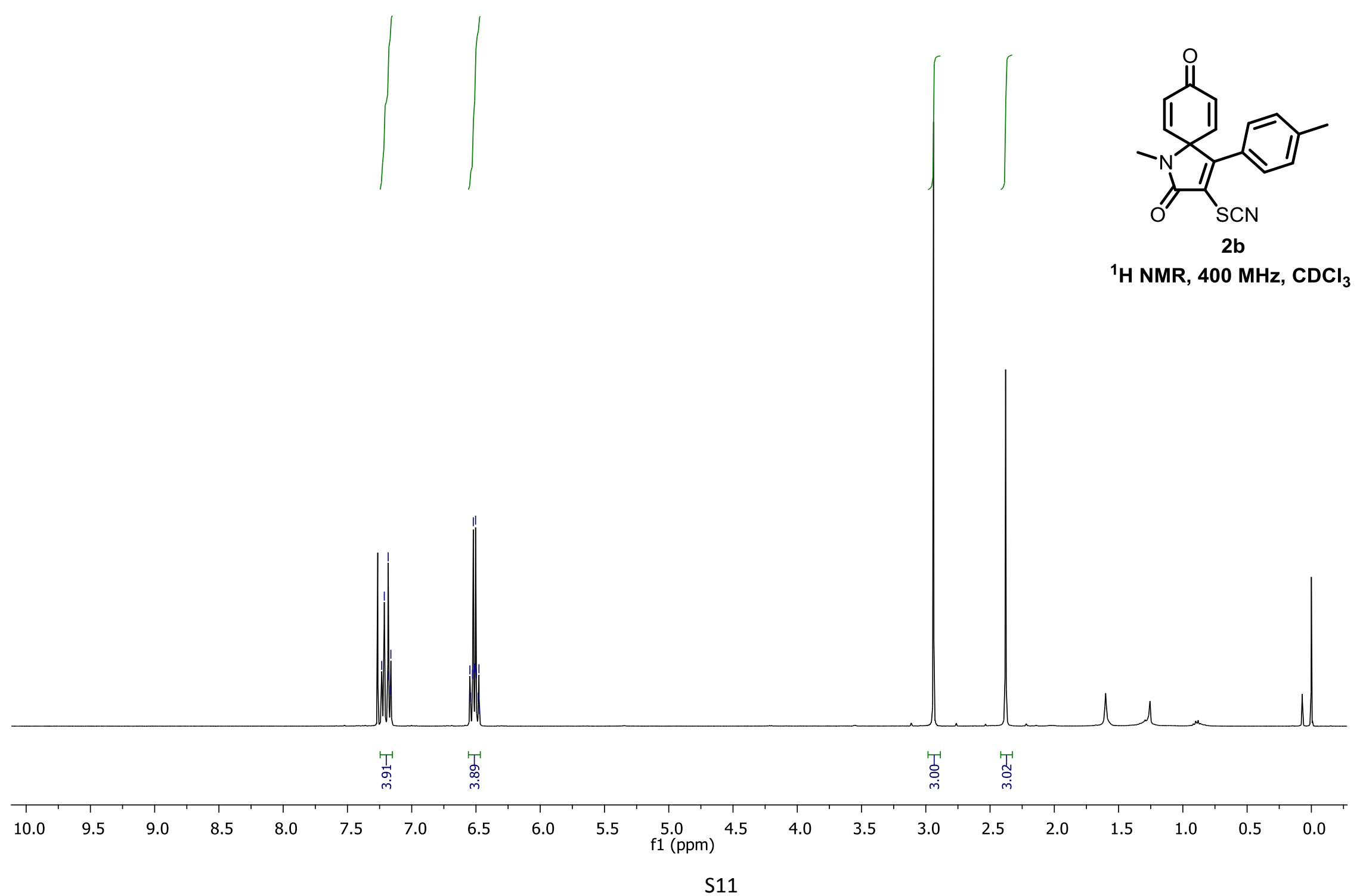




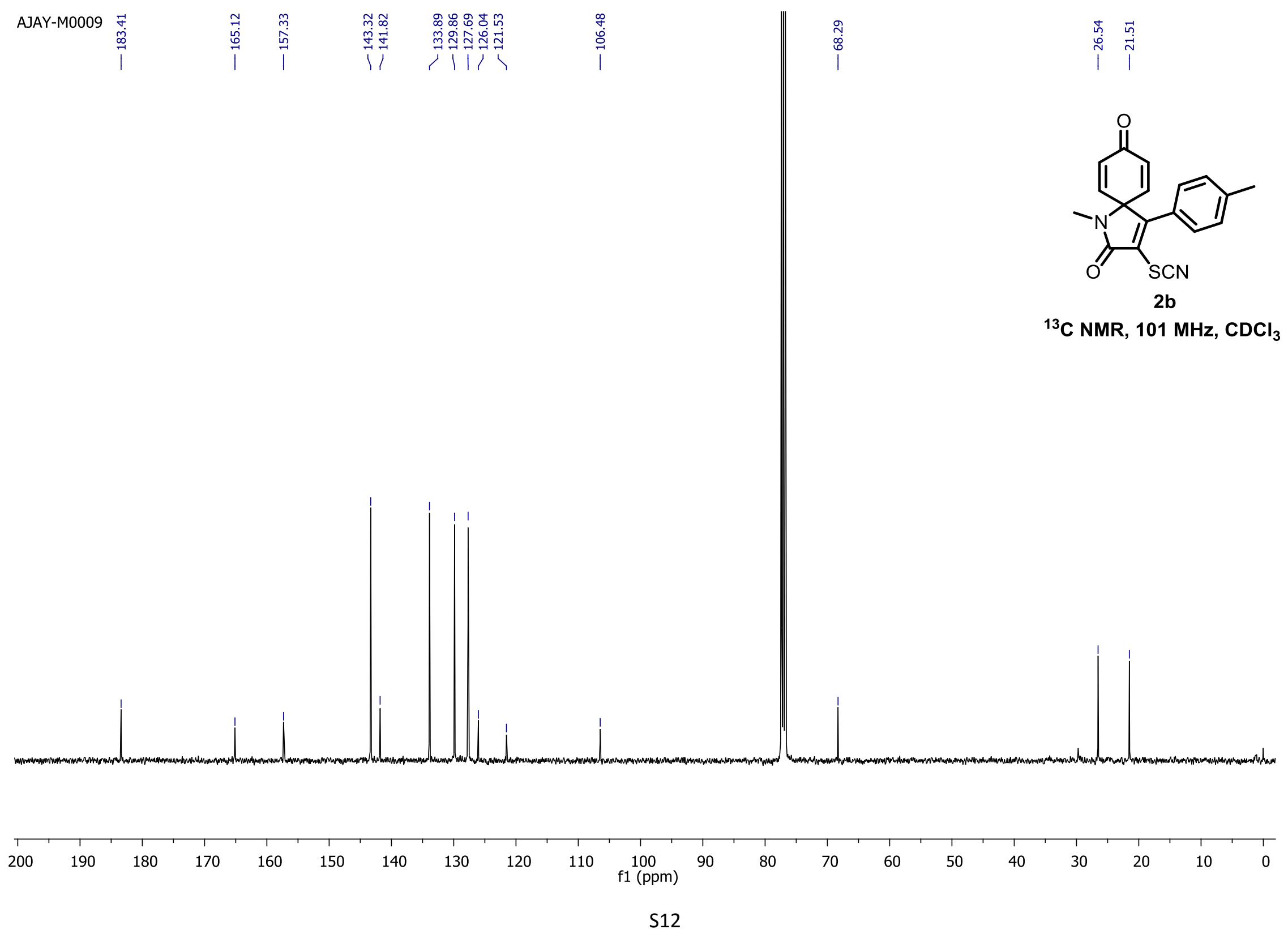




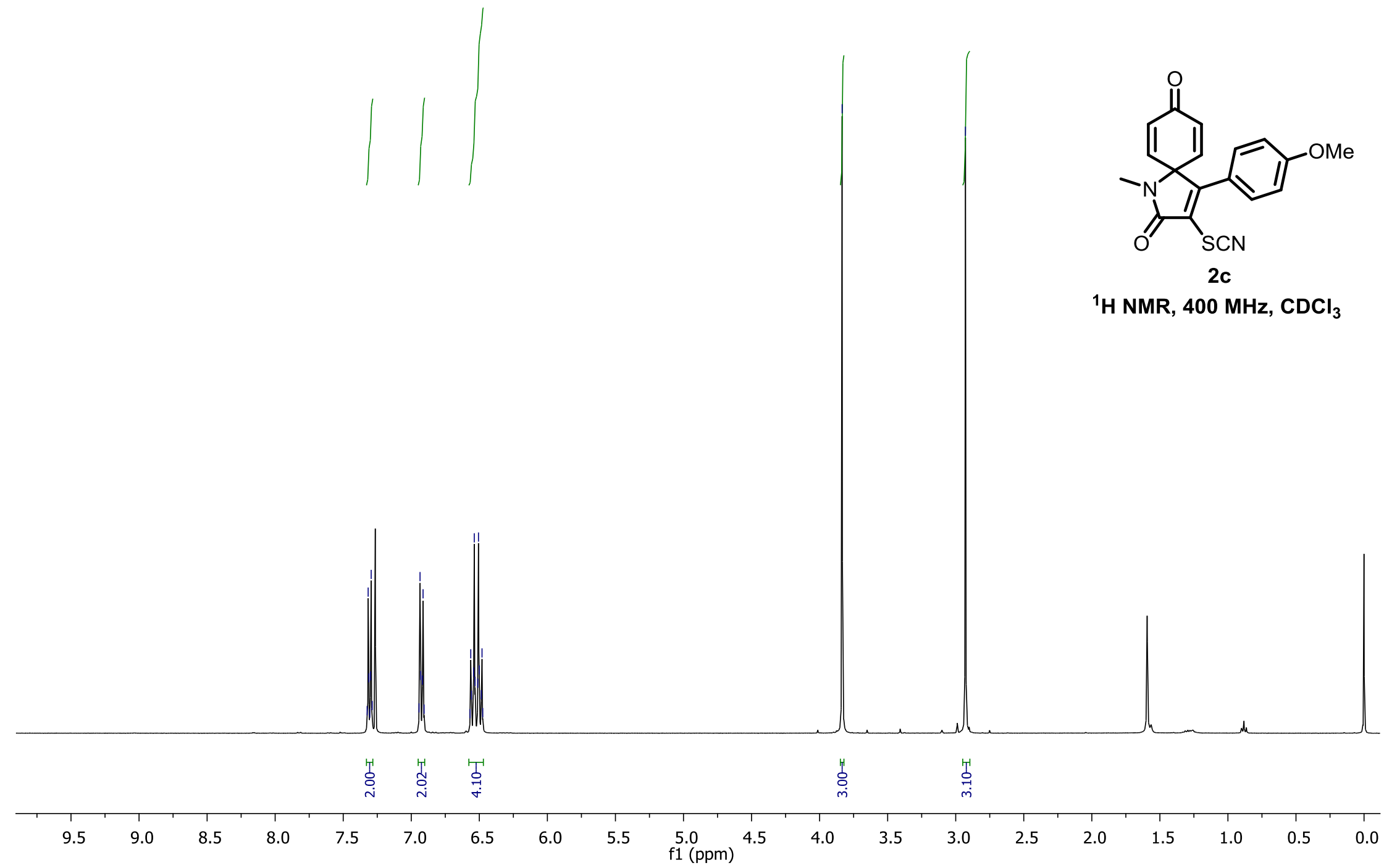




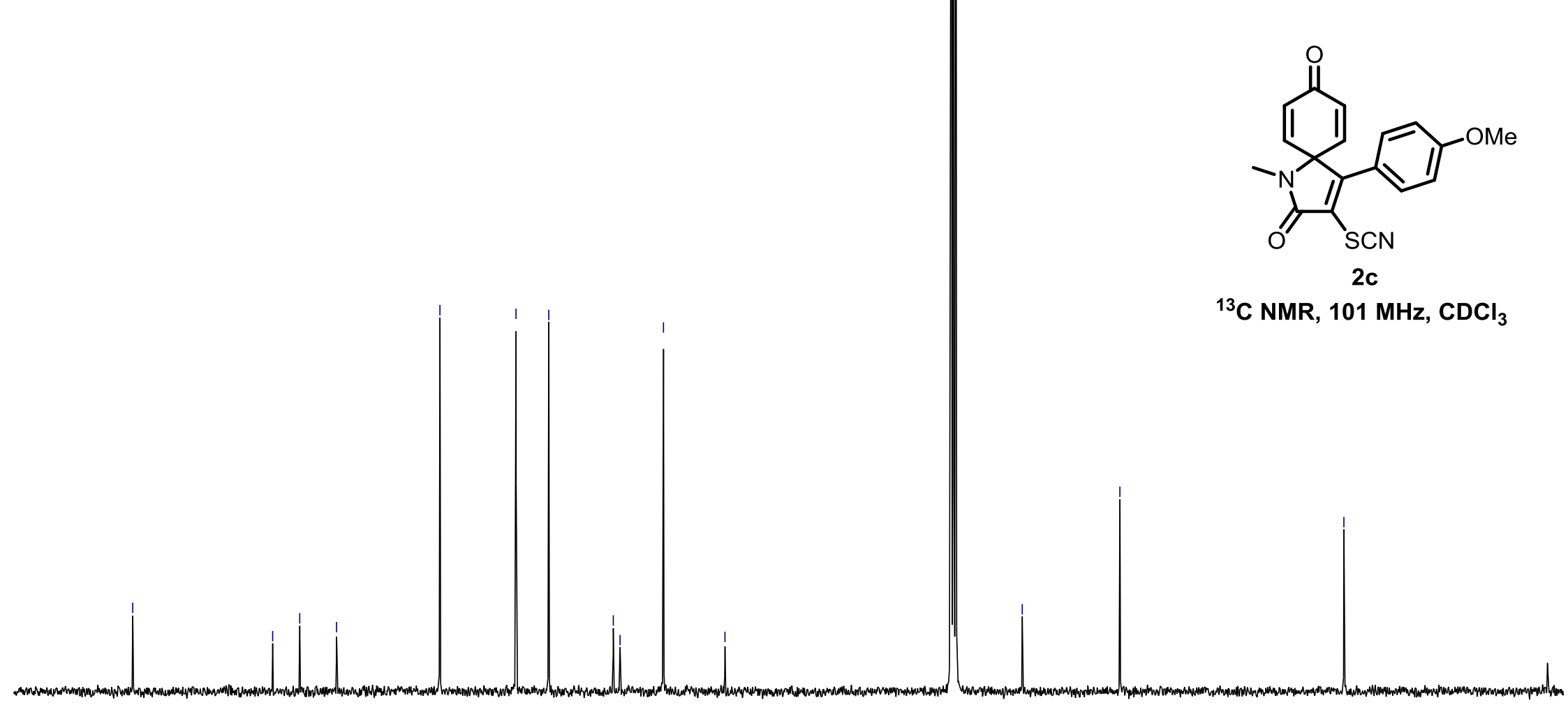




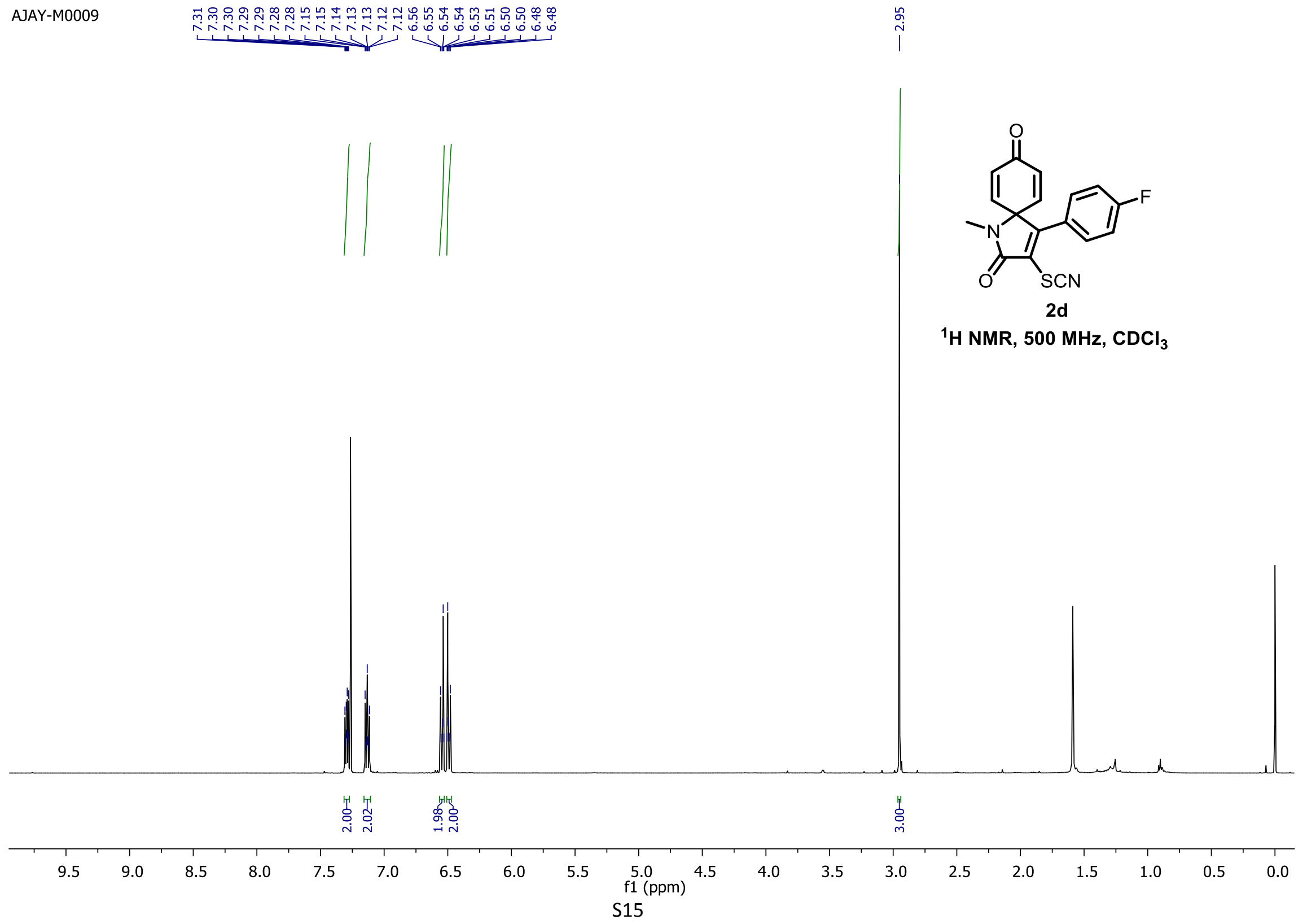



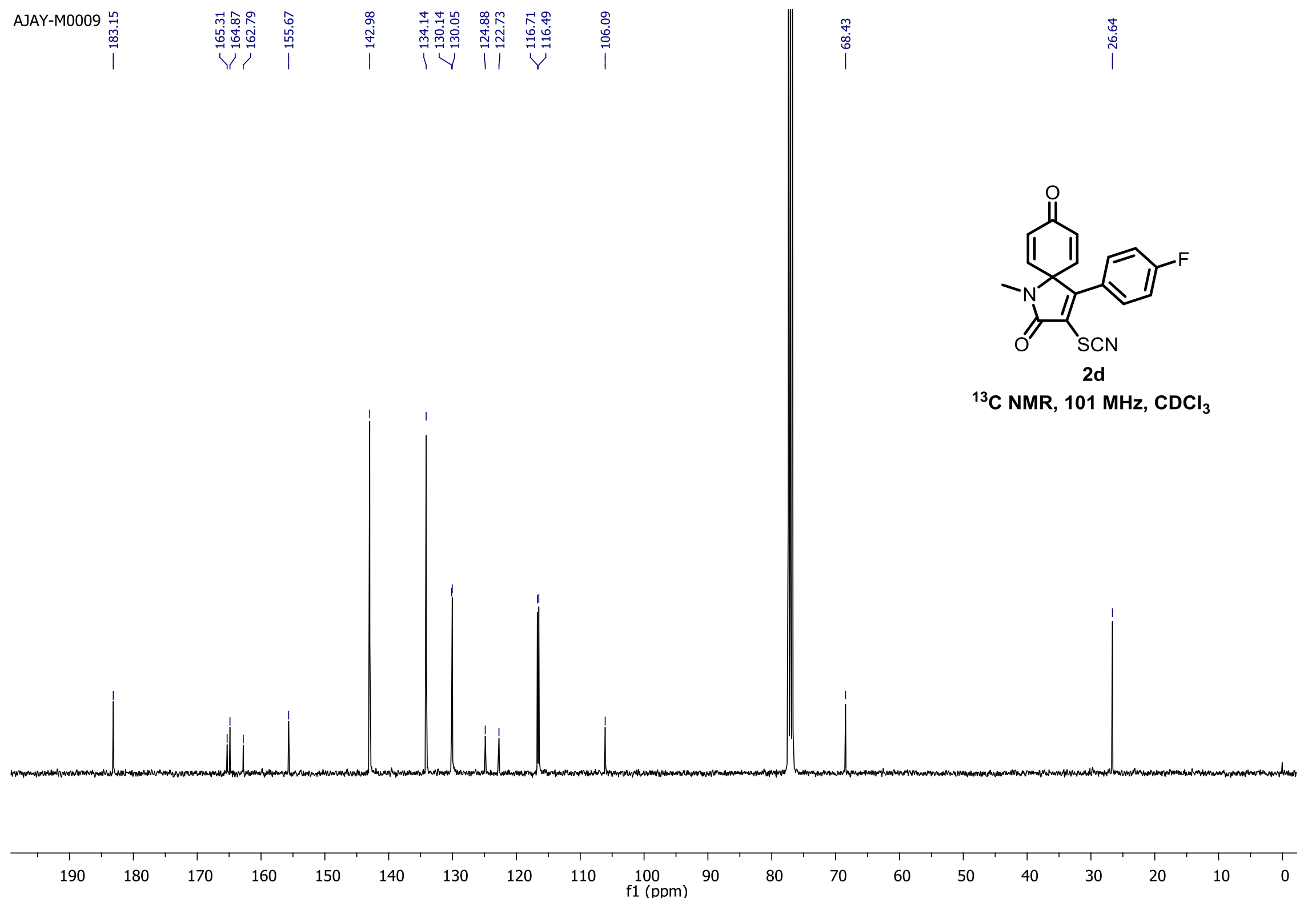


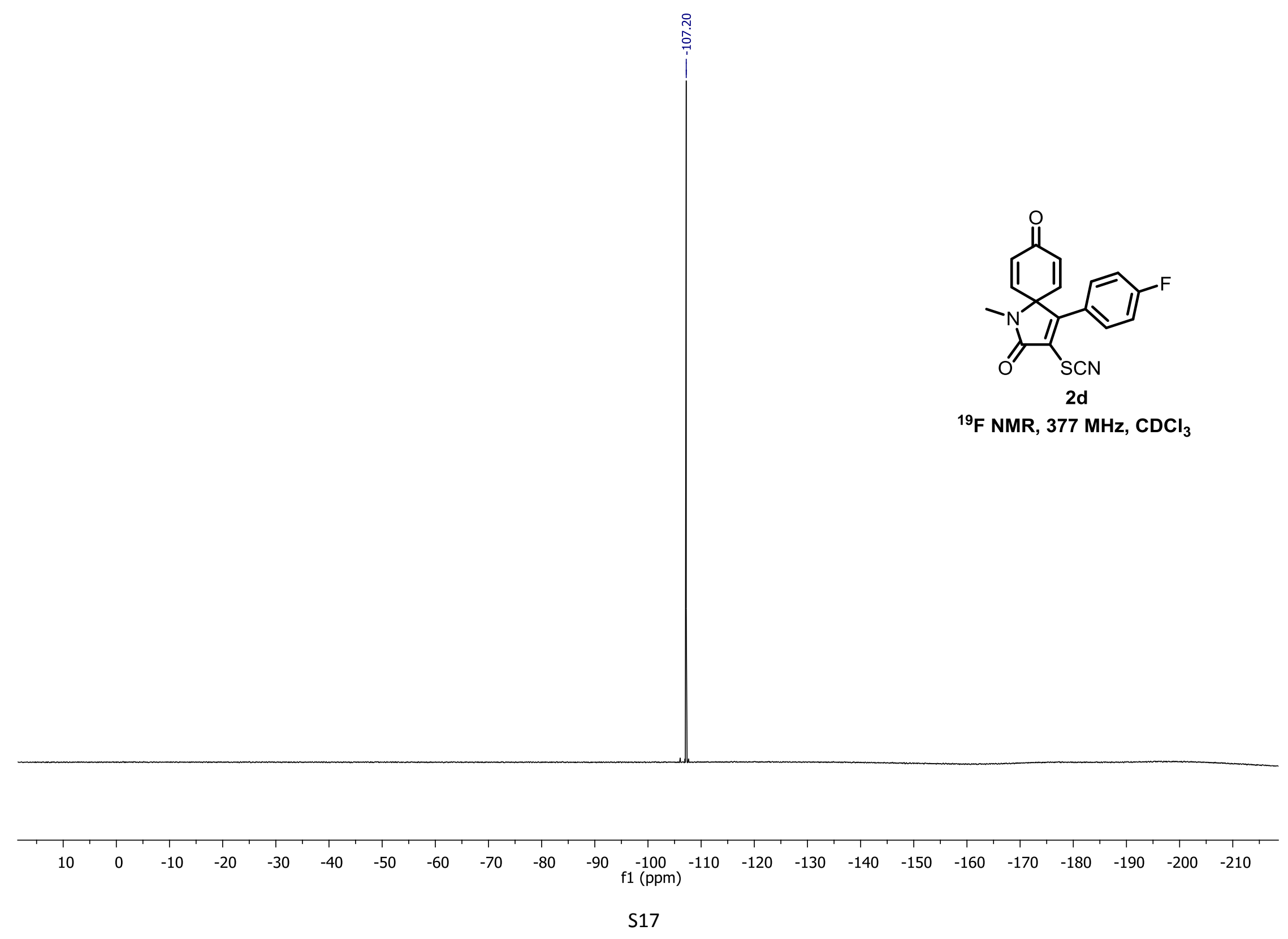




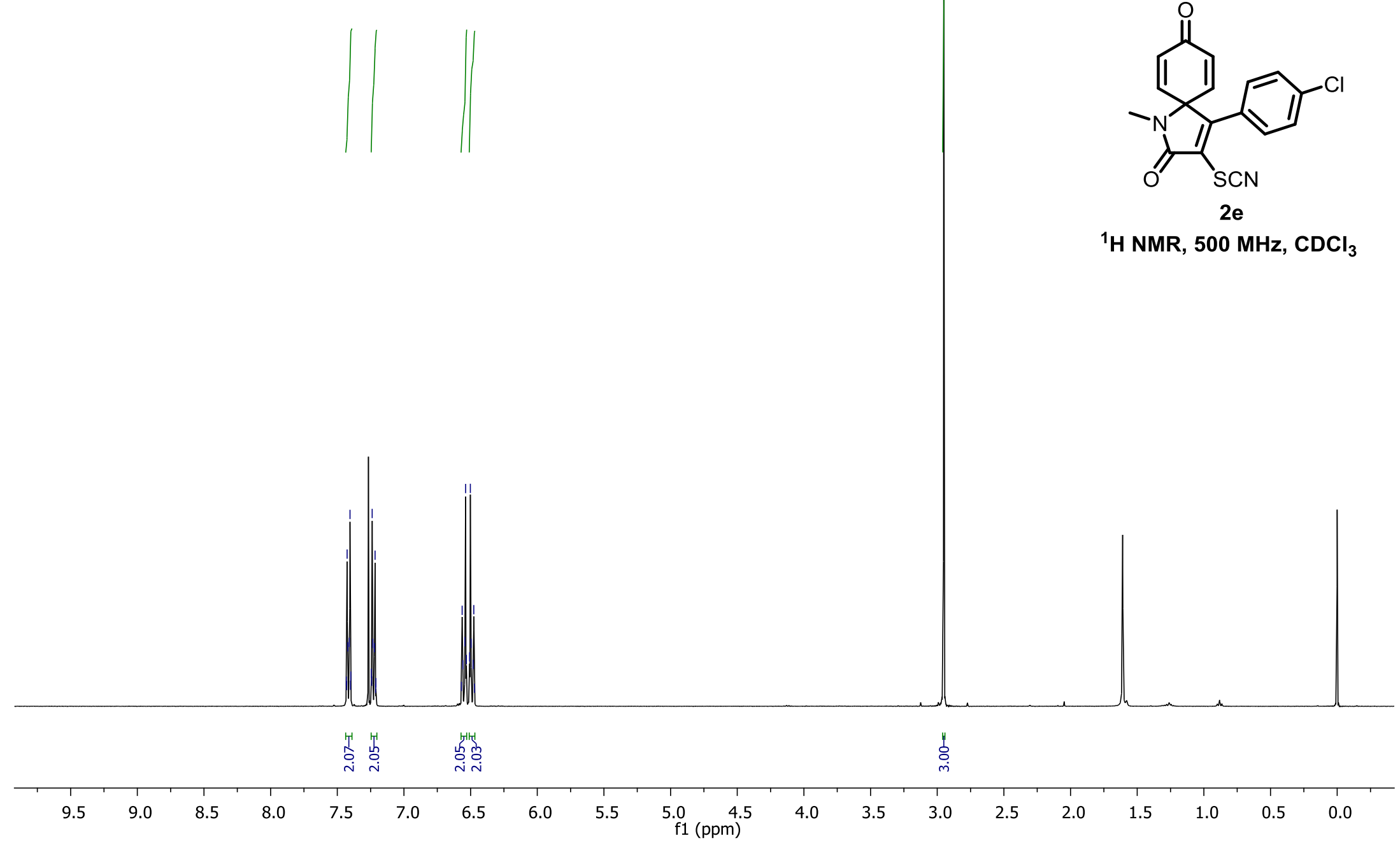



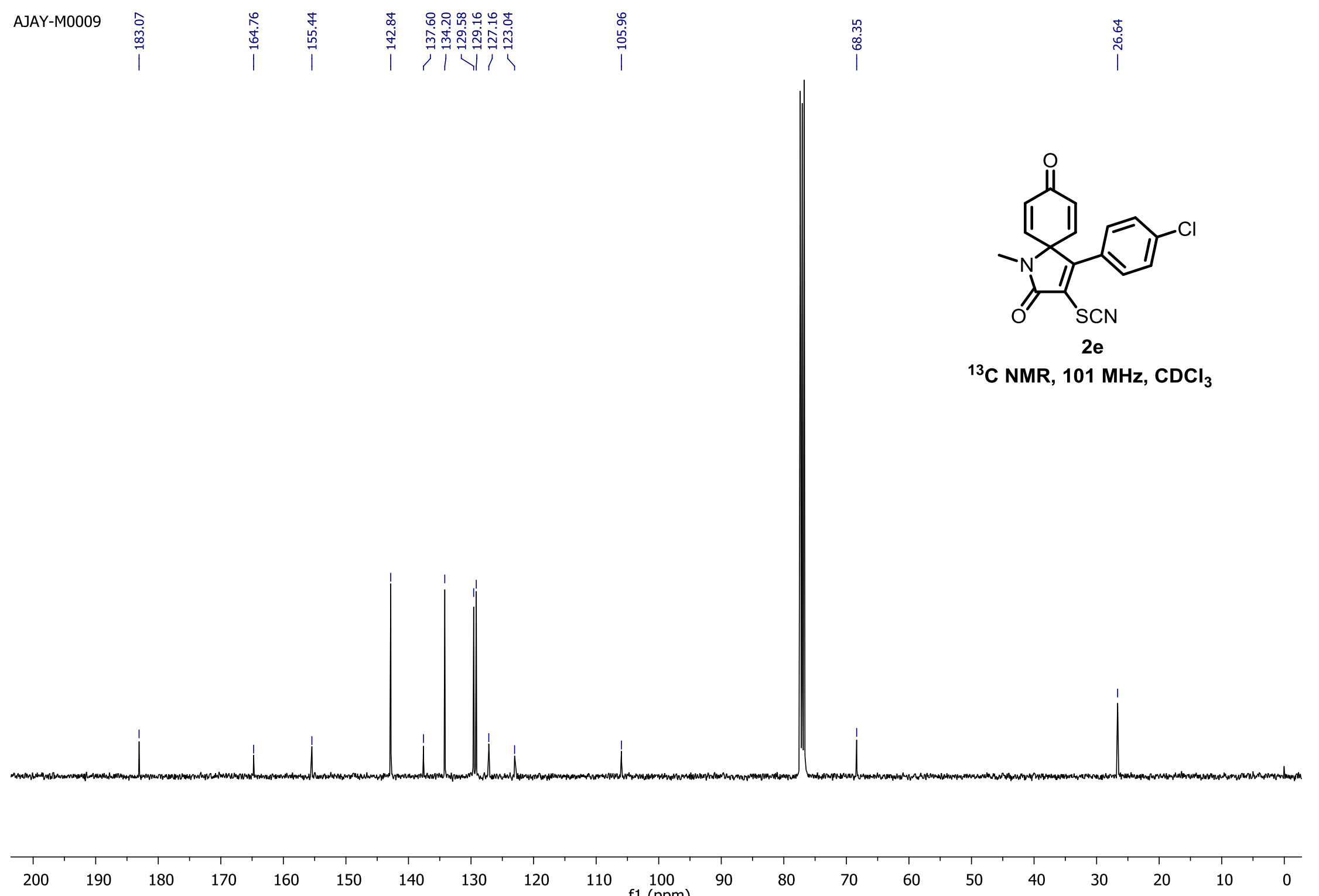


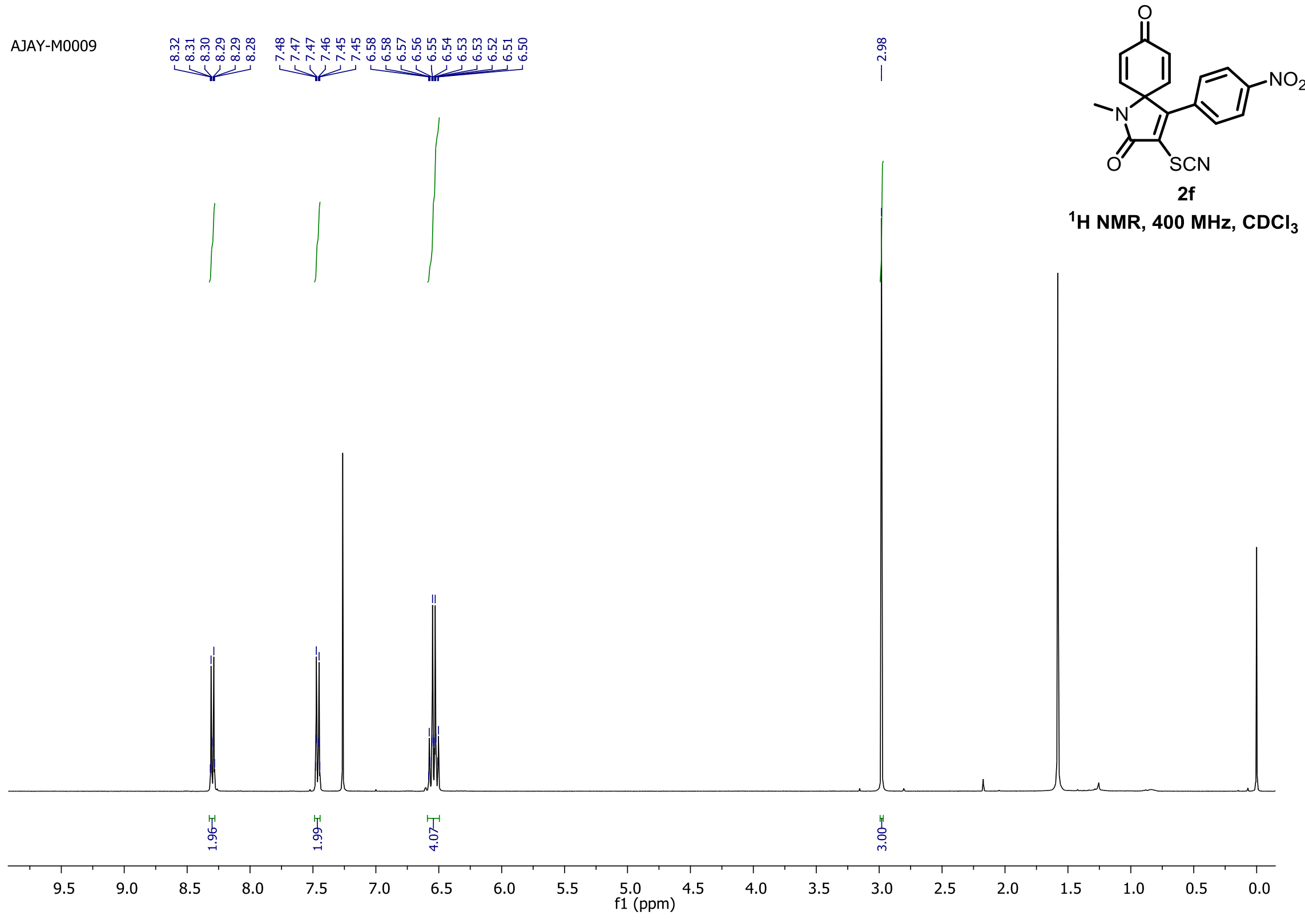




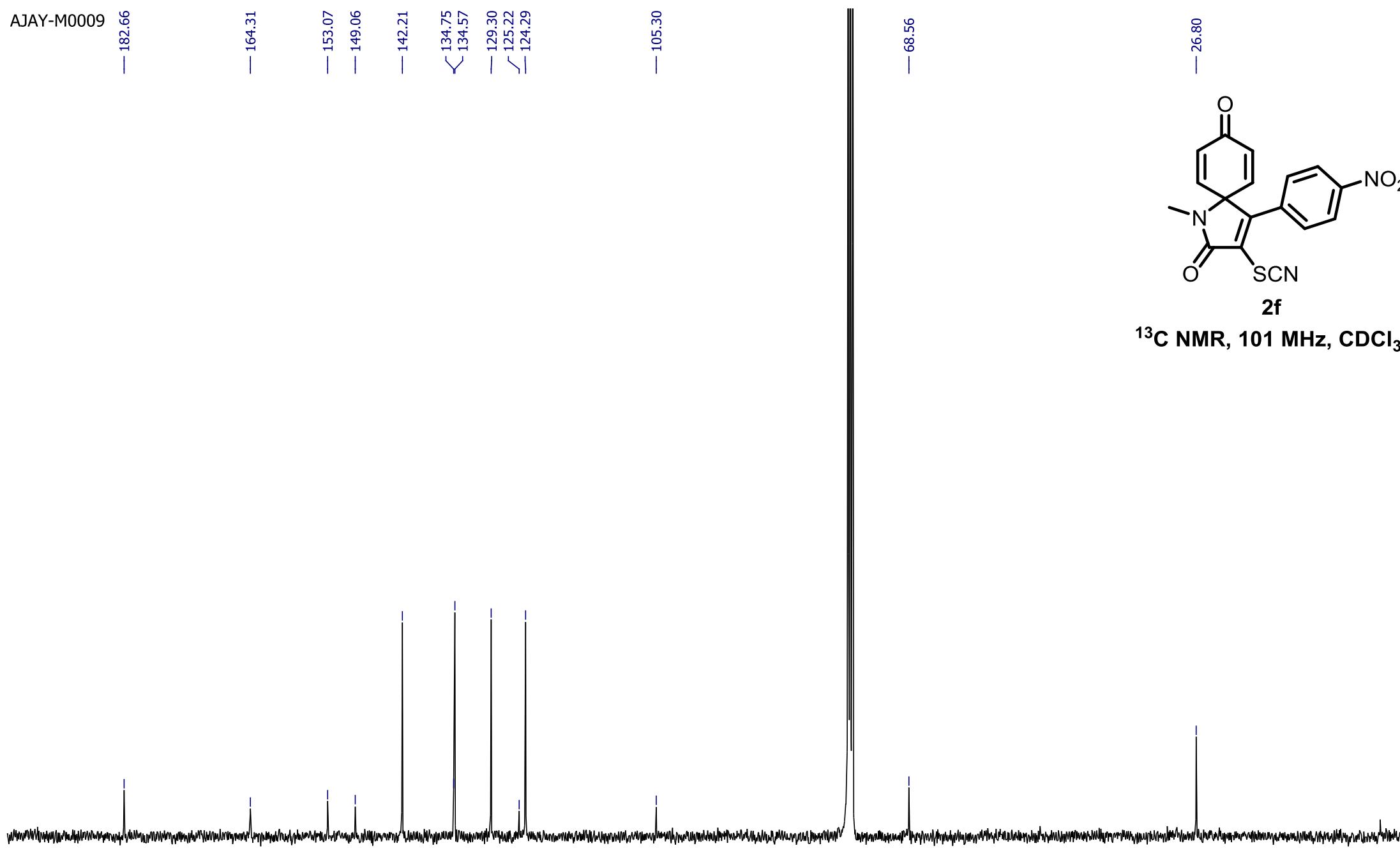



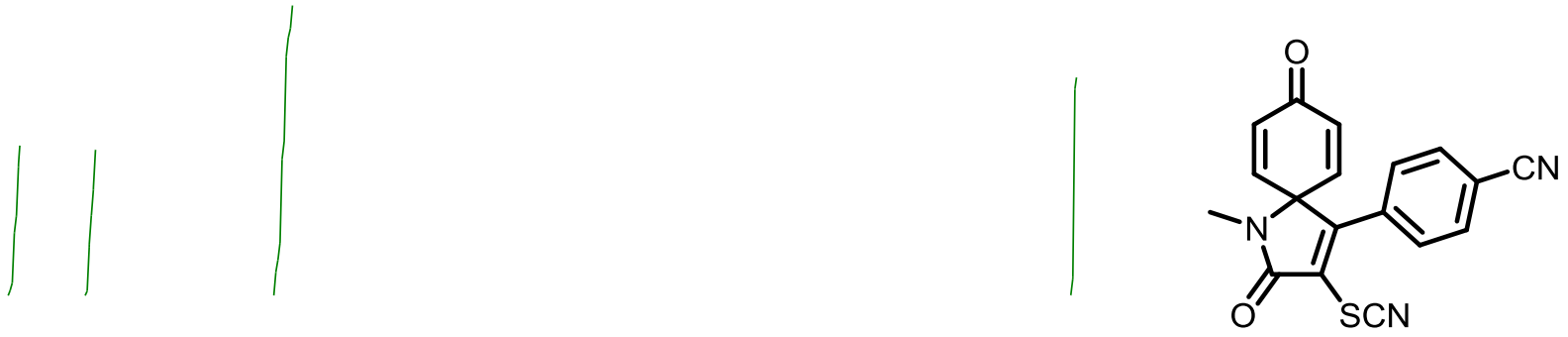

$2 \mathrm{~g}$

${ }^{1} \mathrm{H}$ NMR, $400 \mathrm{MHz}, \mathrm{CDCl}_{3}$

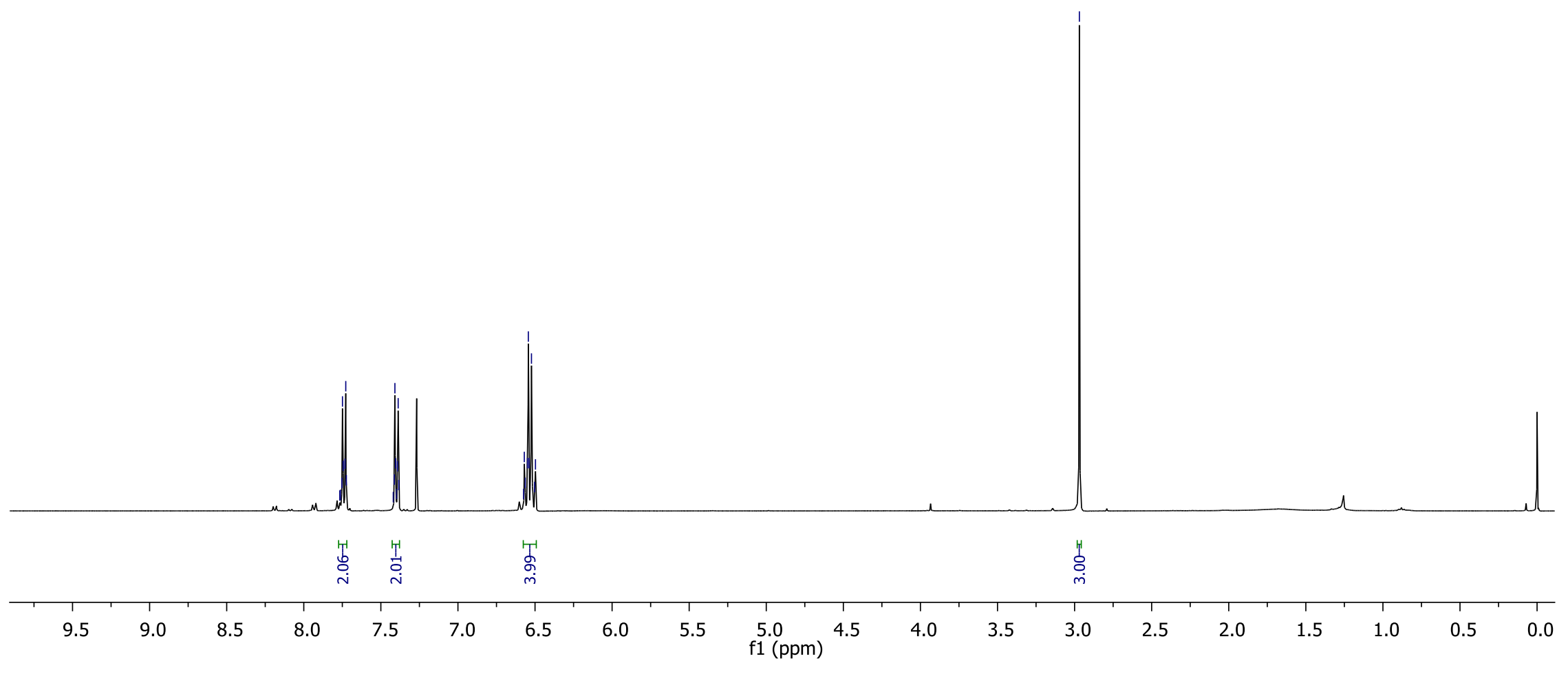




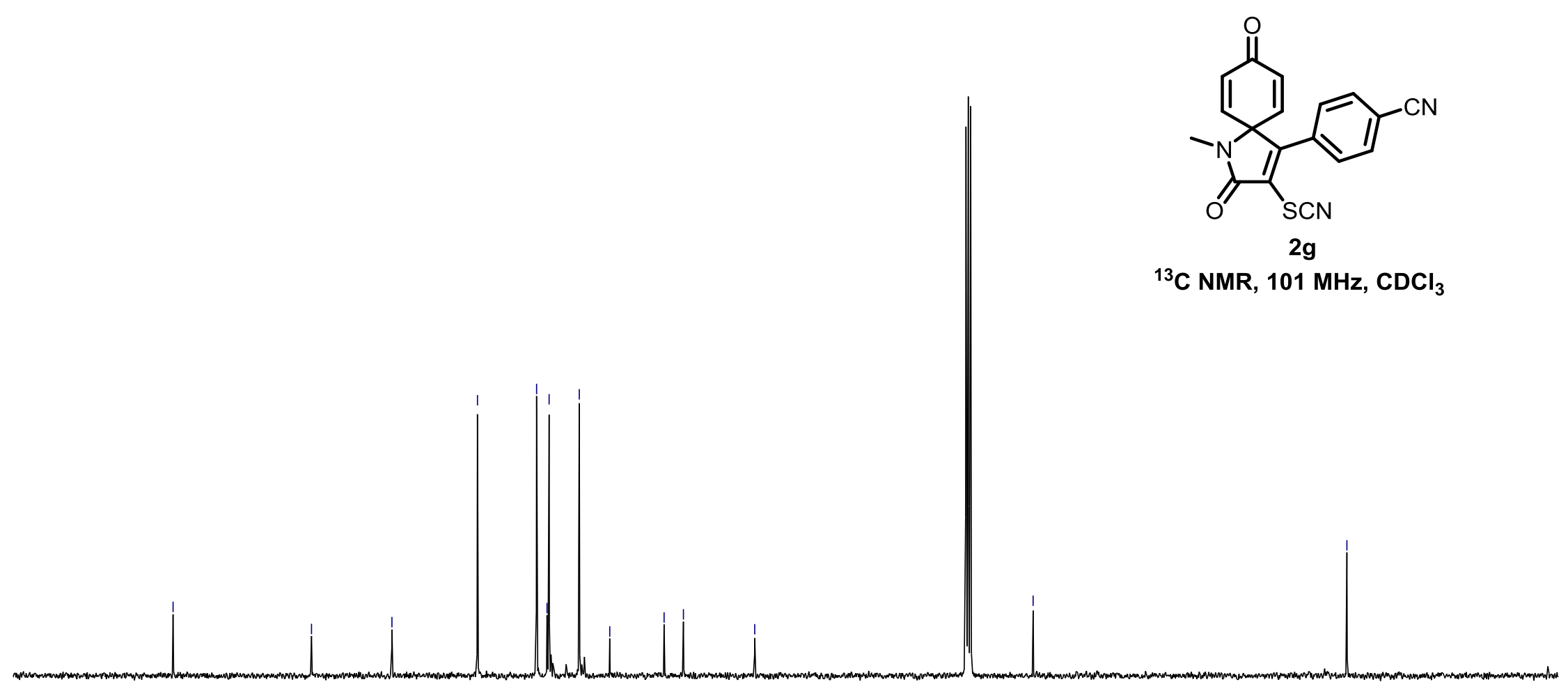




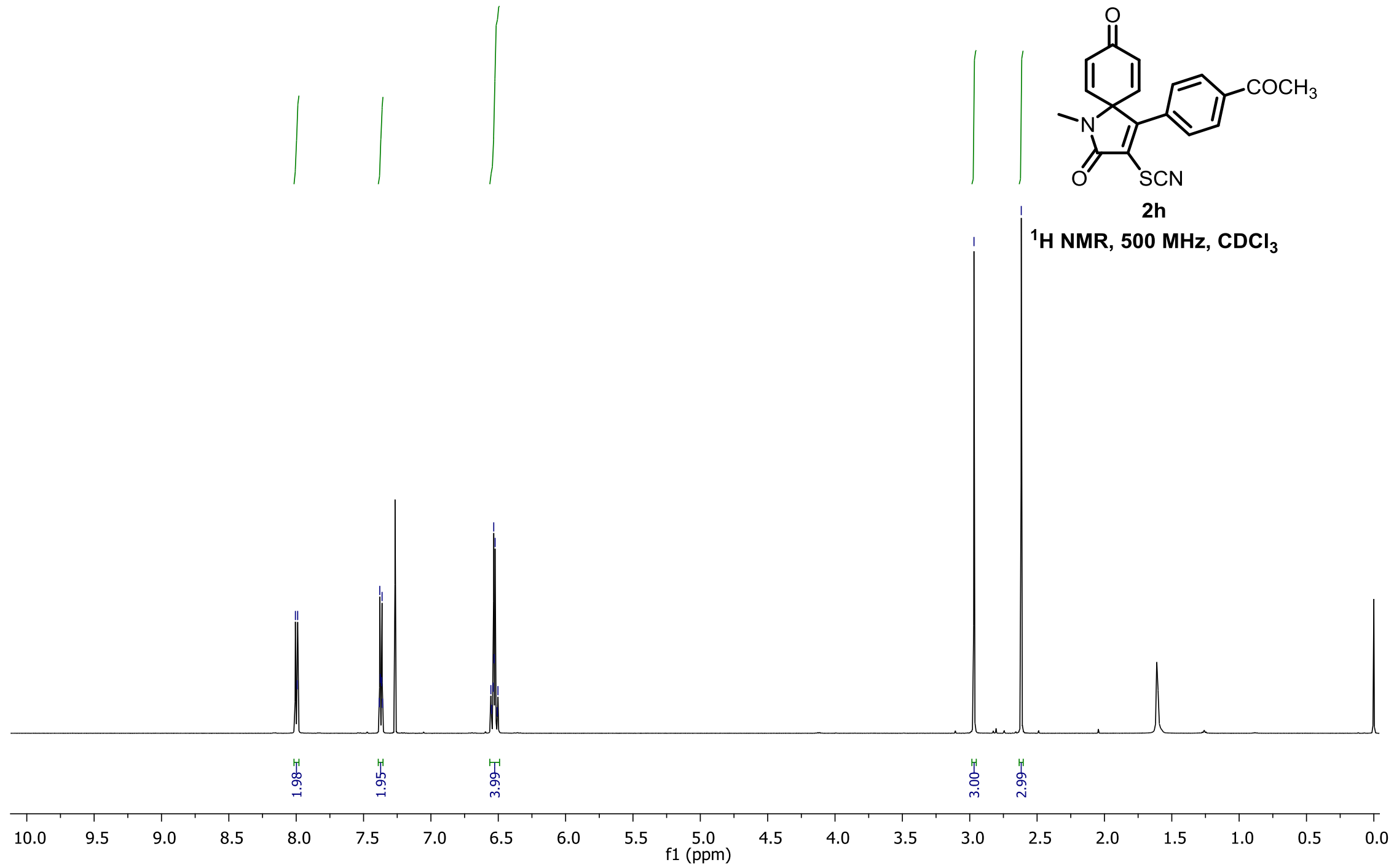



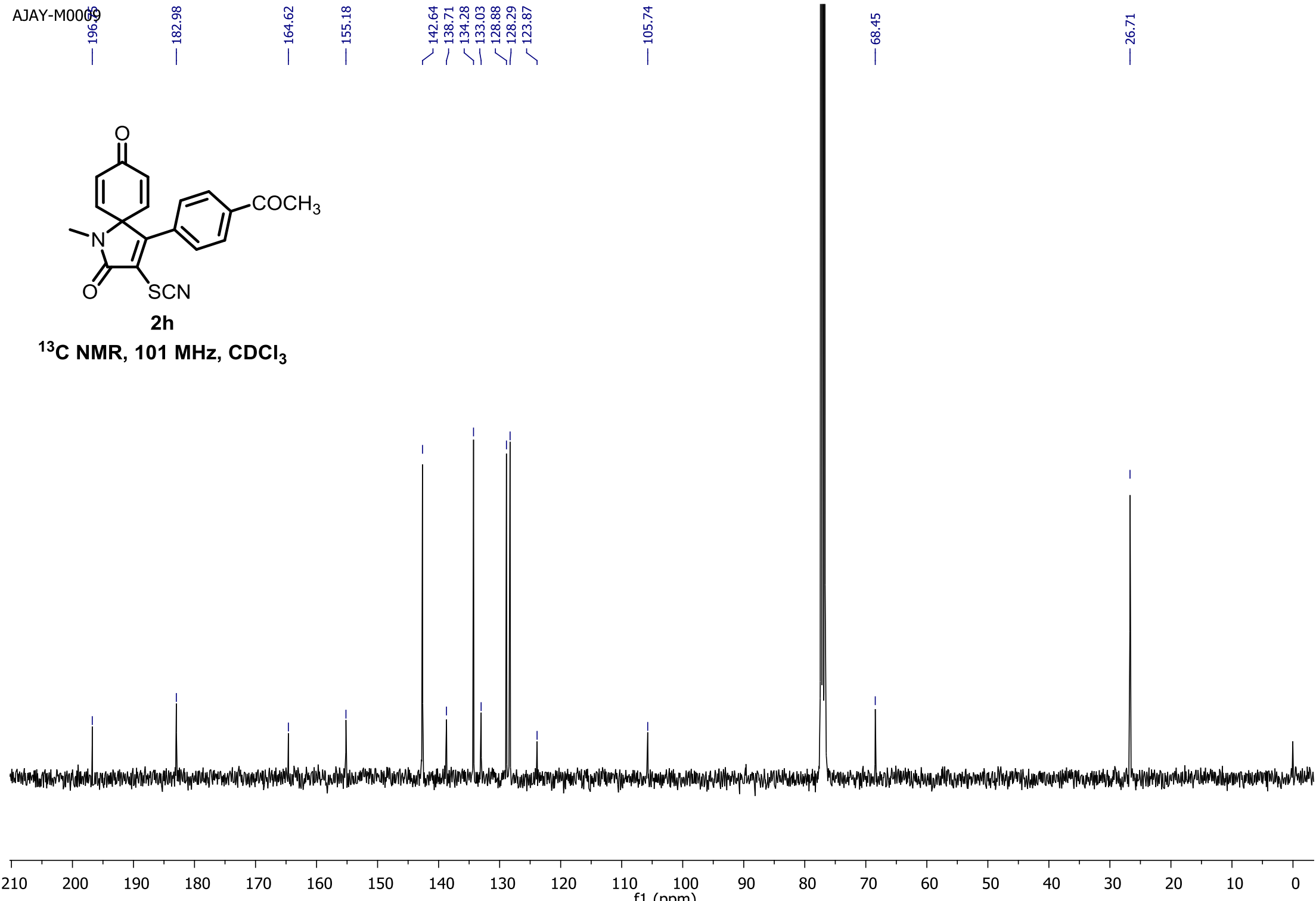

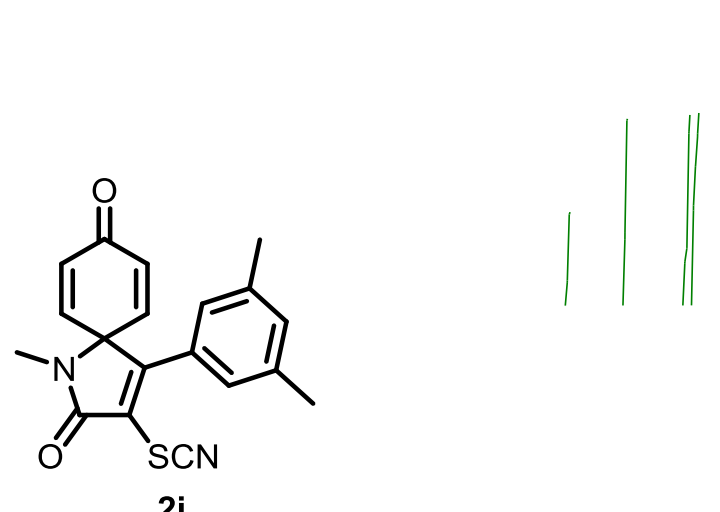

$2 \mathrm{i}$

${ }^{1} \mathrm{H}$ NMR, $500 \mathrm{MHz}, \mathrm{CDCl}_{3}$

Y

i

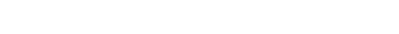

.
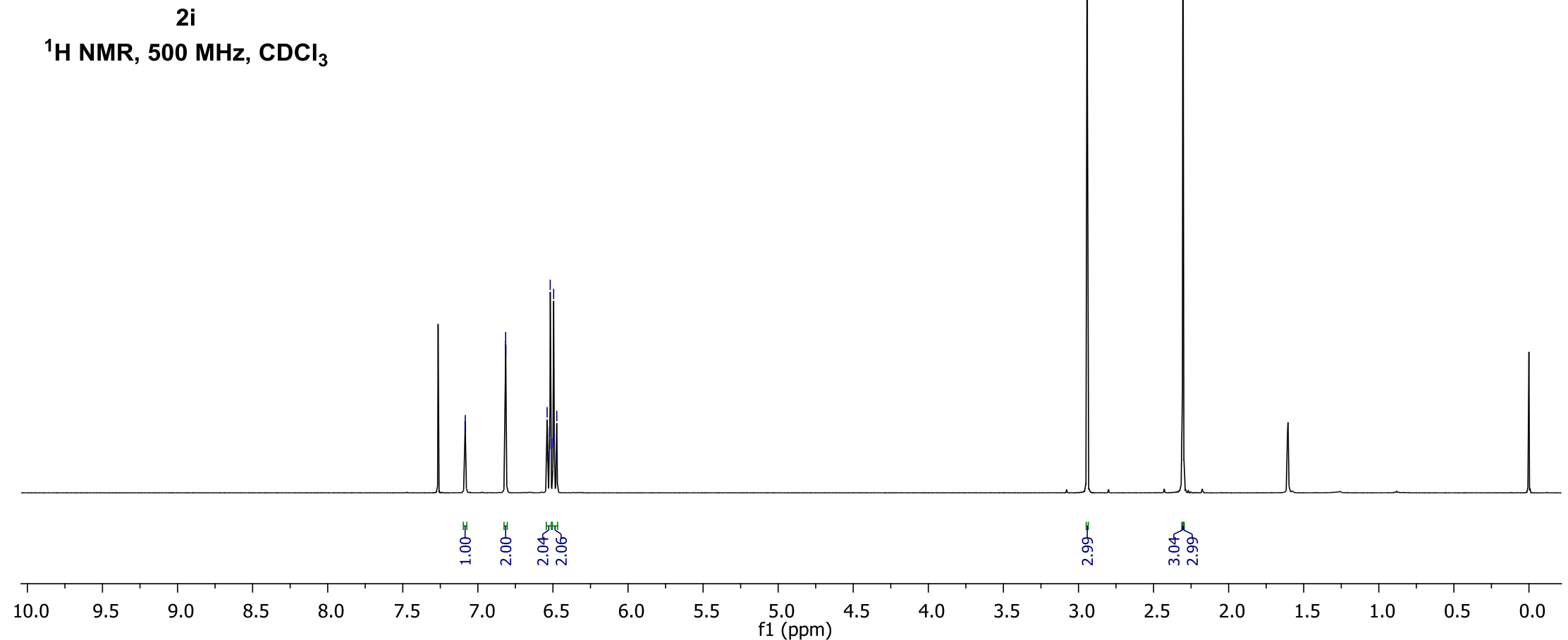

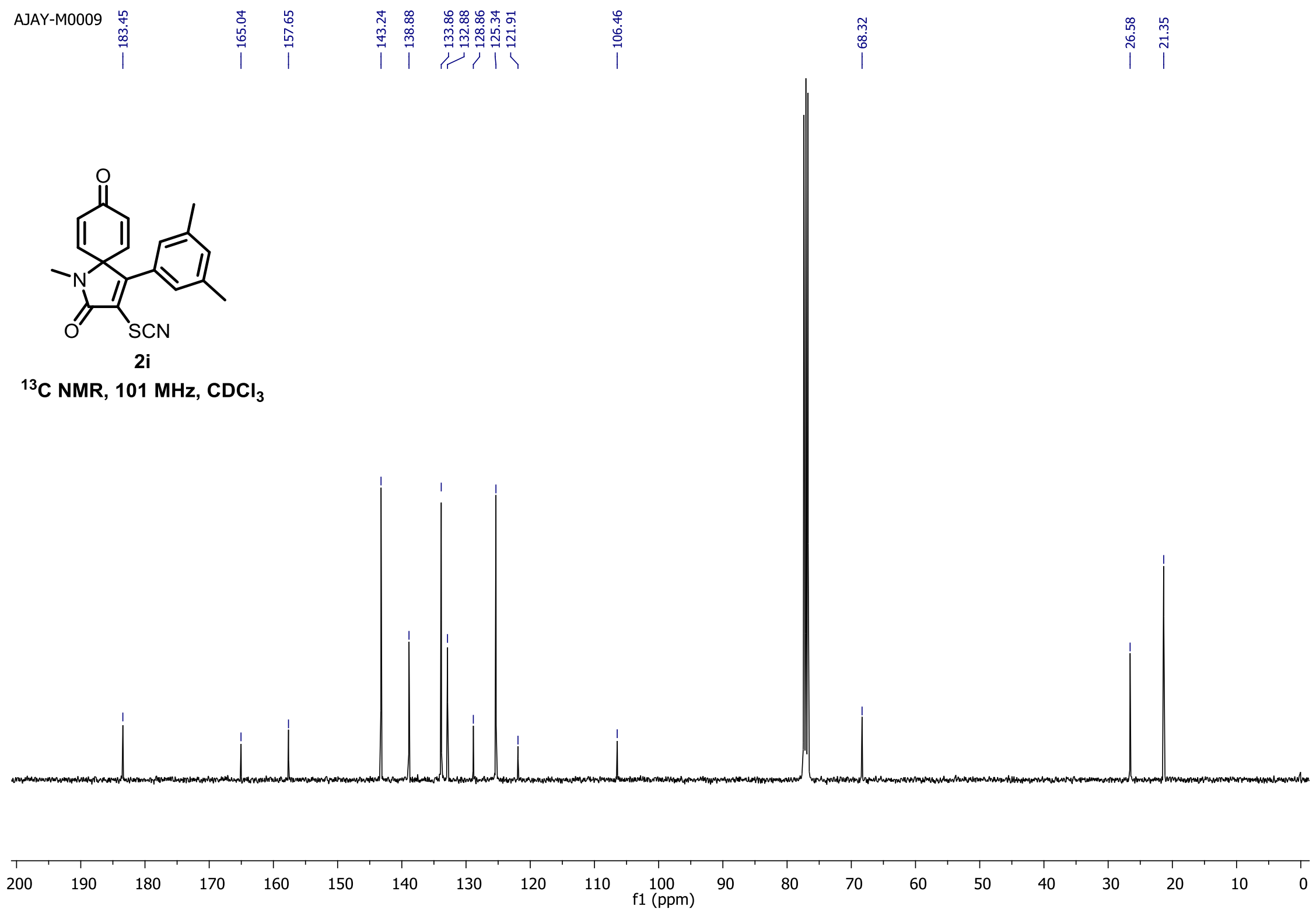


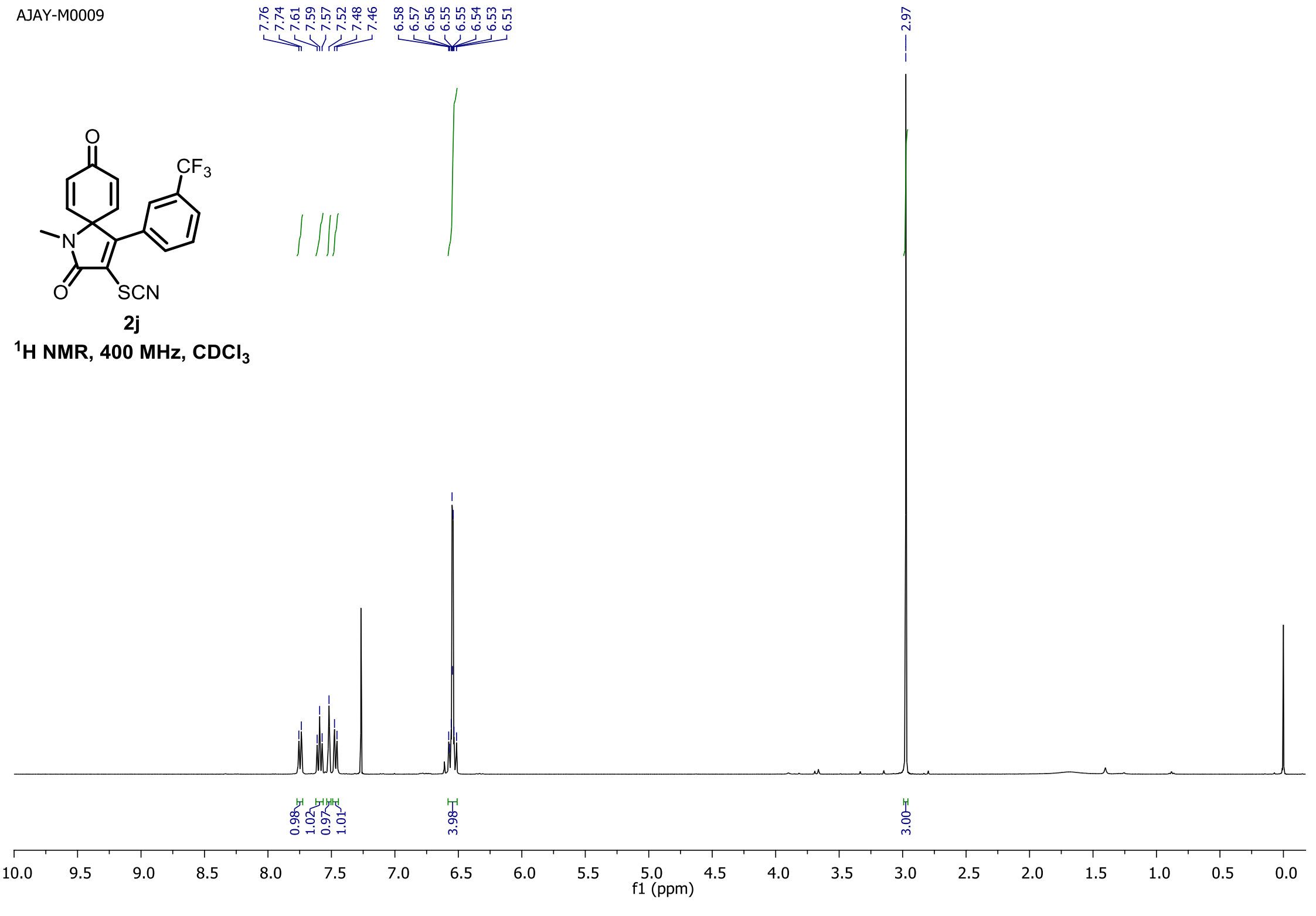




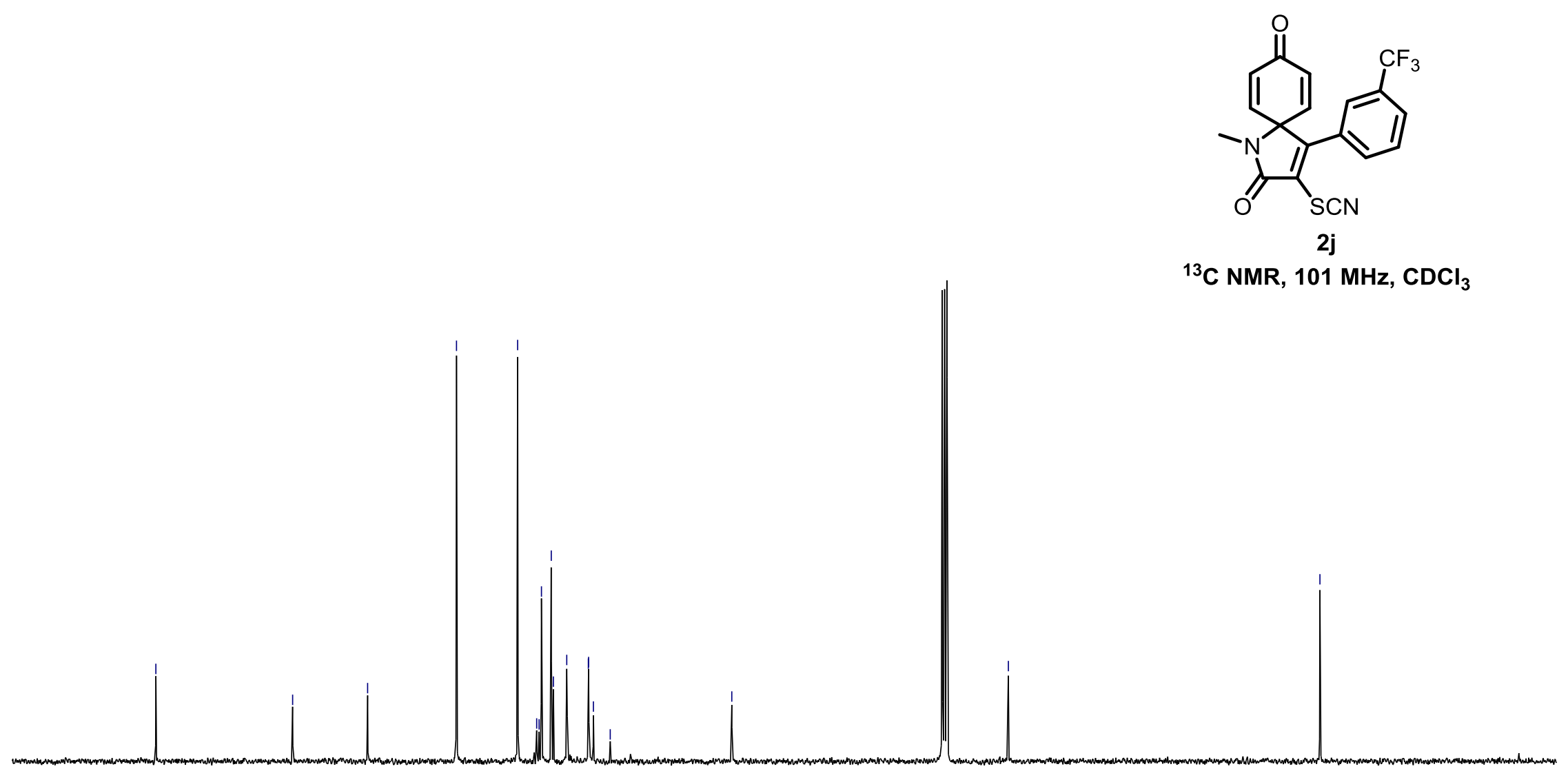




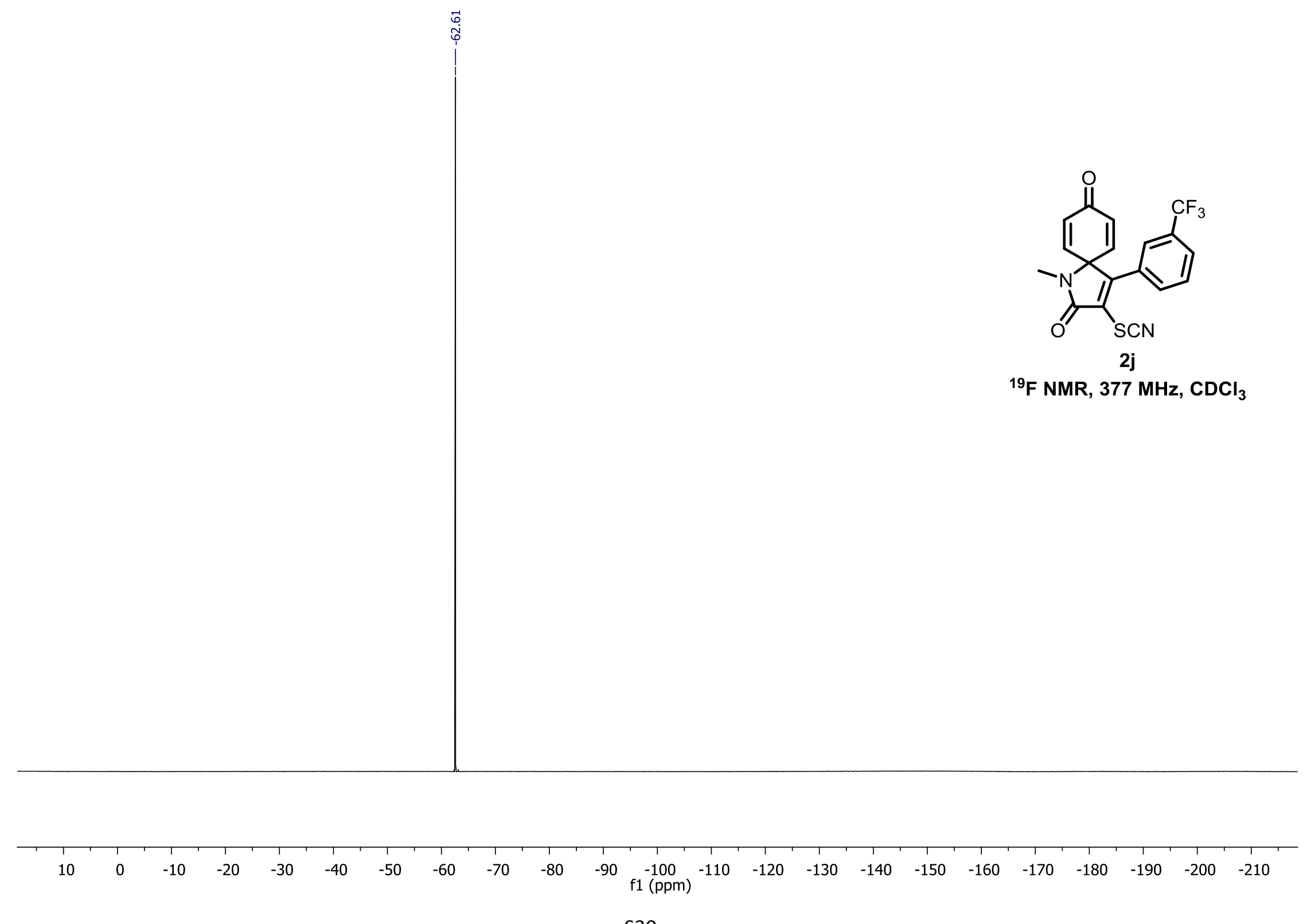




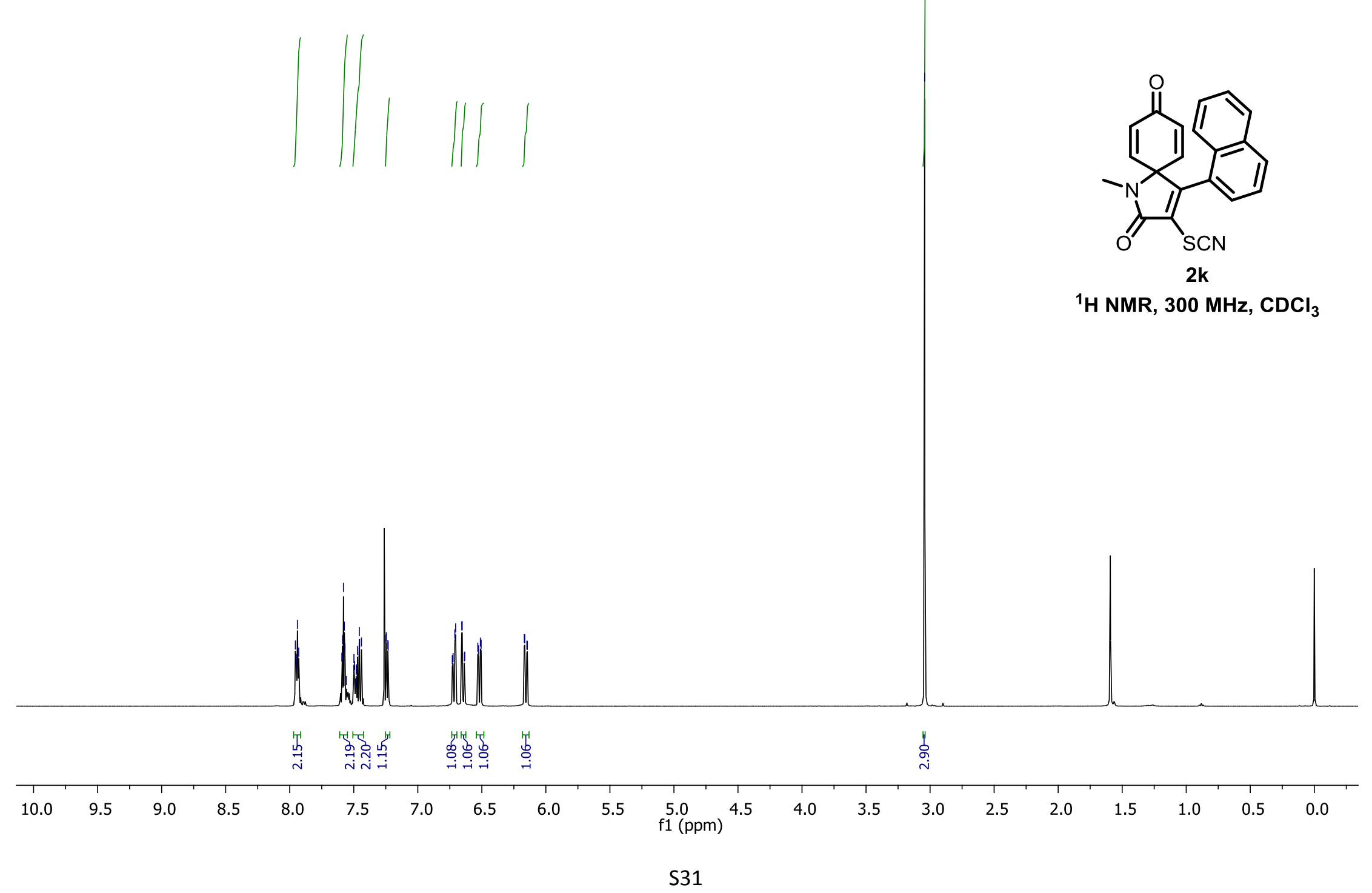



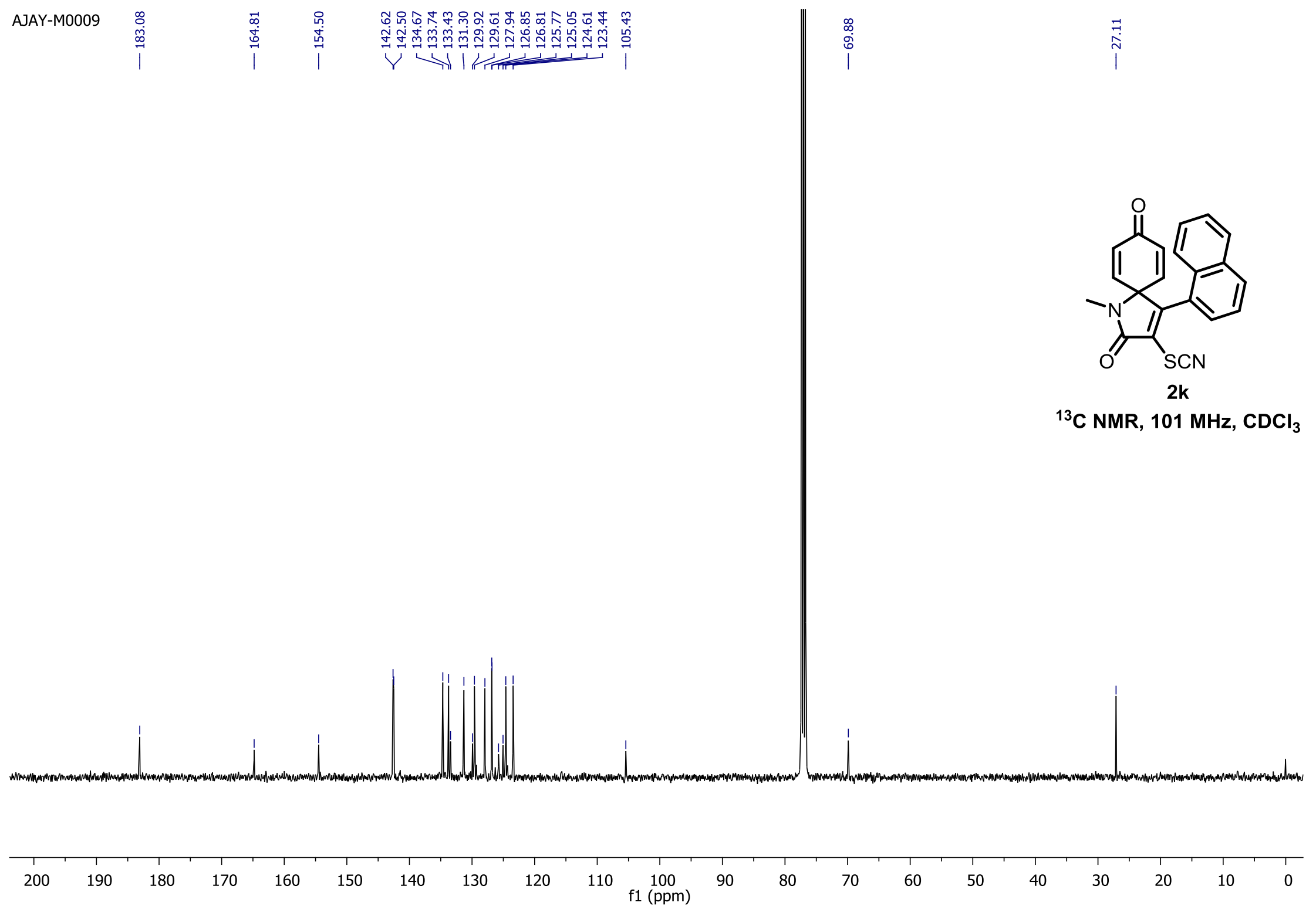


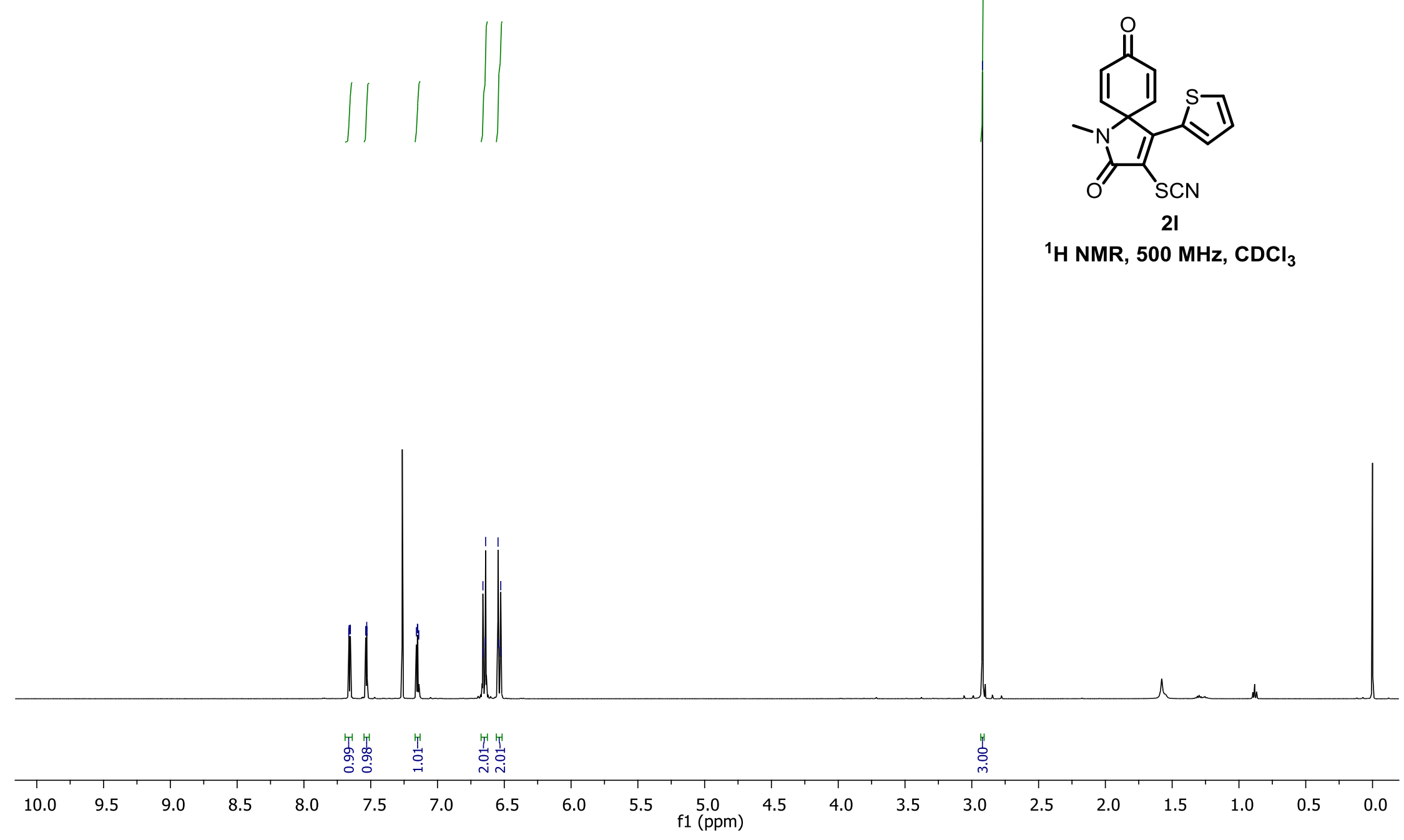




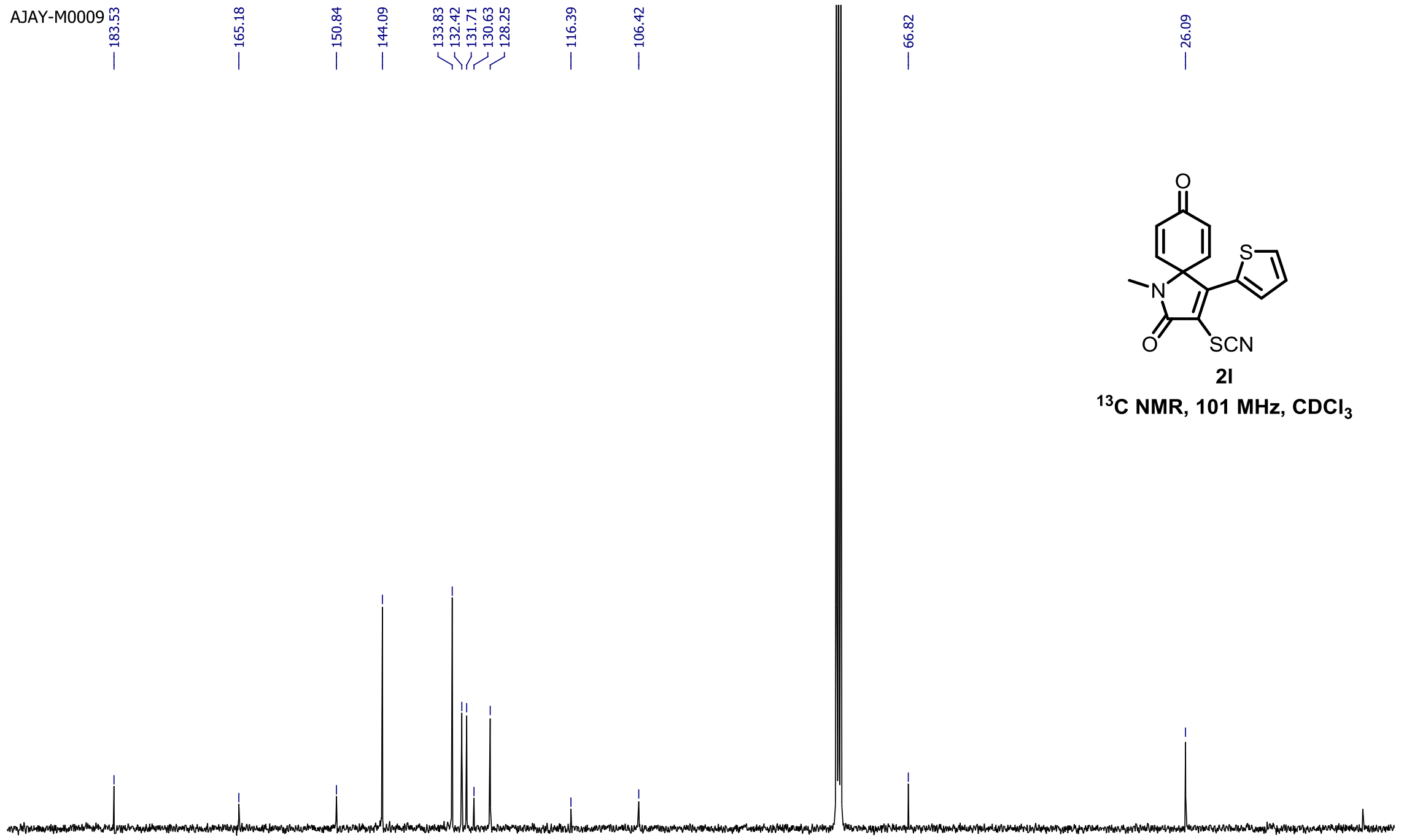


AJAY

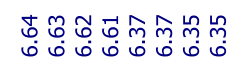

过

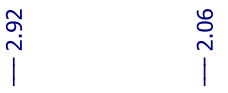
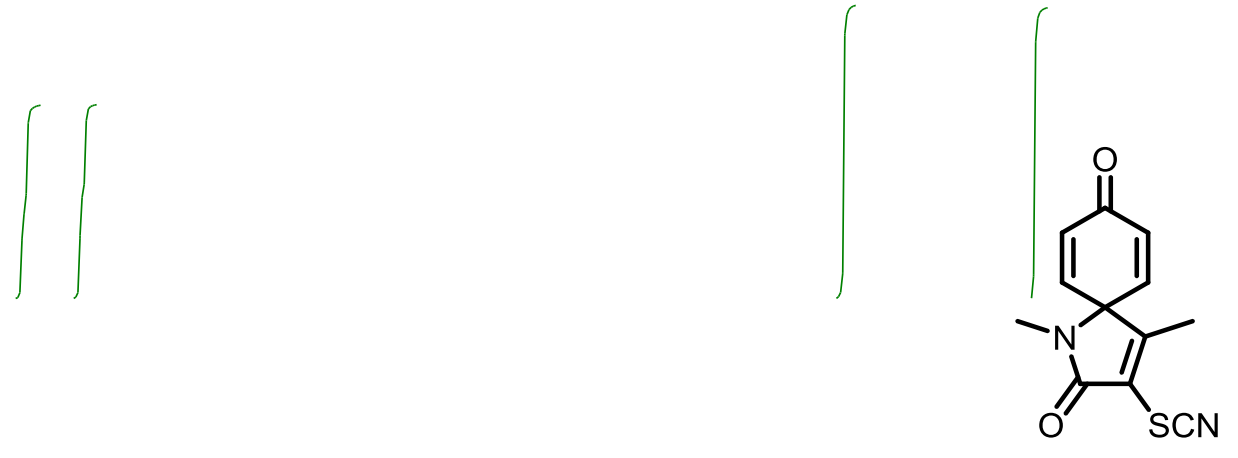

$2 \mathrm{~m}$

${ }^{1} \mathrm{H}$ NMR, $400 \mathrm{MHz}^{\mathrm{CDCl}}{ }_{3}$

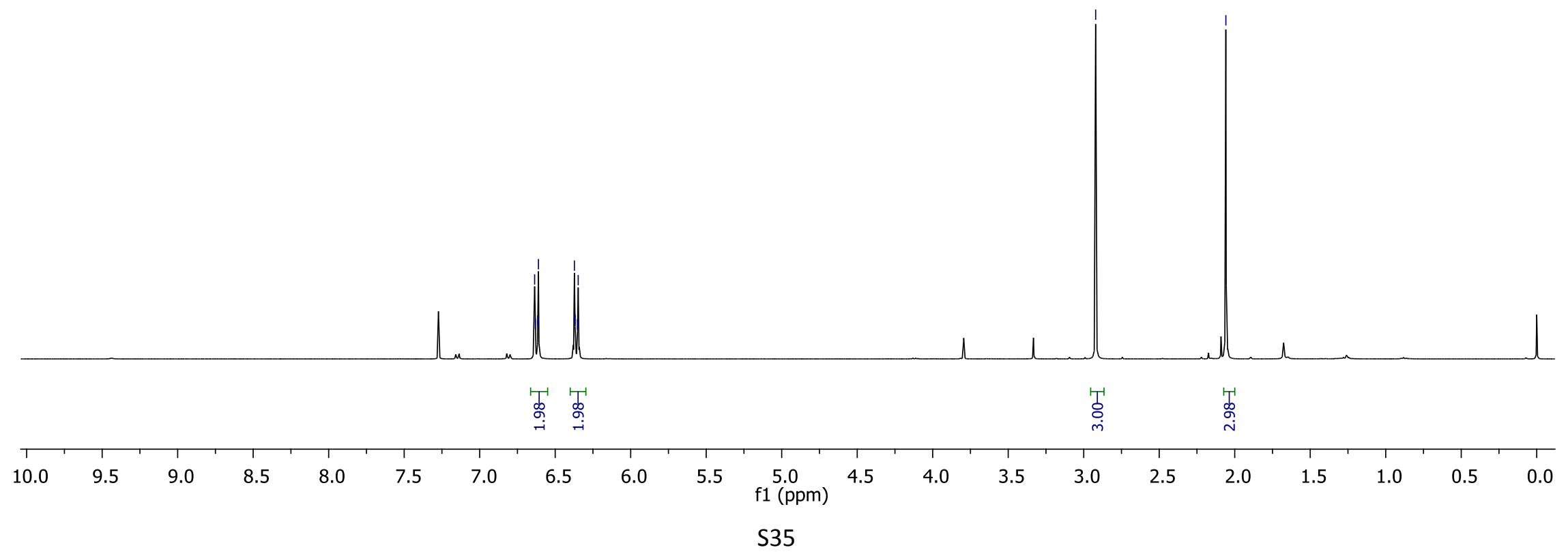




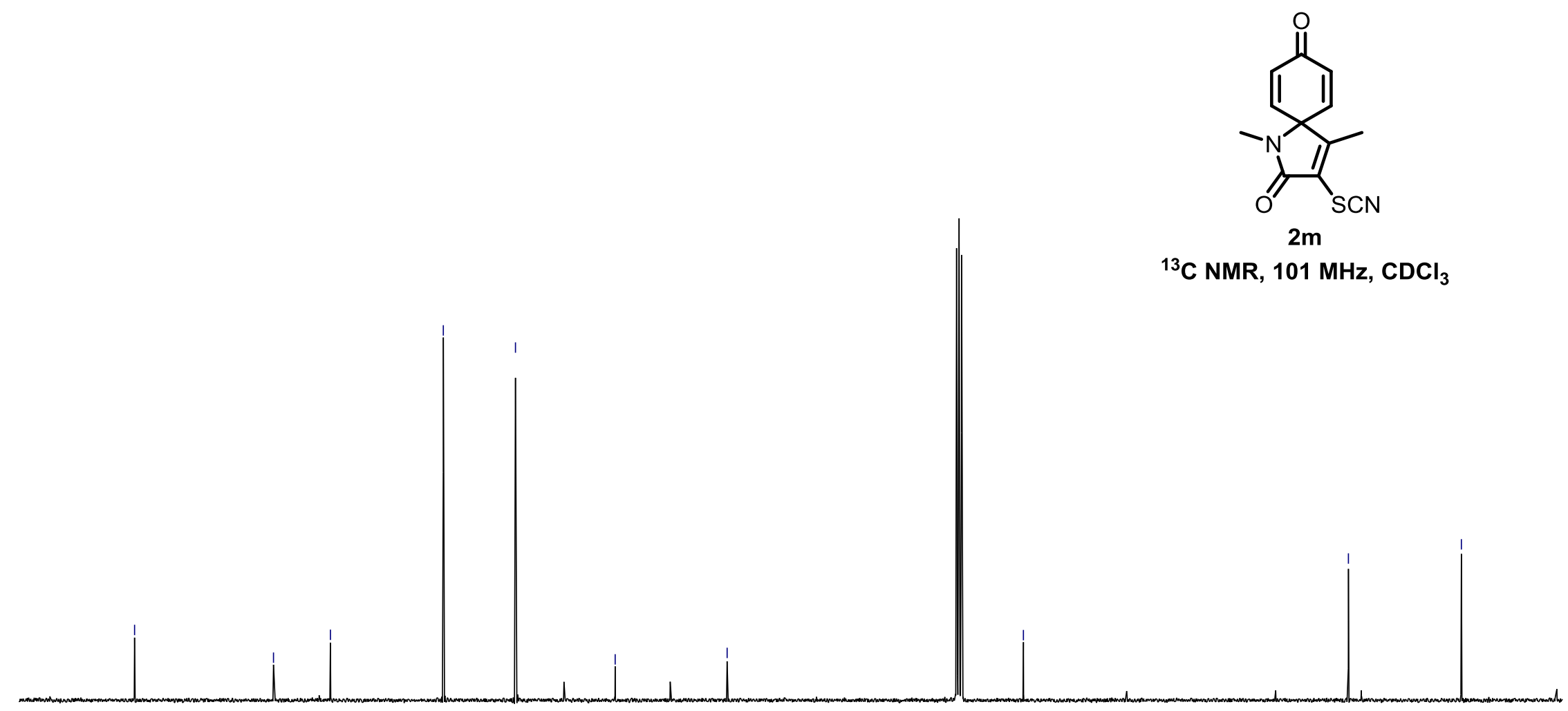




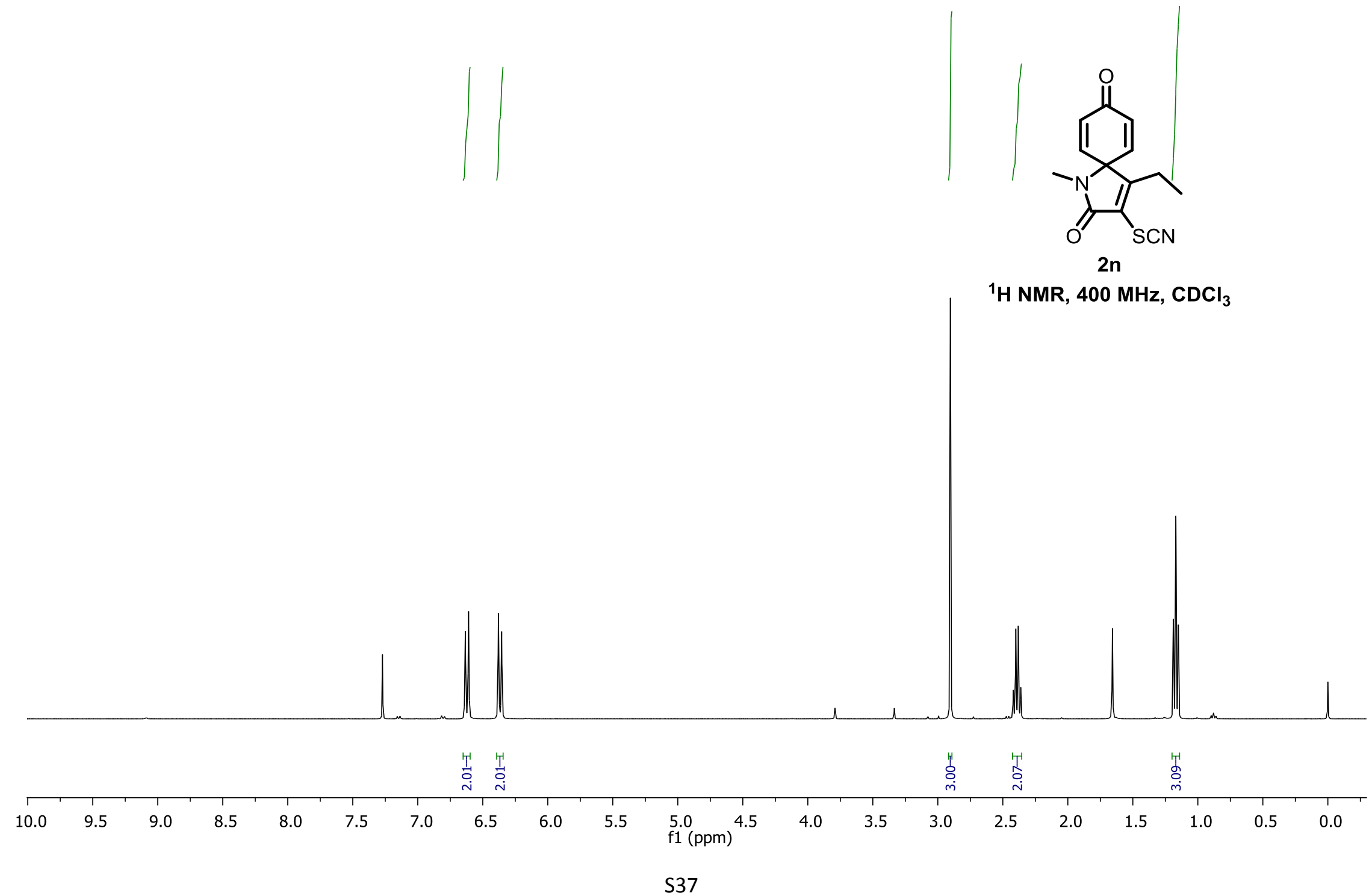



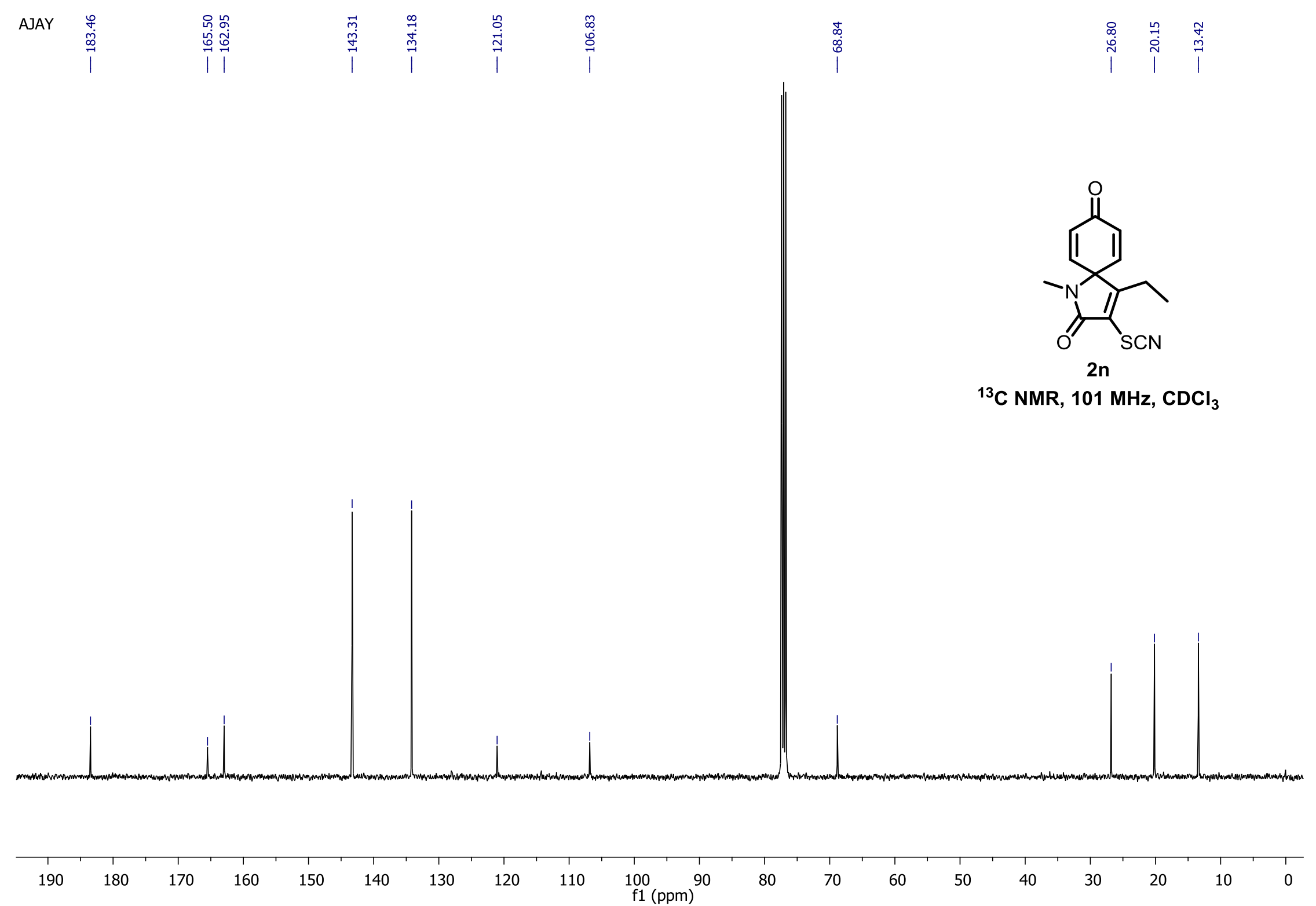
DA
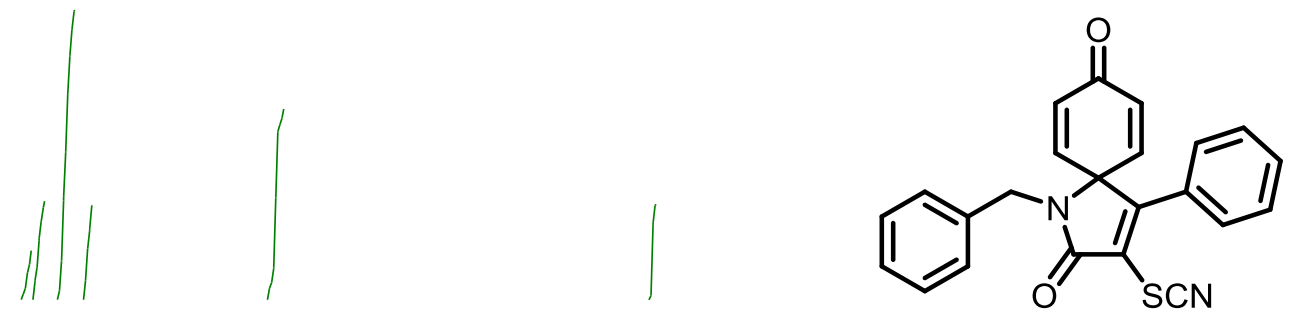

20

${ }^{1} \mathrm{H}$ NMR, $400 \mathrm{MHz}^{\mathrm{CDCl}_{3}}$

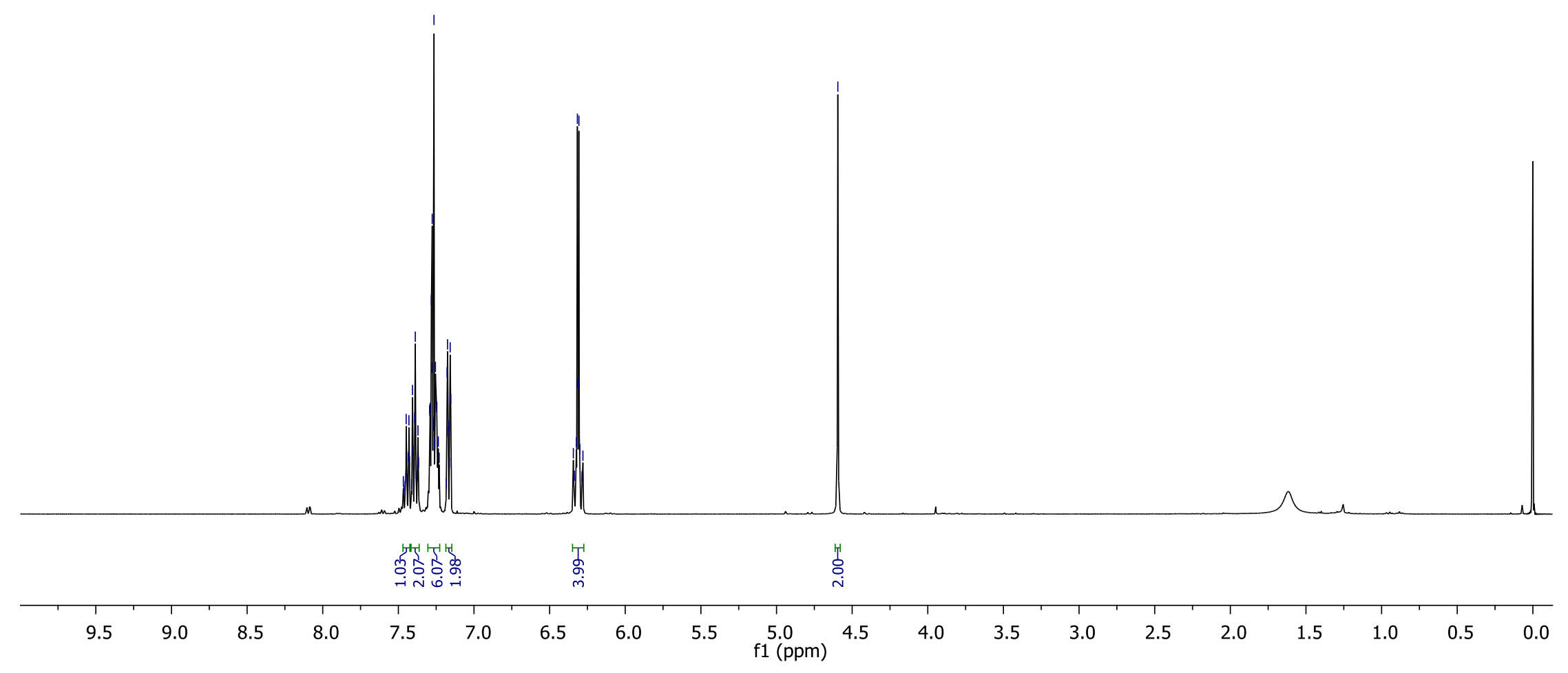




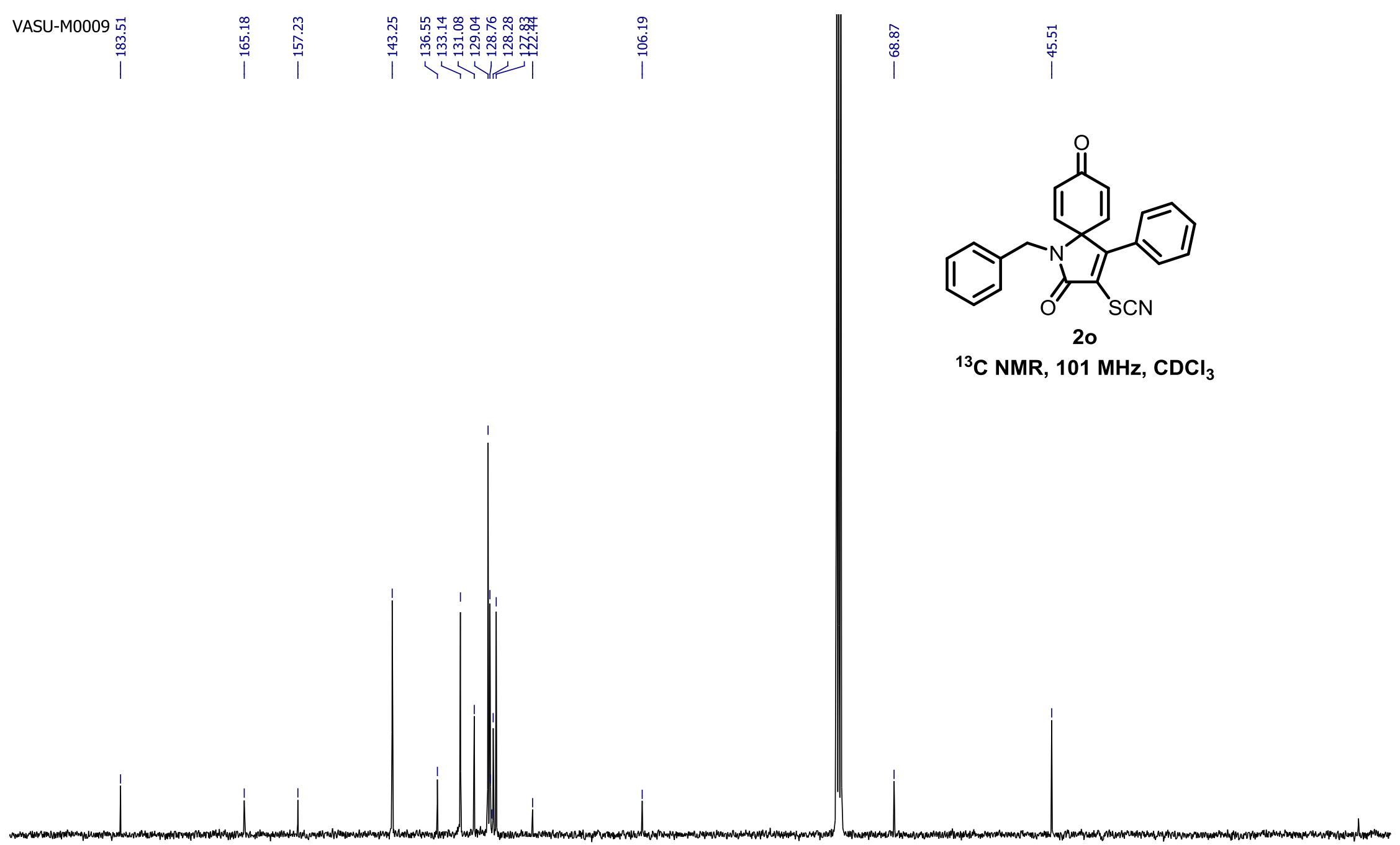

100
$\mathrm{f} 1(\mathrm{ppm})$ 


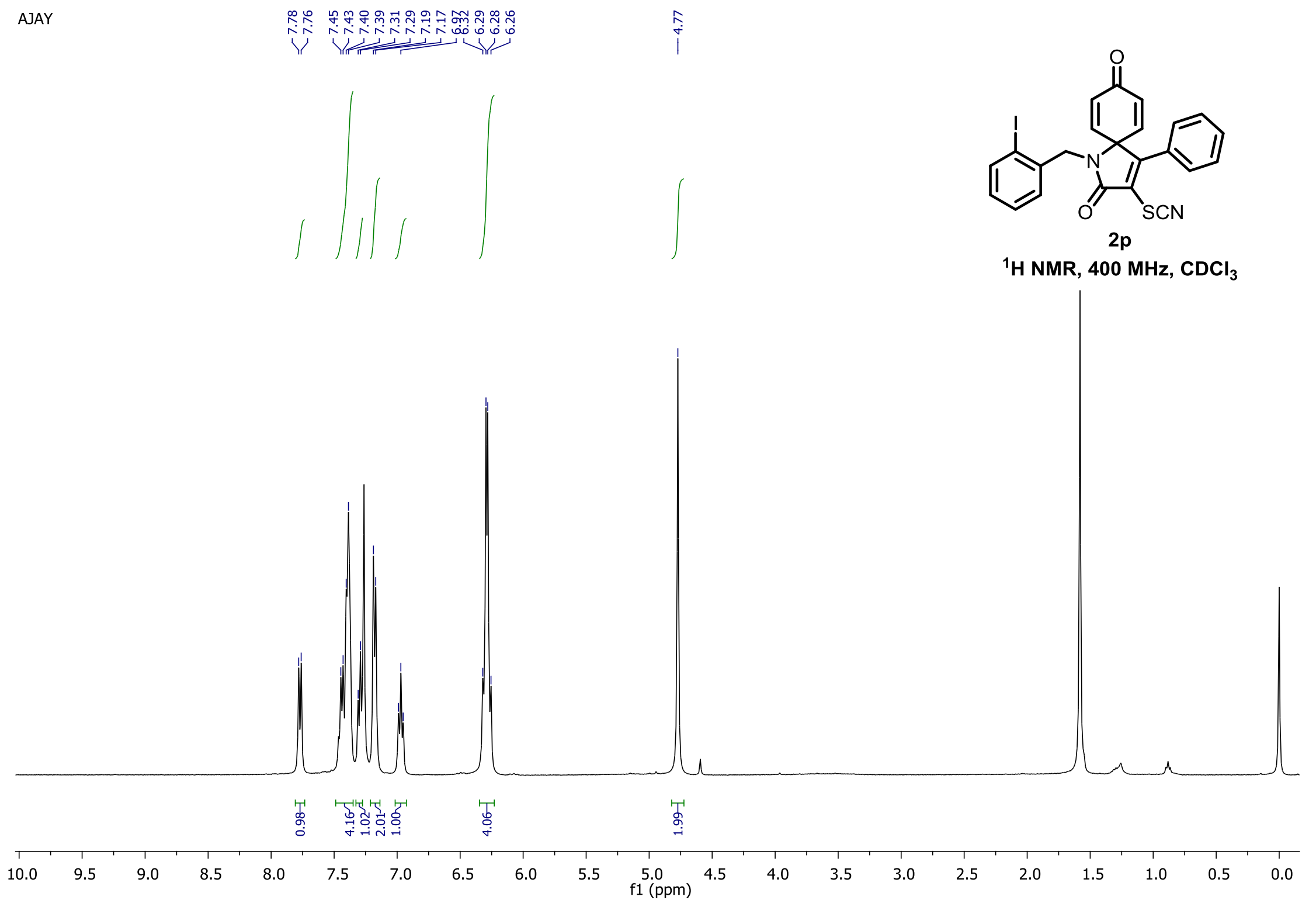



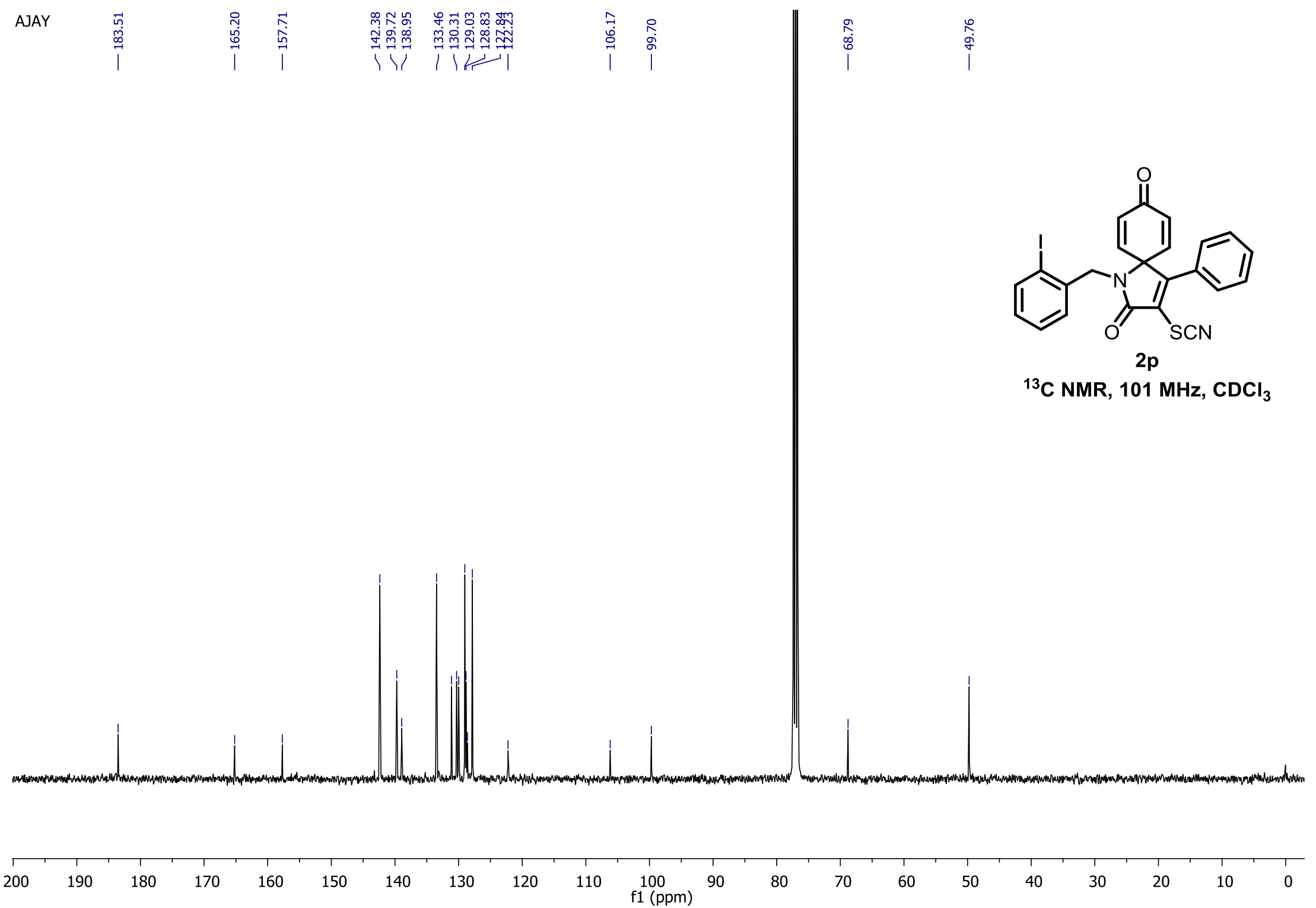


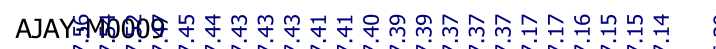

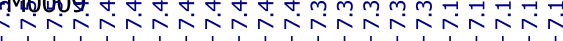

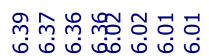

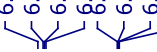

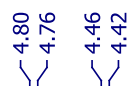

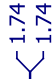
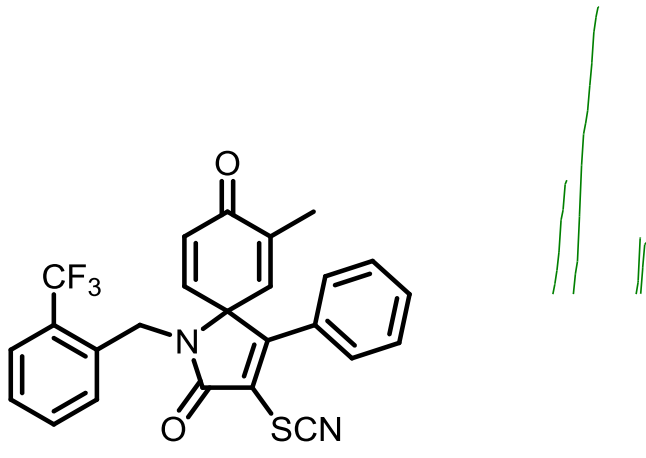

$2 q$

${ }^{1} \mathrm{H}$ NMR, $400 \mathrm{MHz}, \mathrm{CDCl}_{3}$
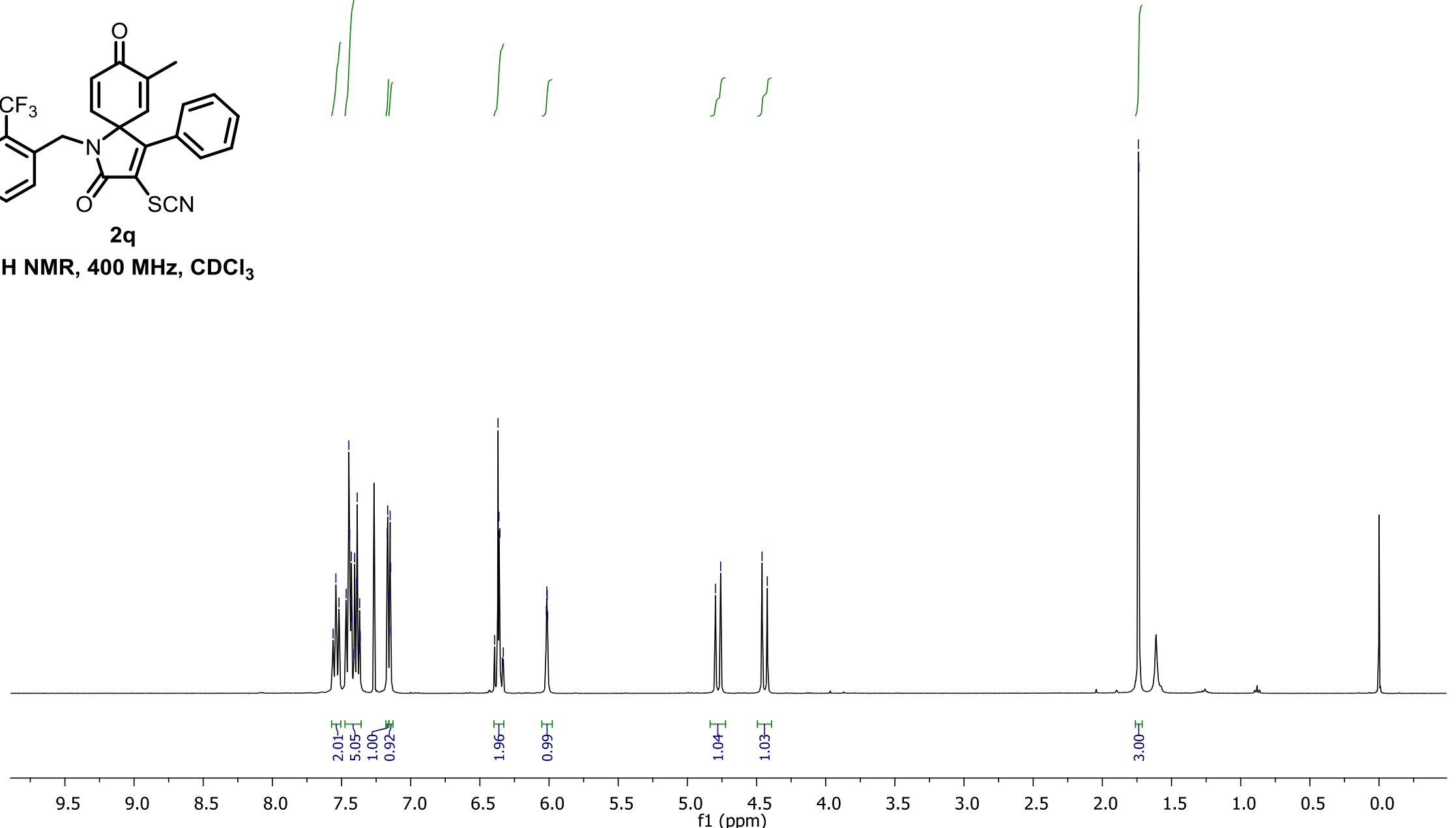

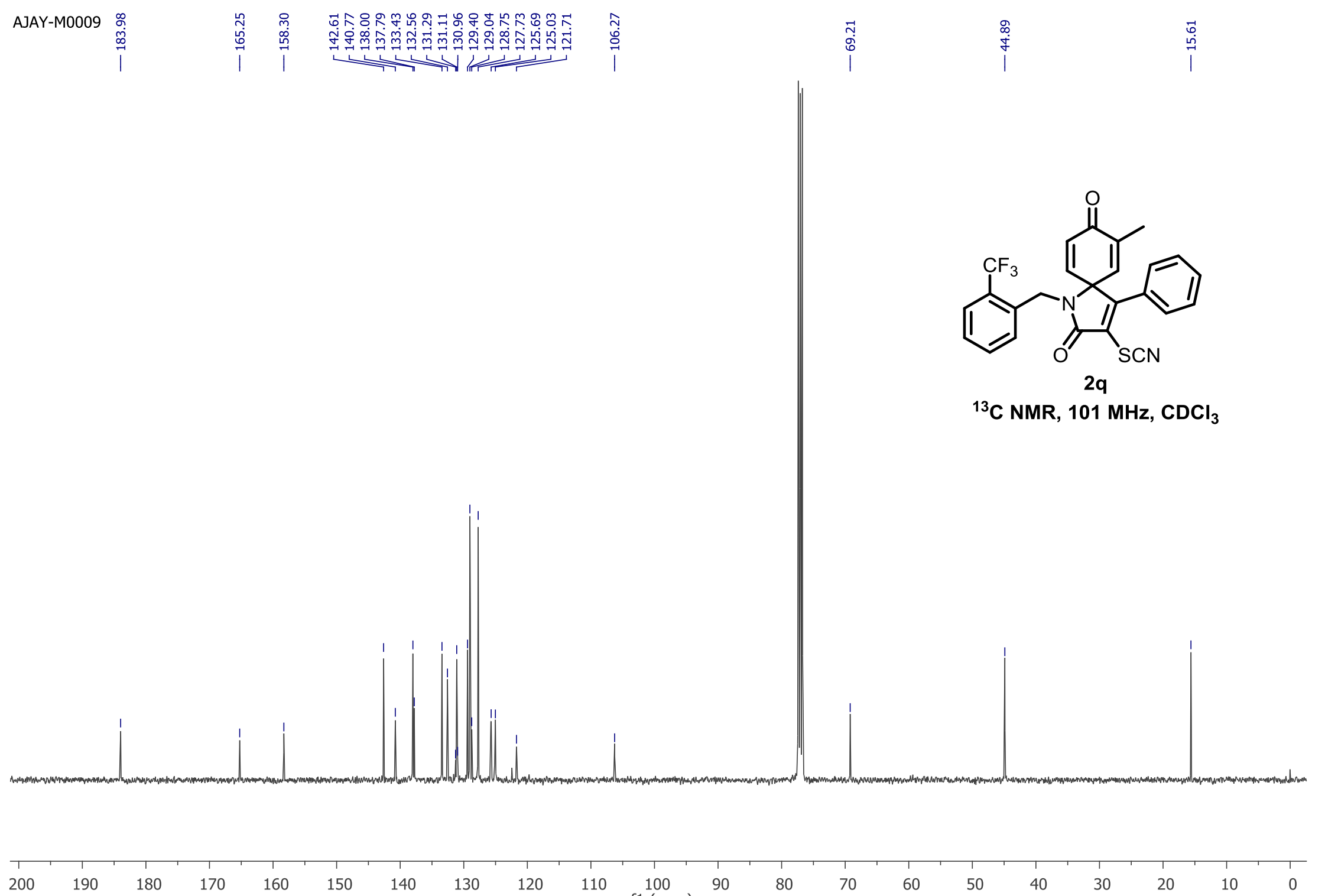


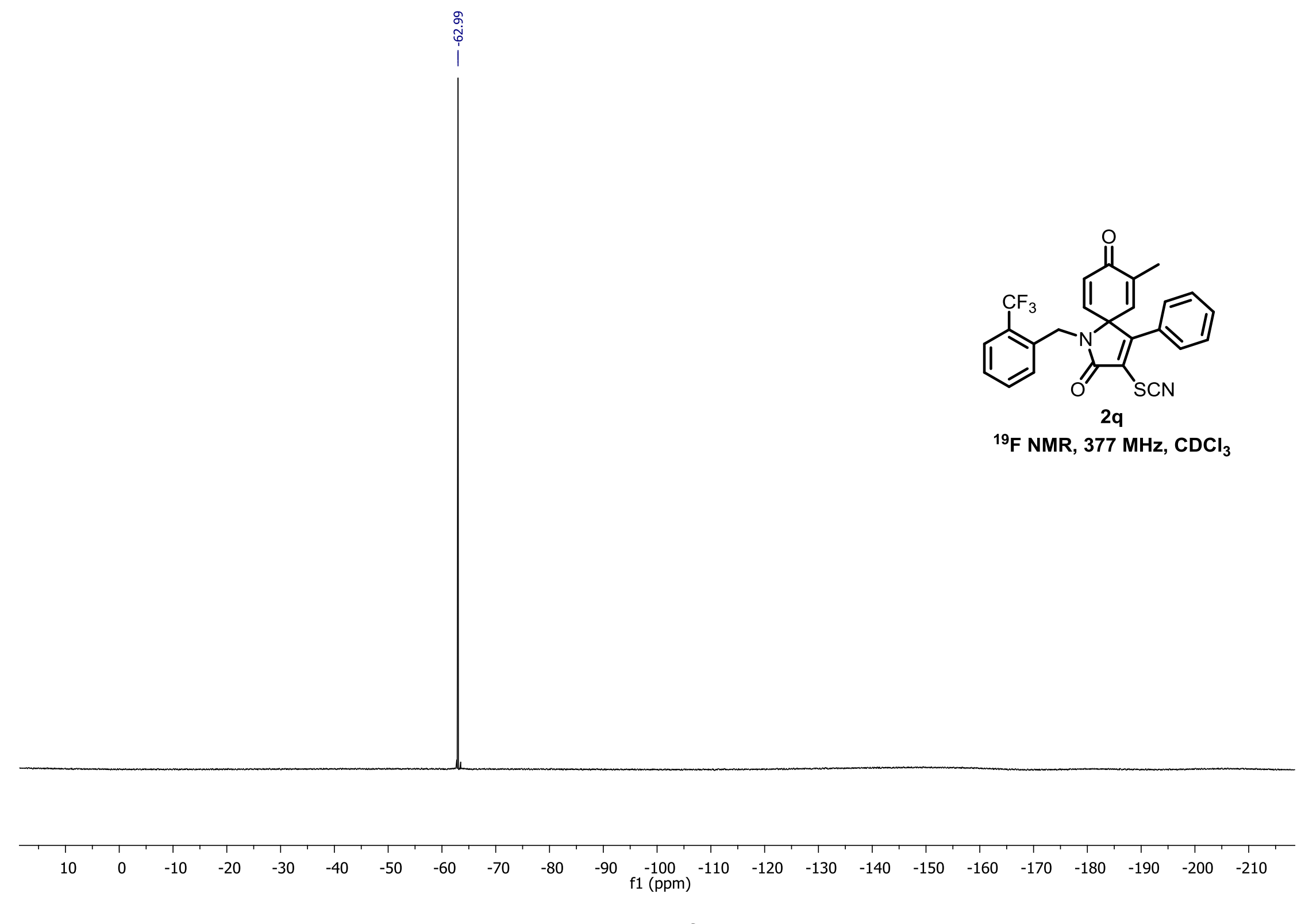




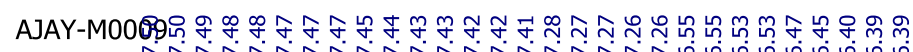

inivinitivis

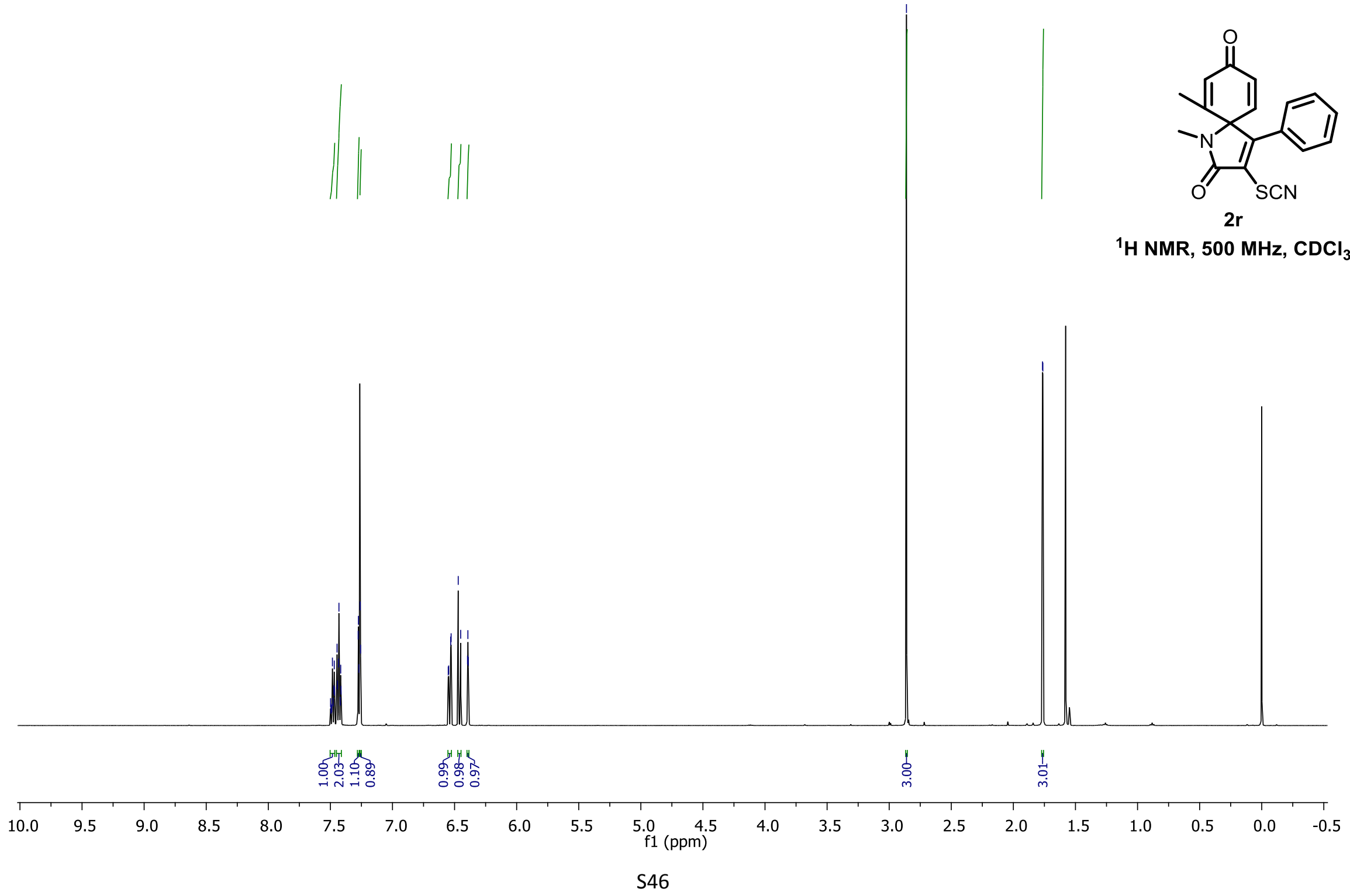




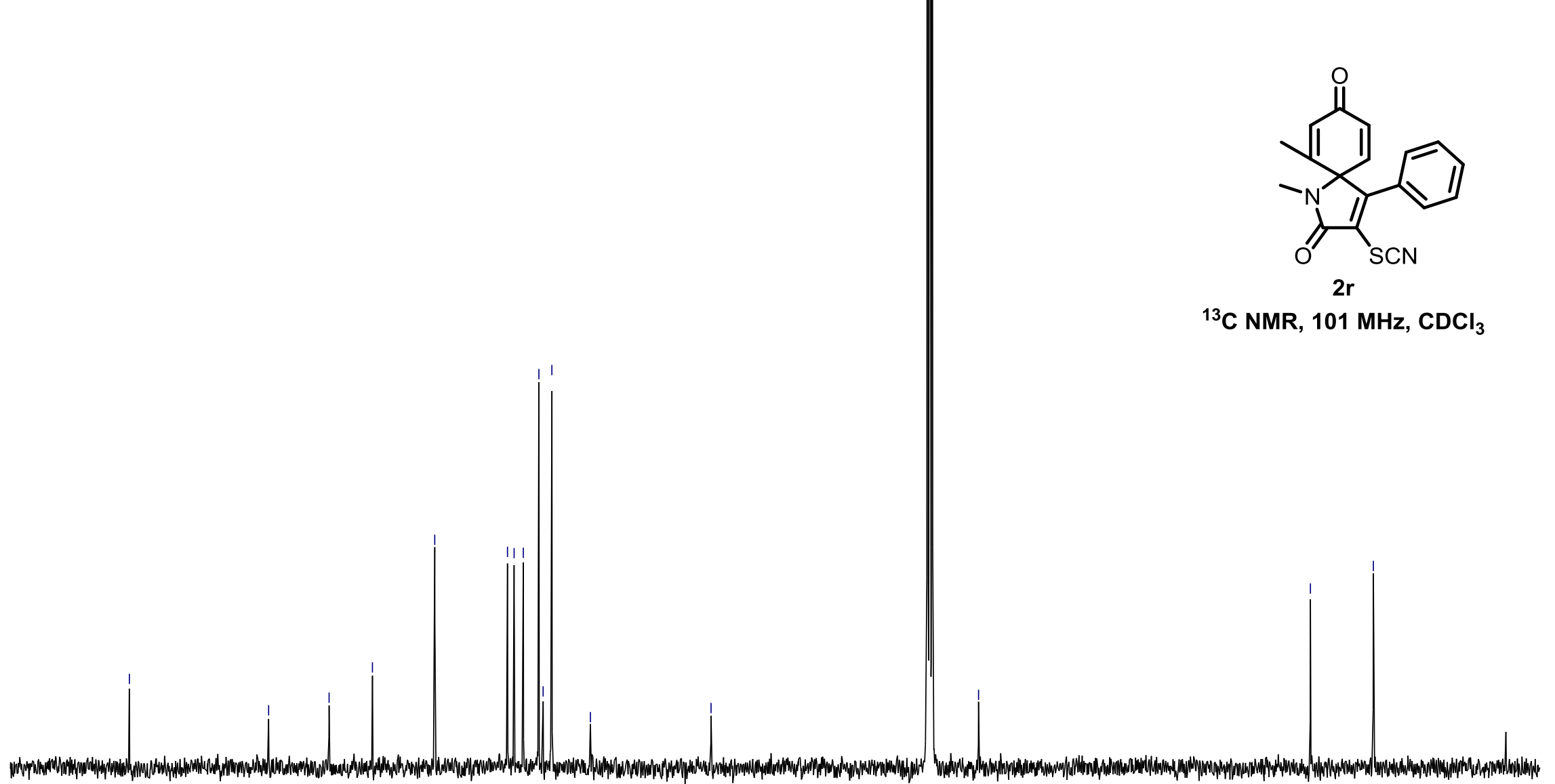

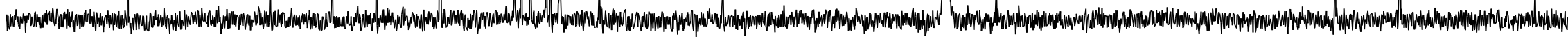




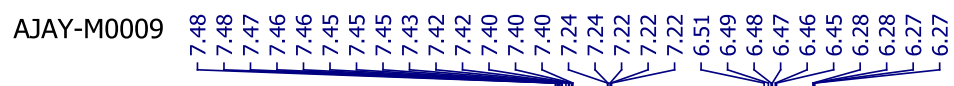

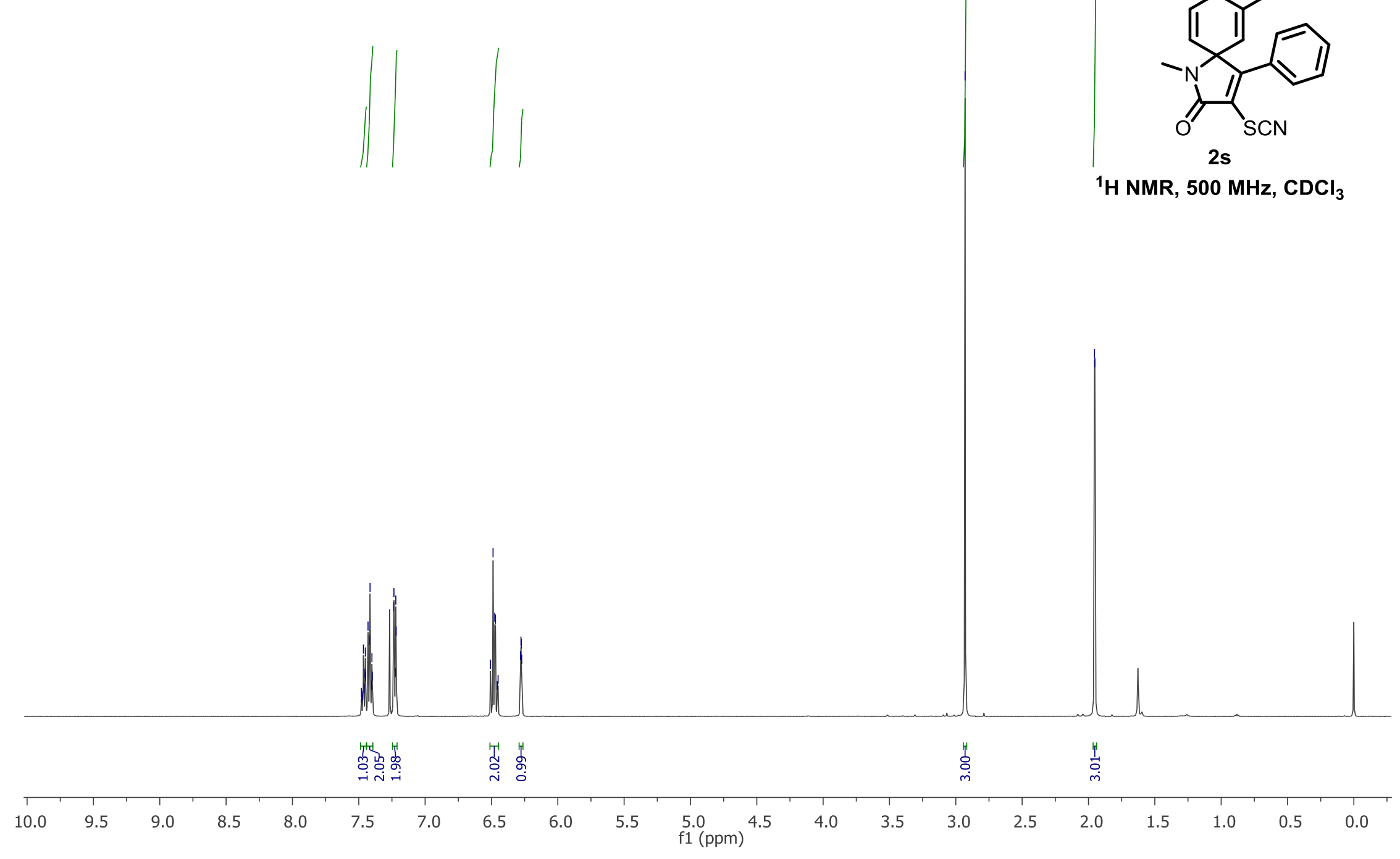



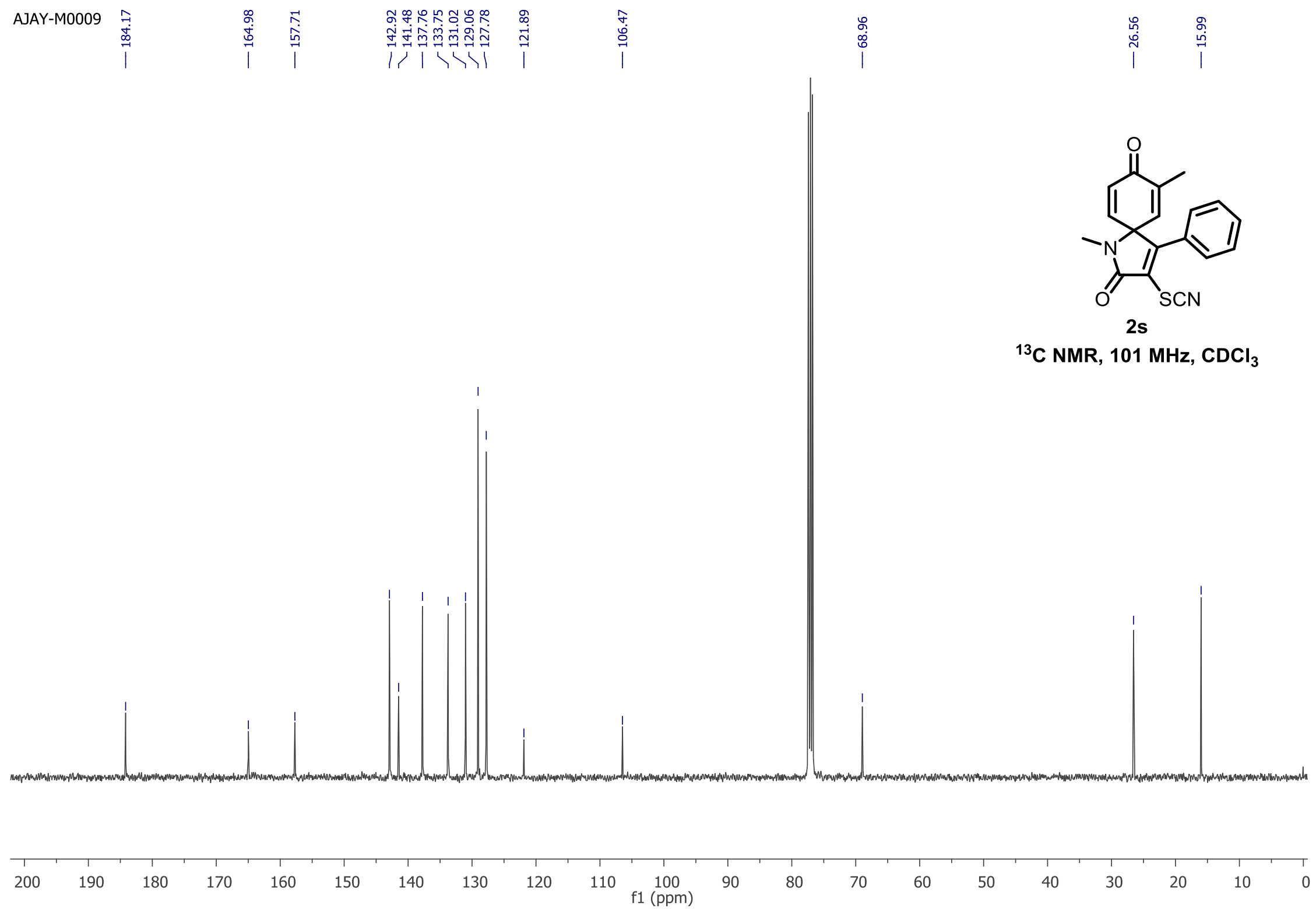


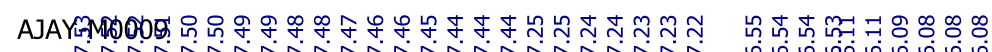

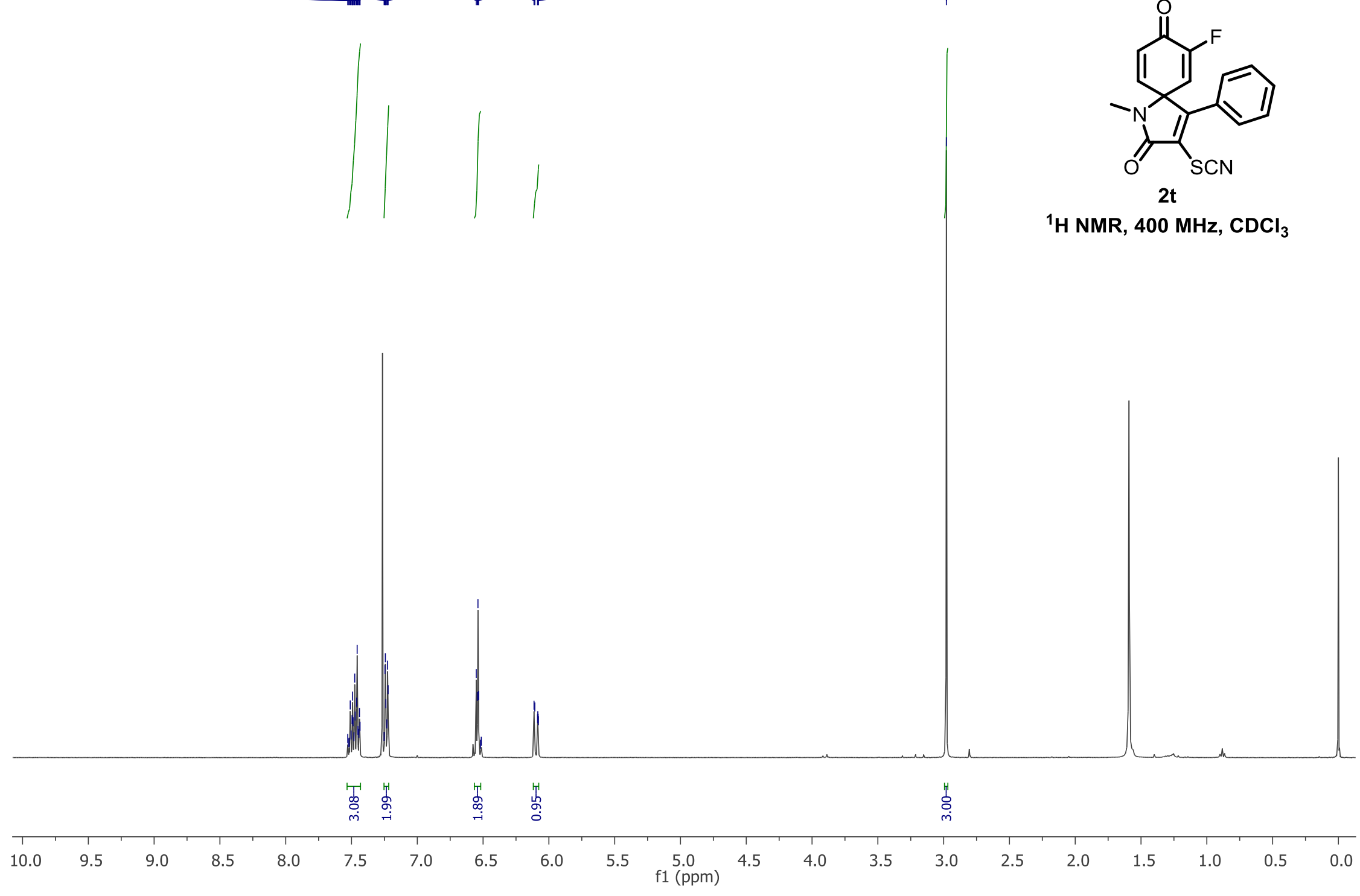




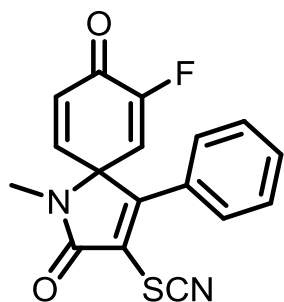

$2 t$

${ }^{13} \mathrm{C}$ NMR, $101 \mathrm{MHz}, \mathrm{CDCl}_{3}$

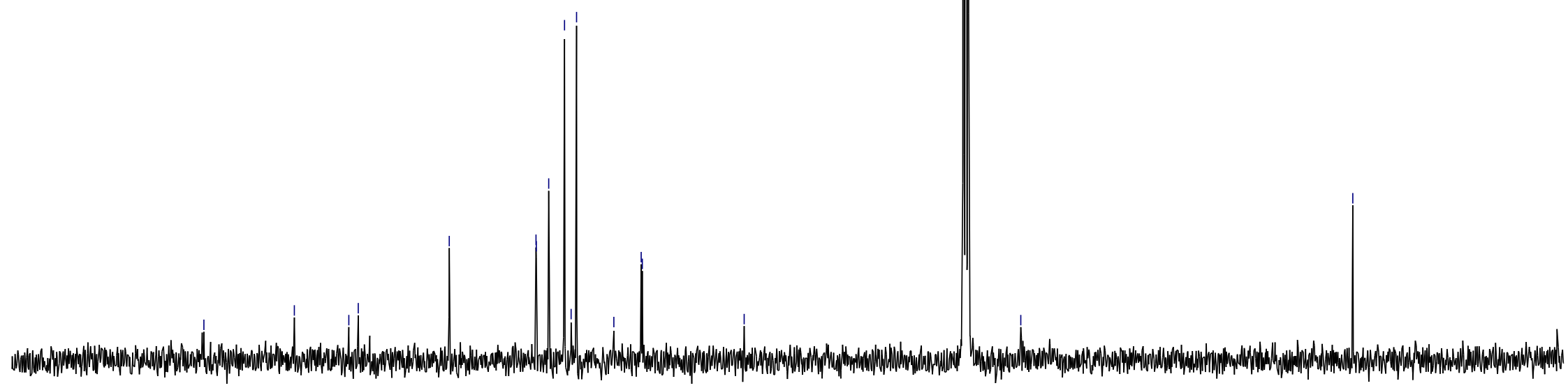




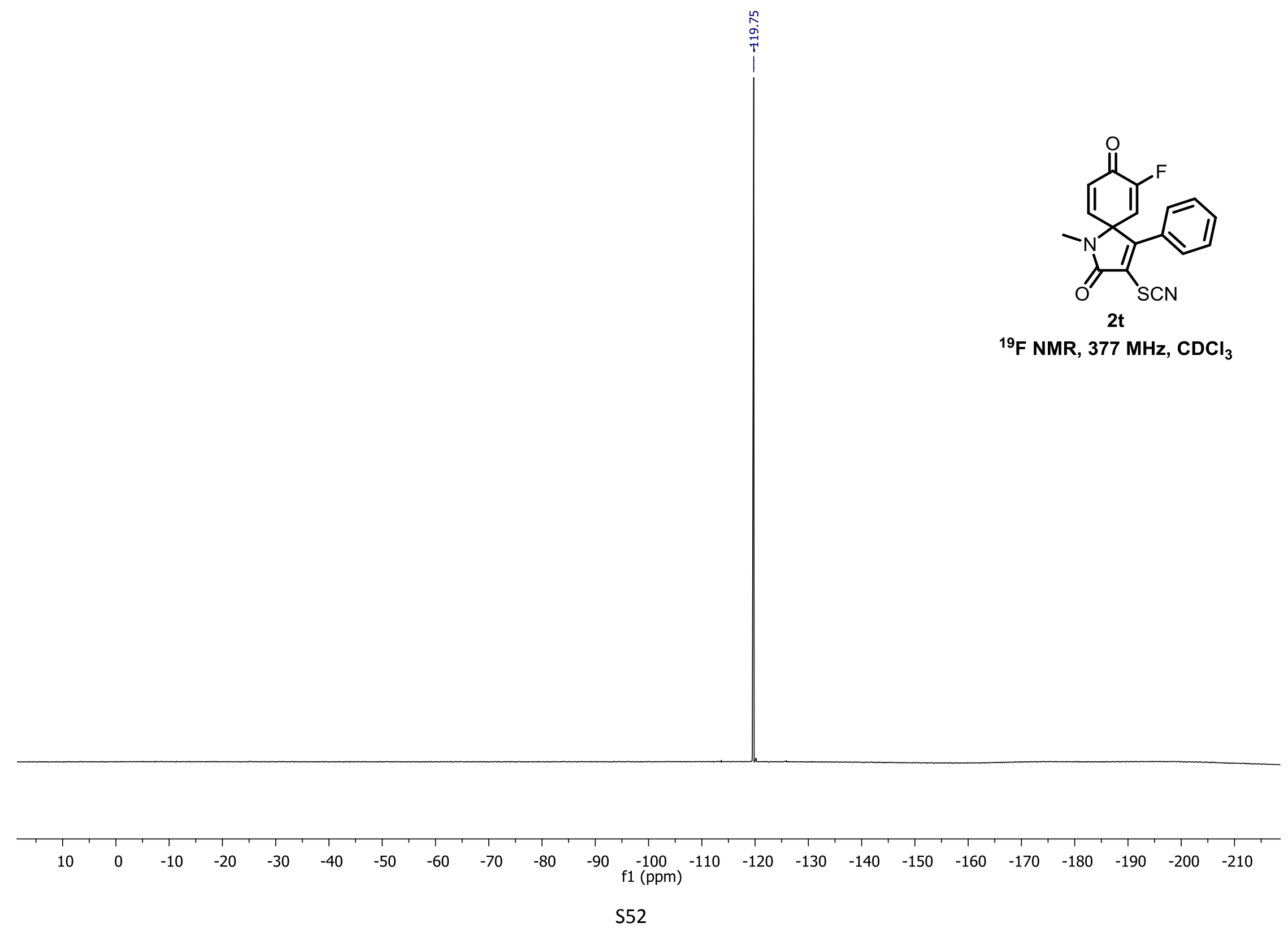



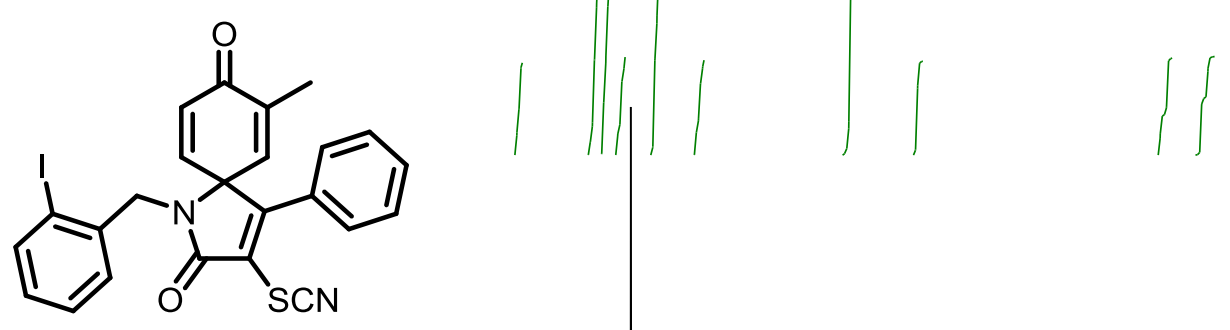

$2 \mathrm{u}$

${ }^{1} \mathrm{H}$ NMR, $500 \mathrm{MHz}, \mathrm{CDCl}_{3}$

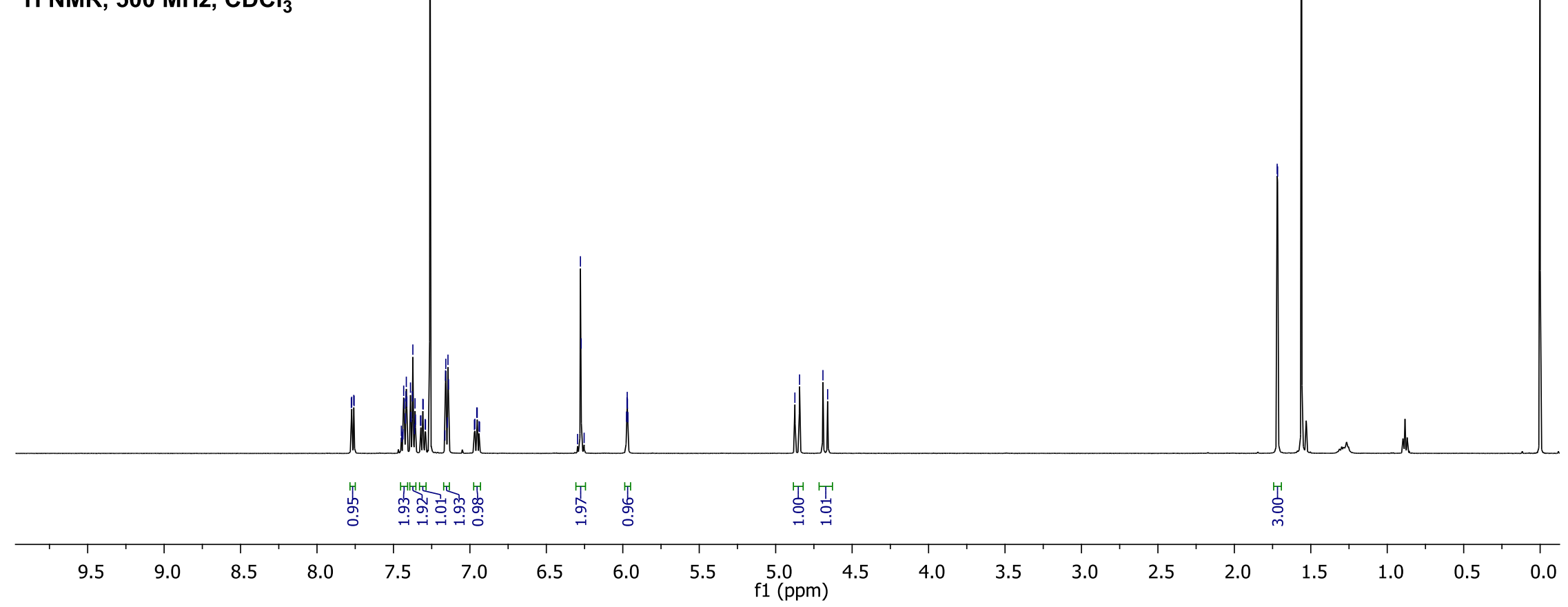




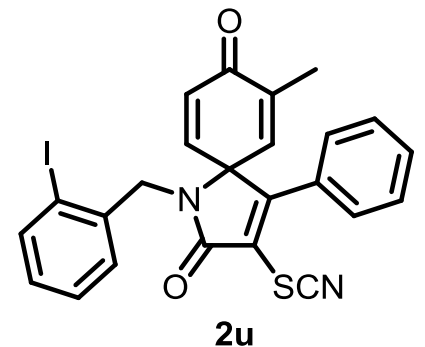

${ }^{13} \mathrm{C} \mathrm{NMR}, 101 \mathrm{MHz}, \mathrm{CDCl}_{3}$

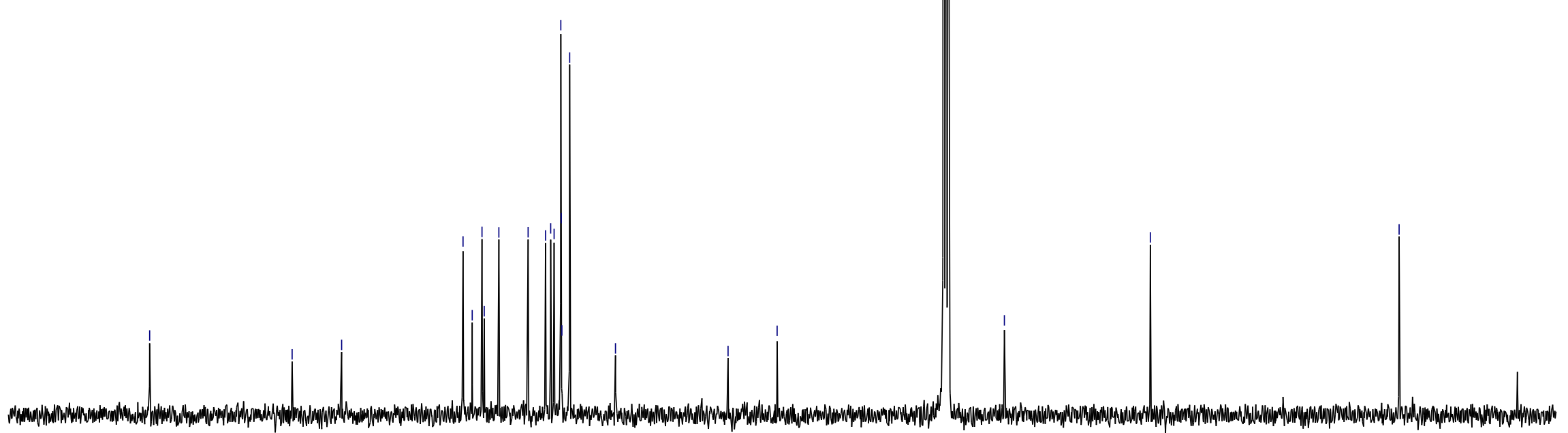




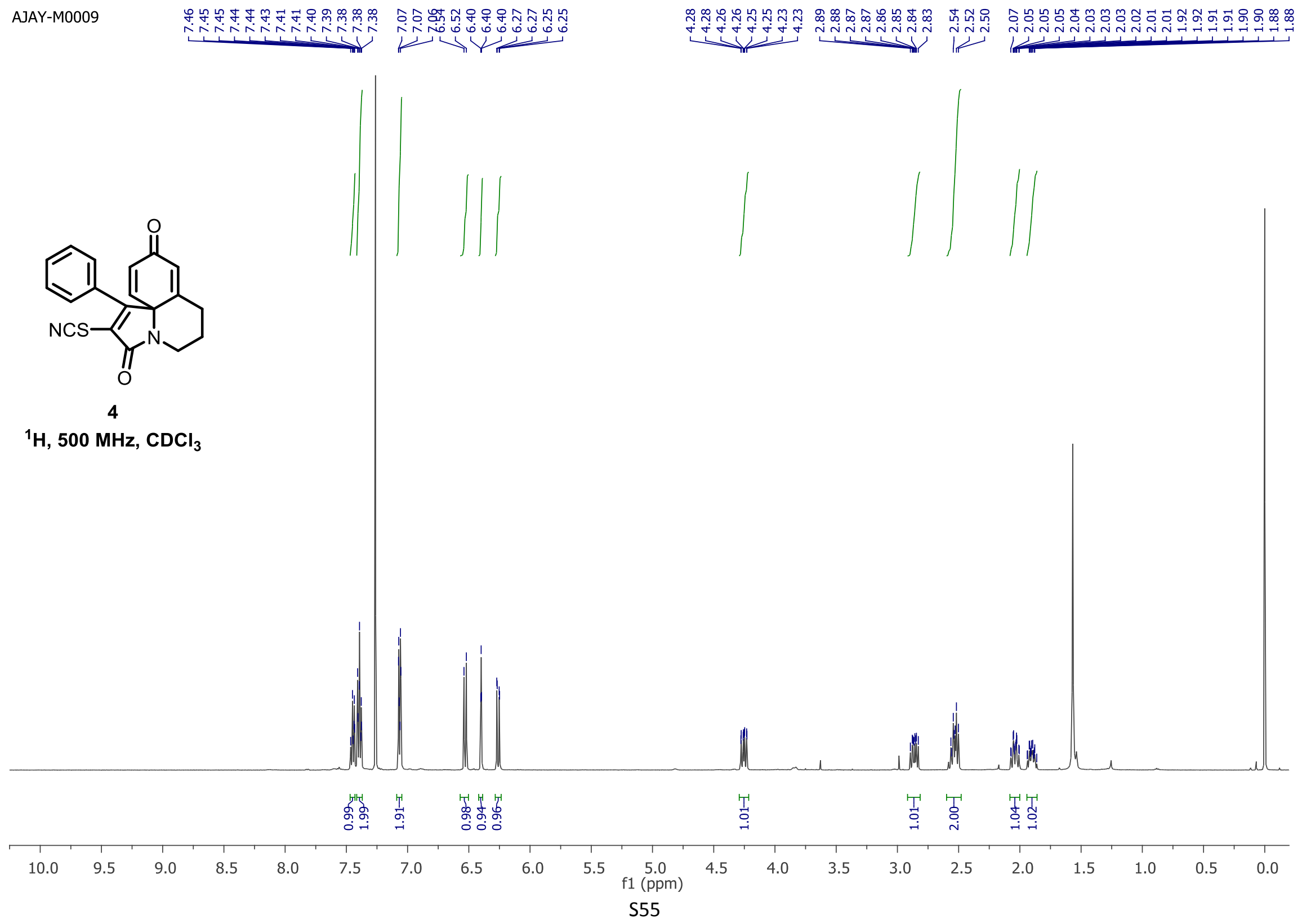



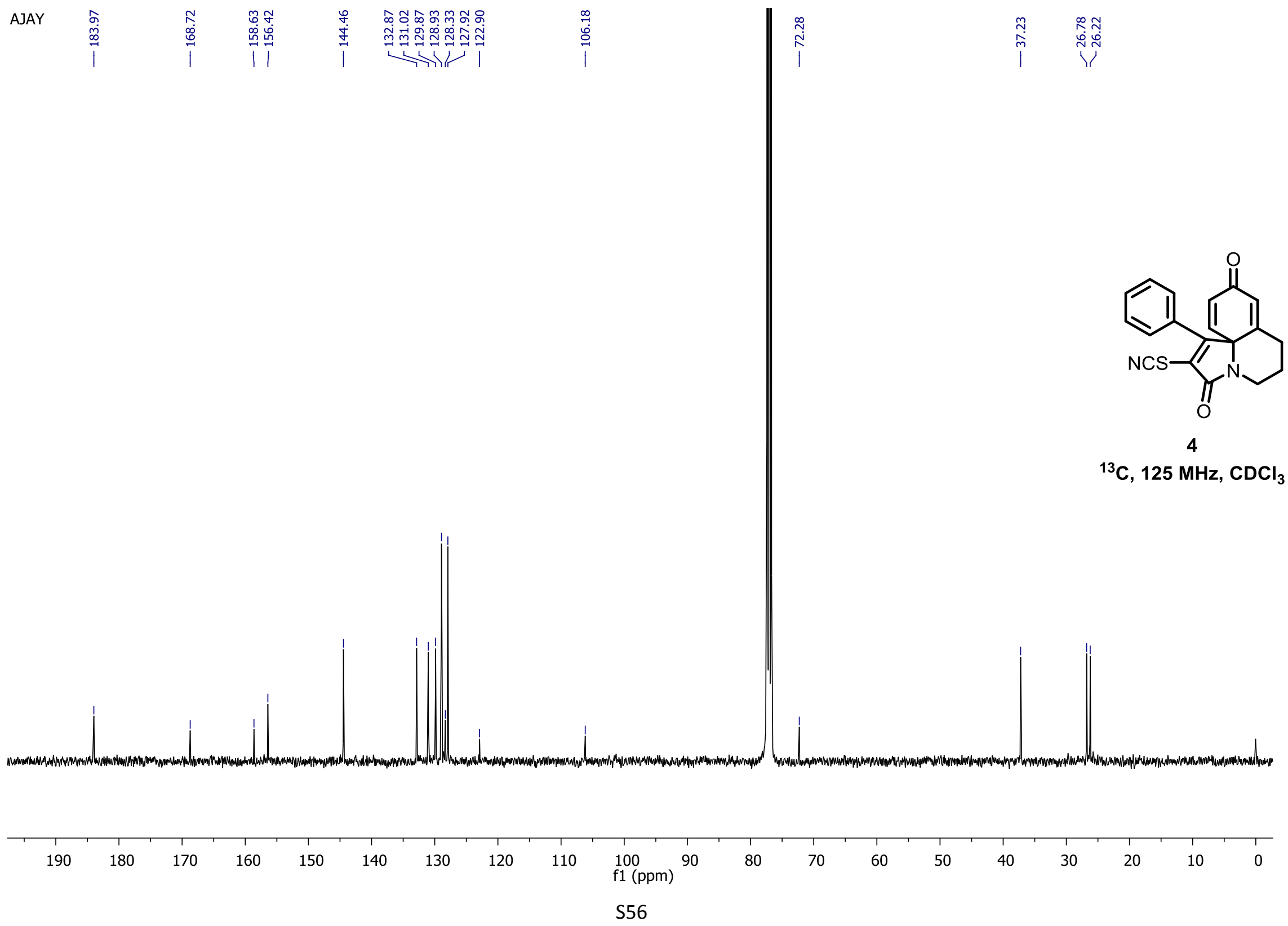


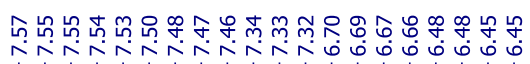

OSPC1886
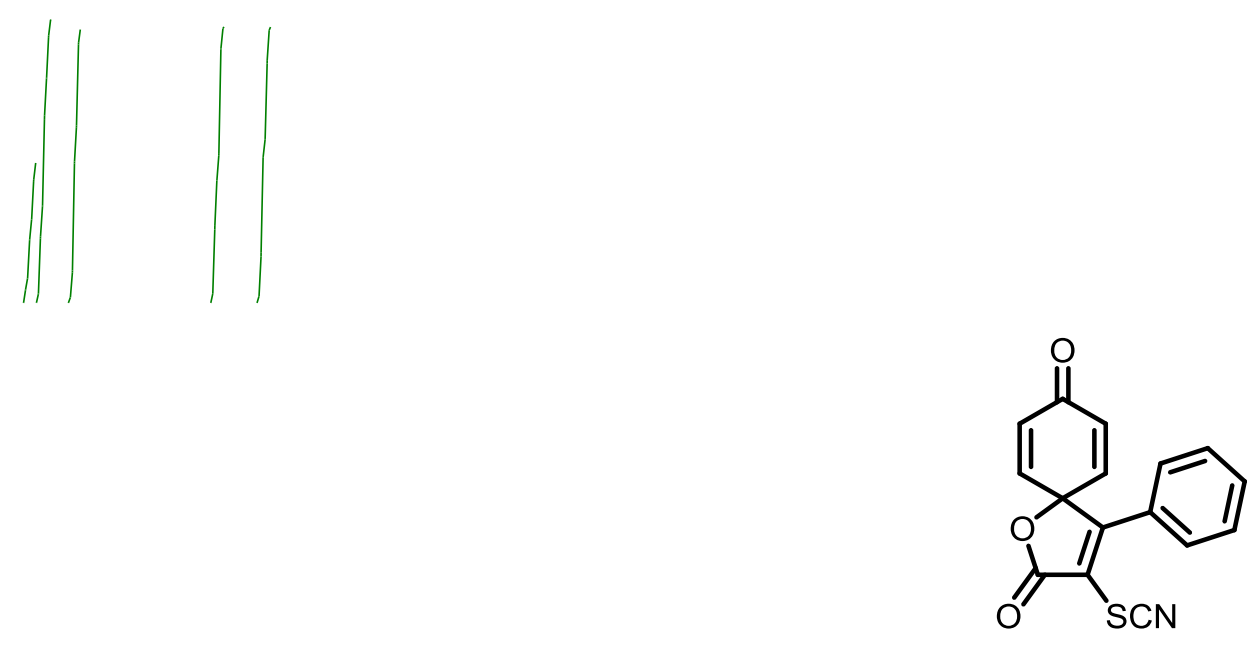

$6 a$

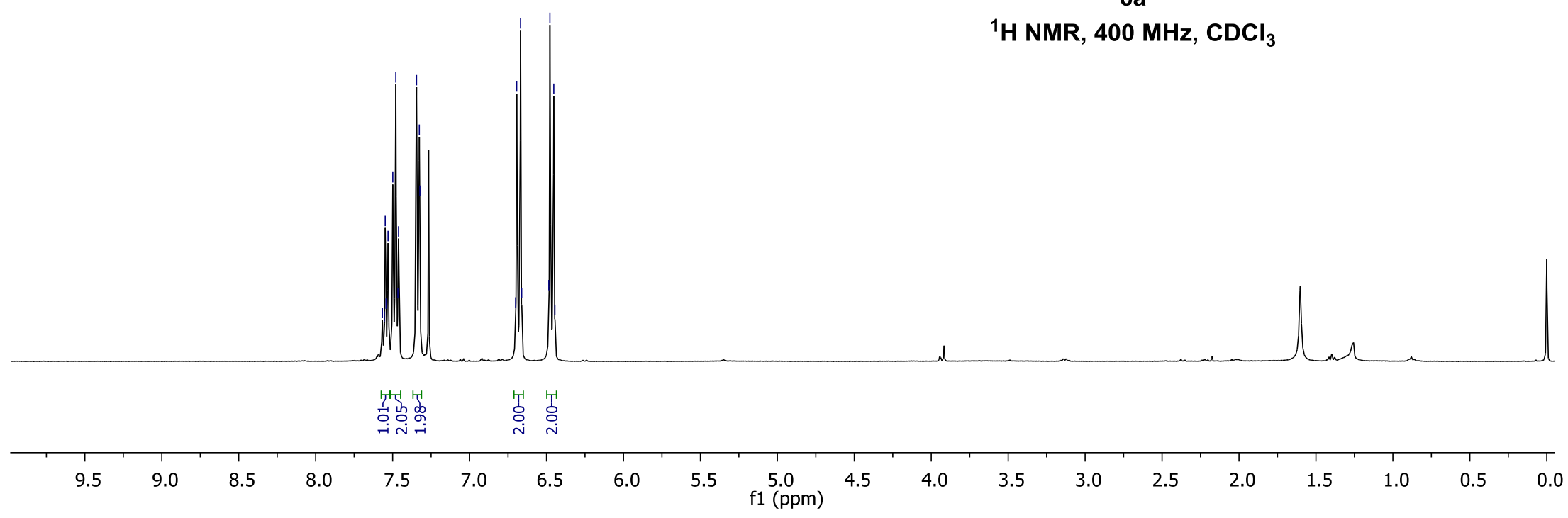



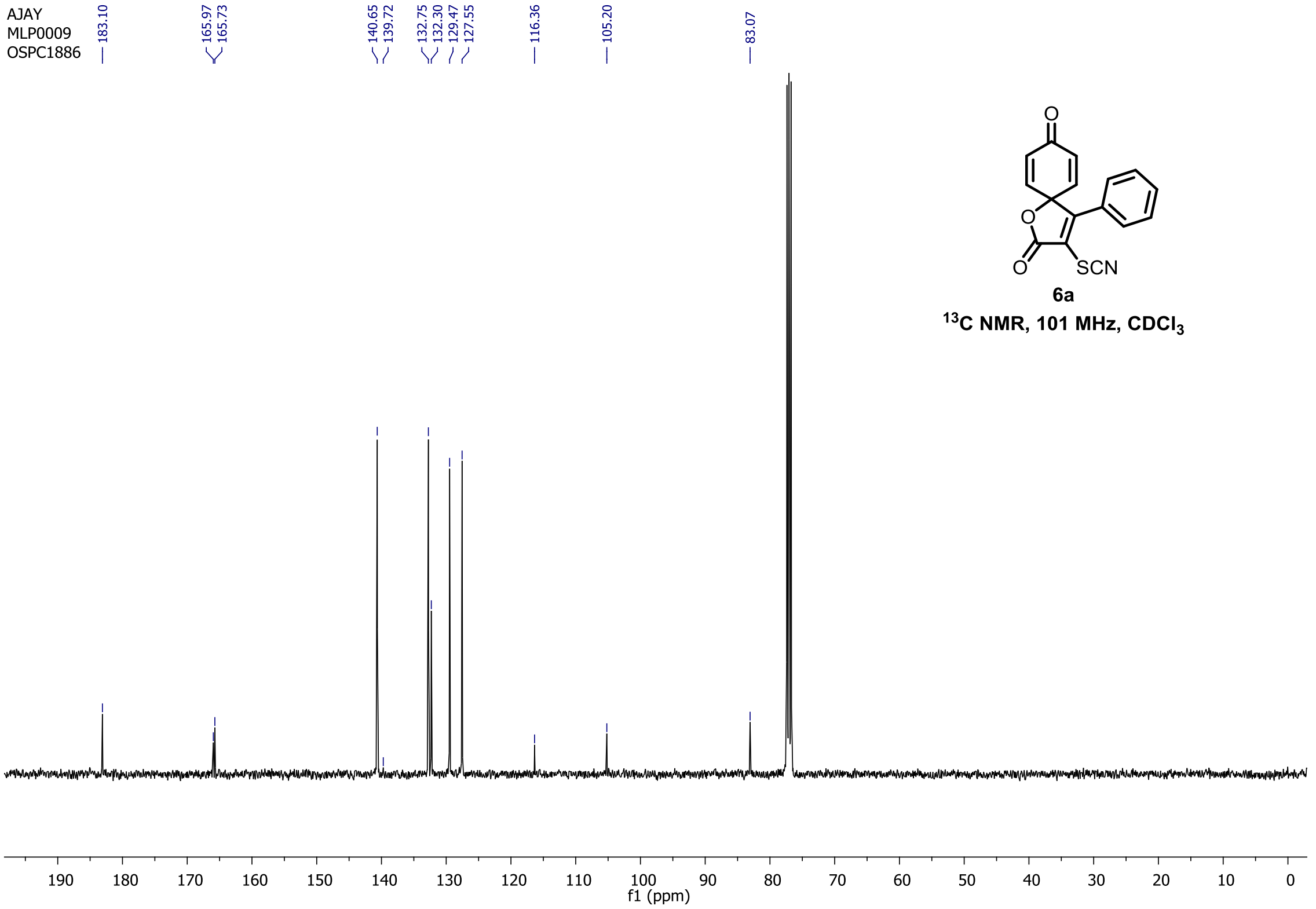


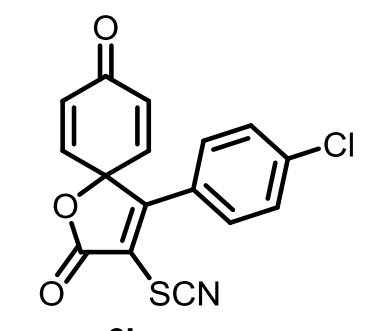

$6 b$

${ }^{1} \mathrm{H}$ NMR, $400 \mathrm{MHz}, \mathrm{CDCl}_{3}$

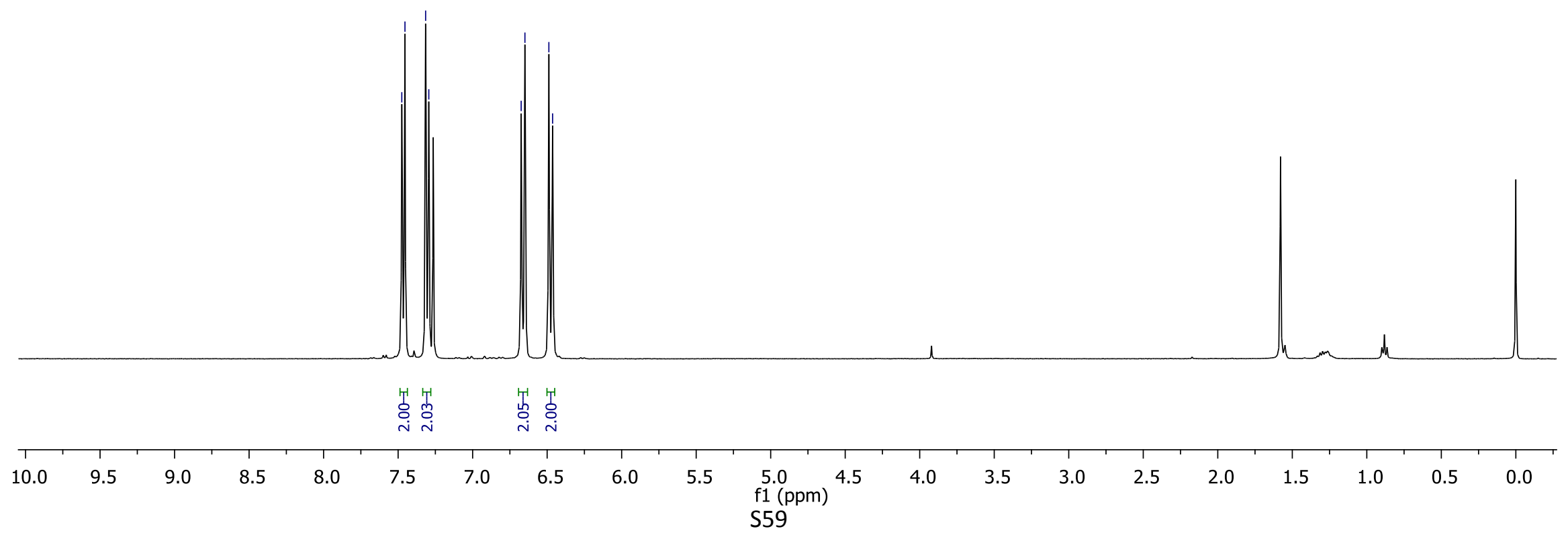



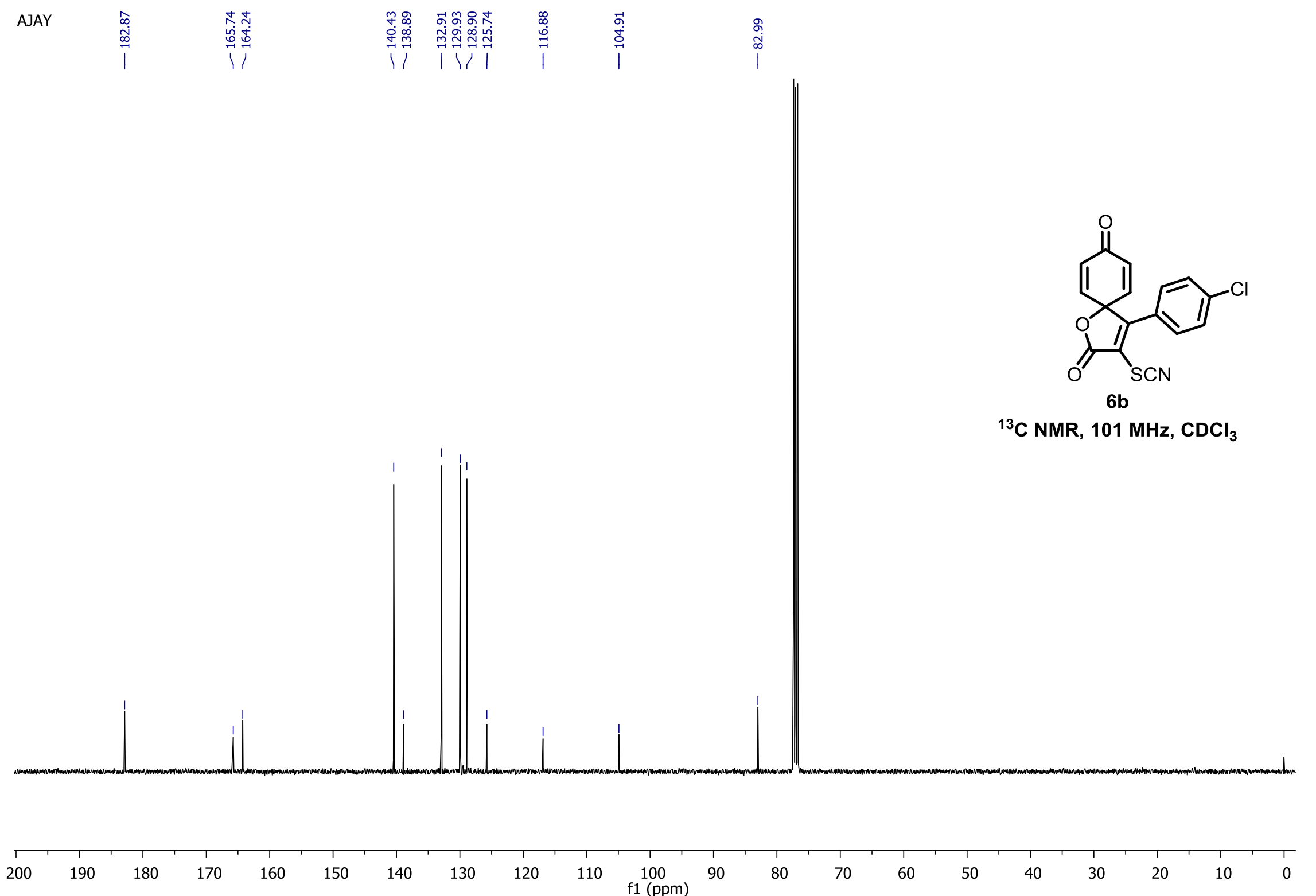
AJAY
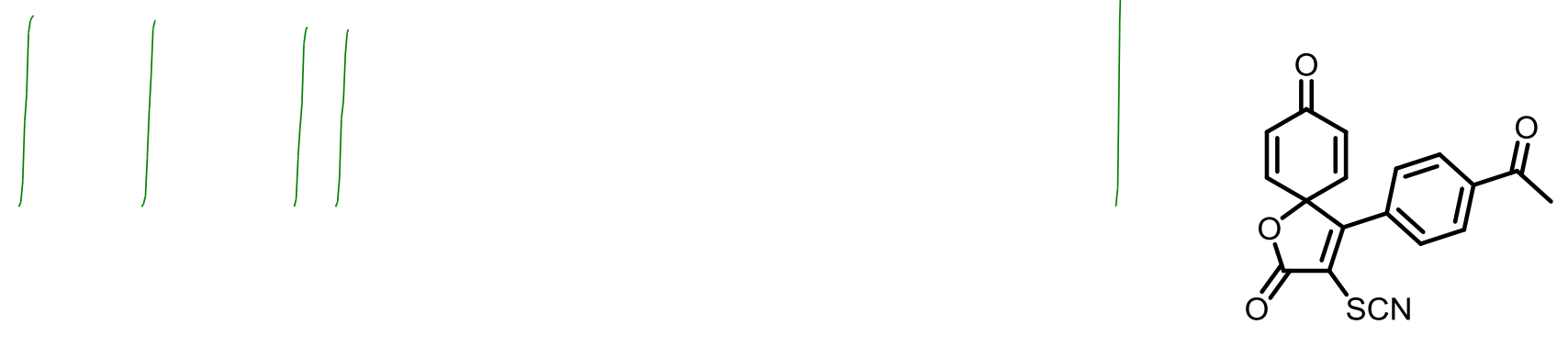

$6 c$

${ }^{1} \mathrm{H}$ NMR, $400 \mathrm{MHz}, \mathrm{CDCl}_{3}$

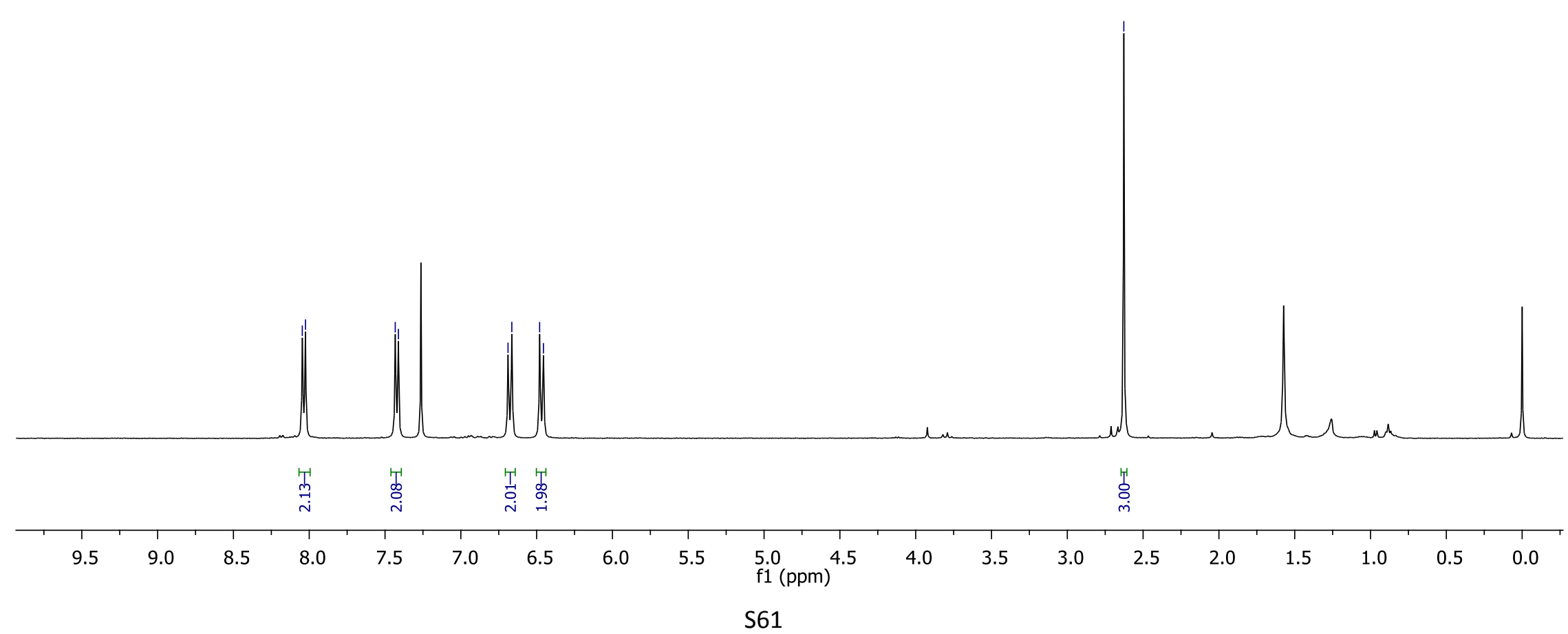


AJAY

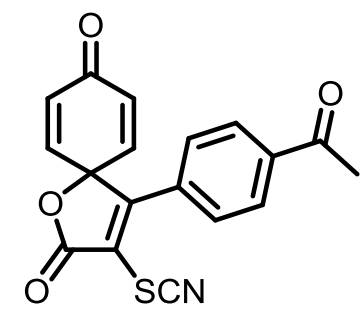

$$
6 c
$$

${ }^{13} \mathrm{C}$ NMR, $101 \mathrm{MHz}, \mathrm{CDCl}_{3}$
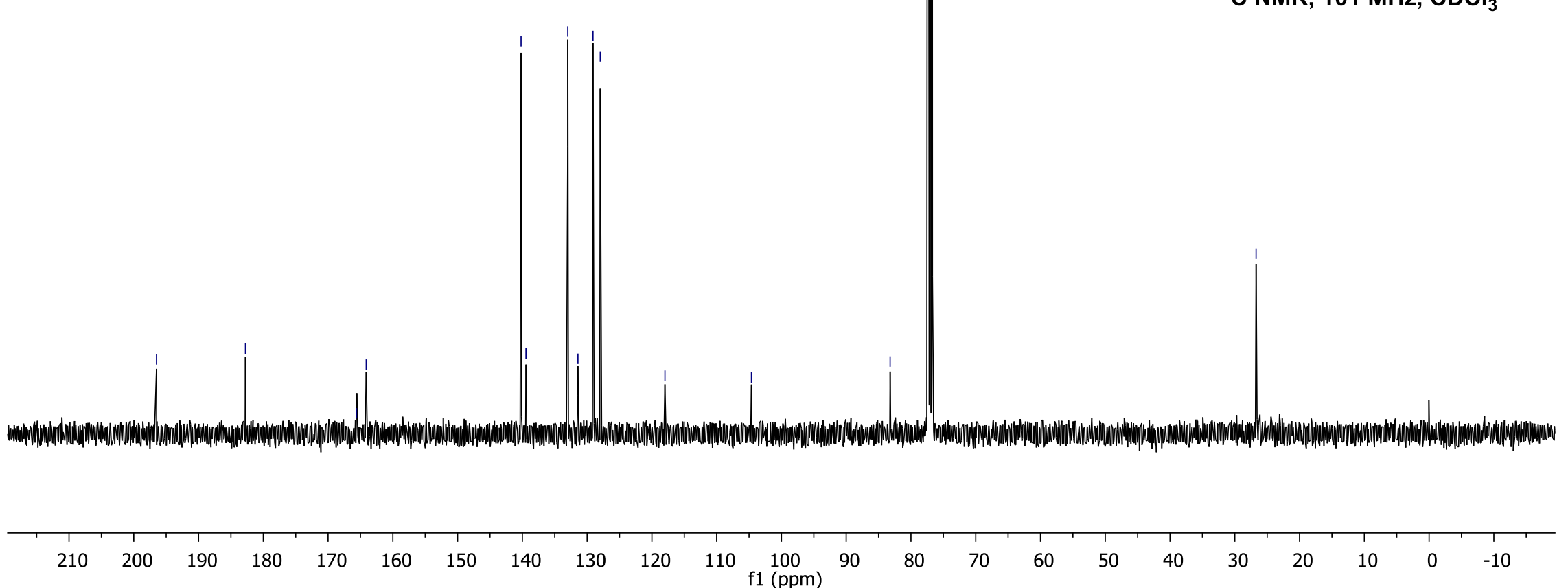
AJAY
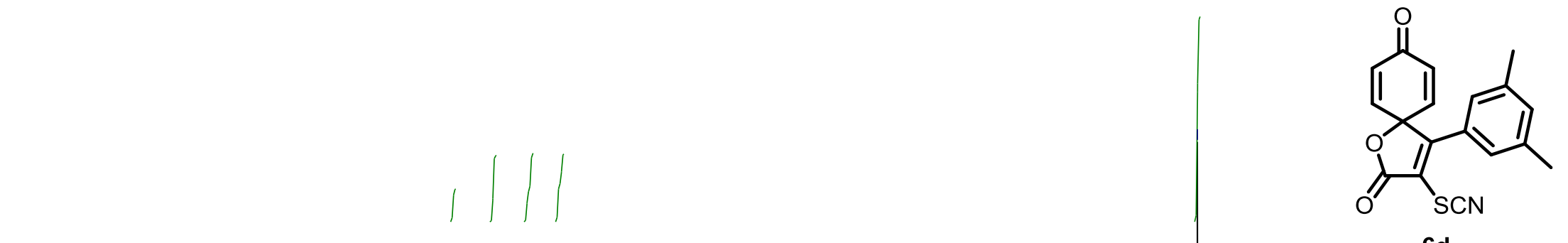

${ }^{1} \mathrm{H}$ NMR, $400 \mathrm{MHz}, \mathrm{CDCl}_{3}$

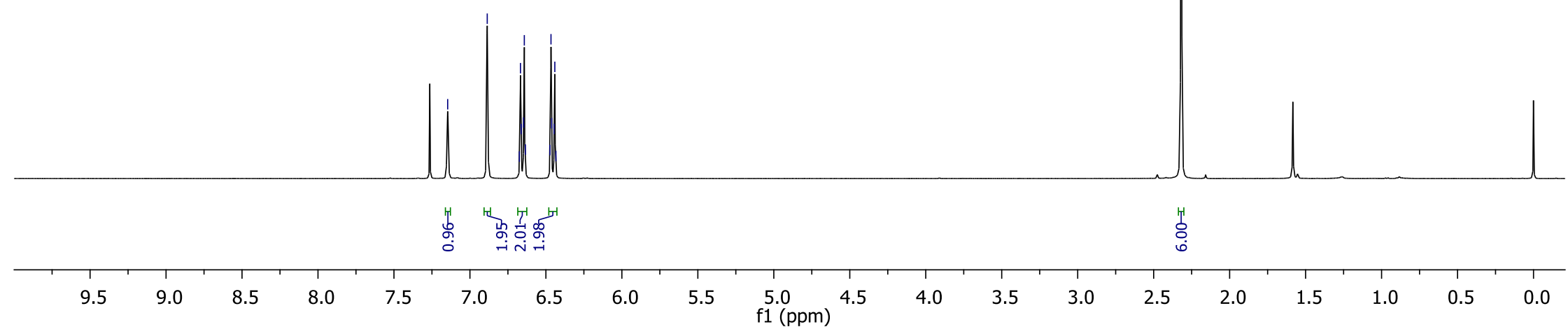




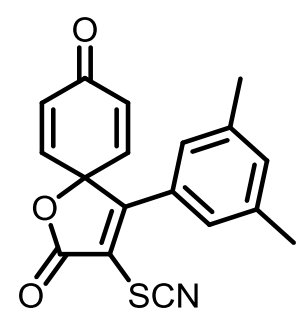

6d

${ }^{13} \mathrm{C}$ NMR, $101 \mathrm{MHz}, \mathrm{CDCl}_{3}$

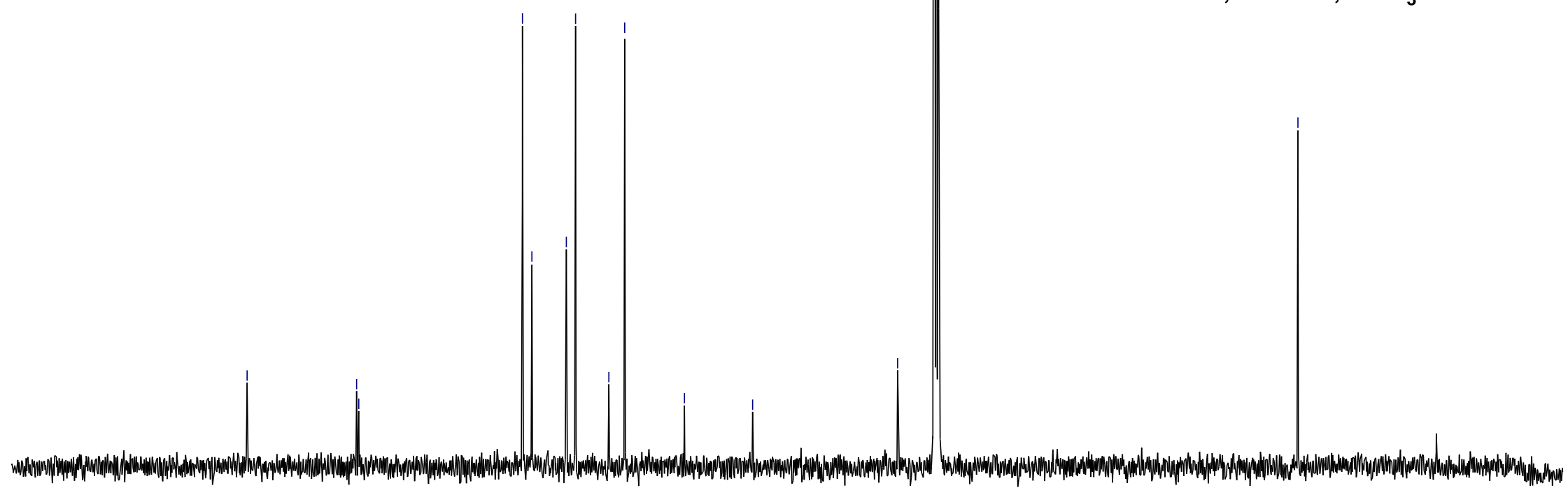

$\begin{array}{llllllllllllllllllllllll}210 & 200 & 190 & 180 & 170 & 160 & 150 & 140 & 130 & 120 & 110 & \begin{array}{c}100 \\ \mathrm{f} 1(\mathrm{ppm})\end{array} & 90 & 80 & 70 & 60 & 50 & 40 & 30 & 20 & 10 & 0 & -10 & \end{array}$ 


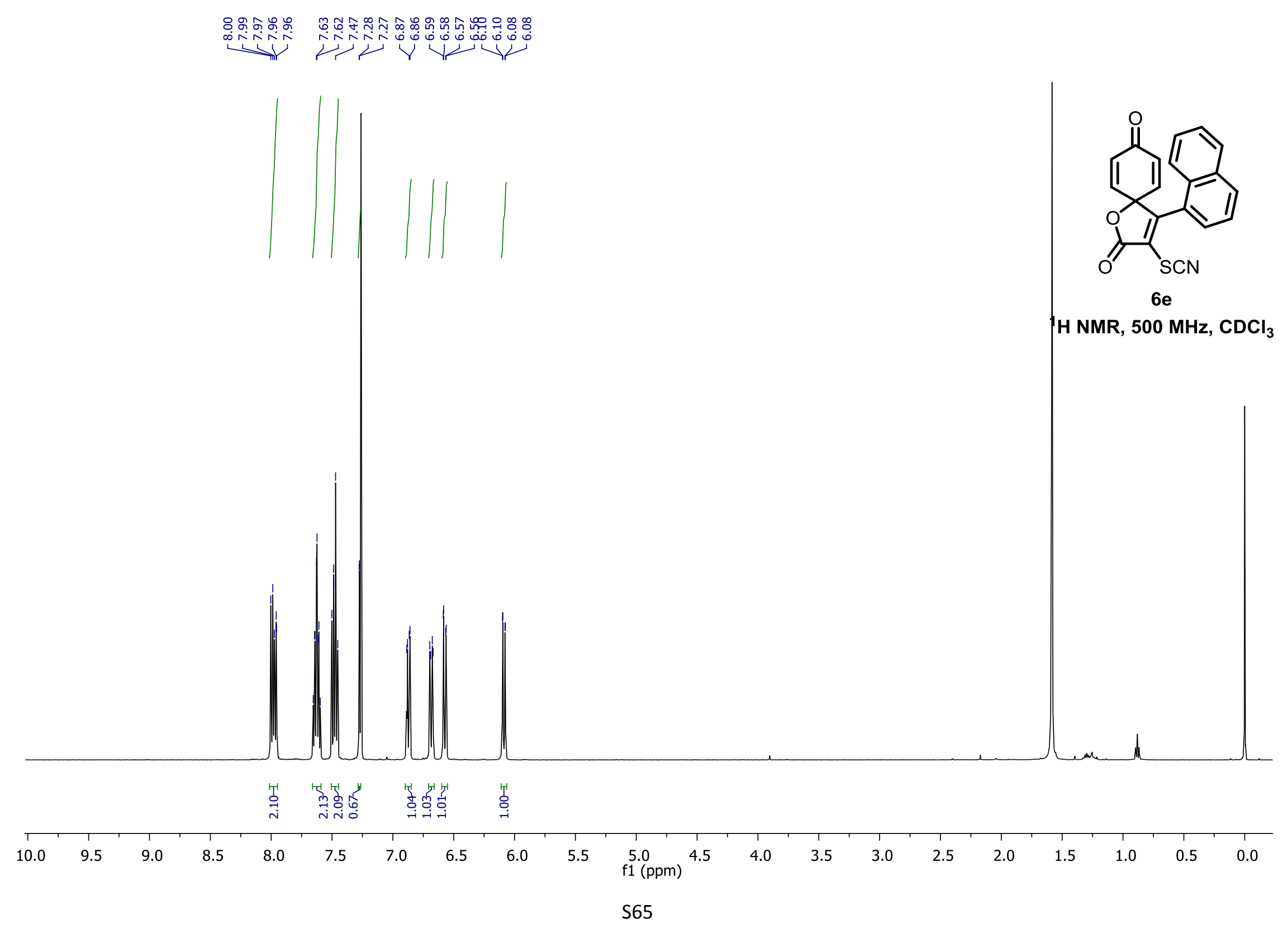




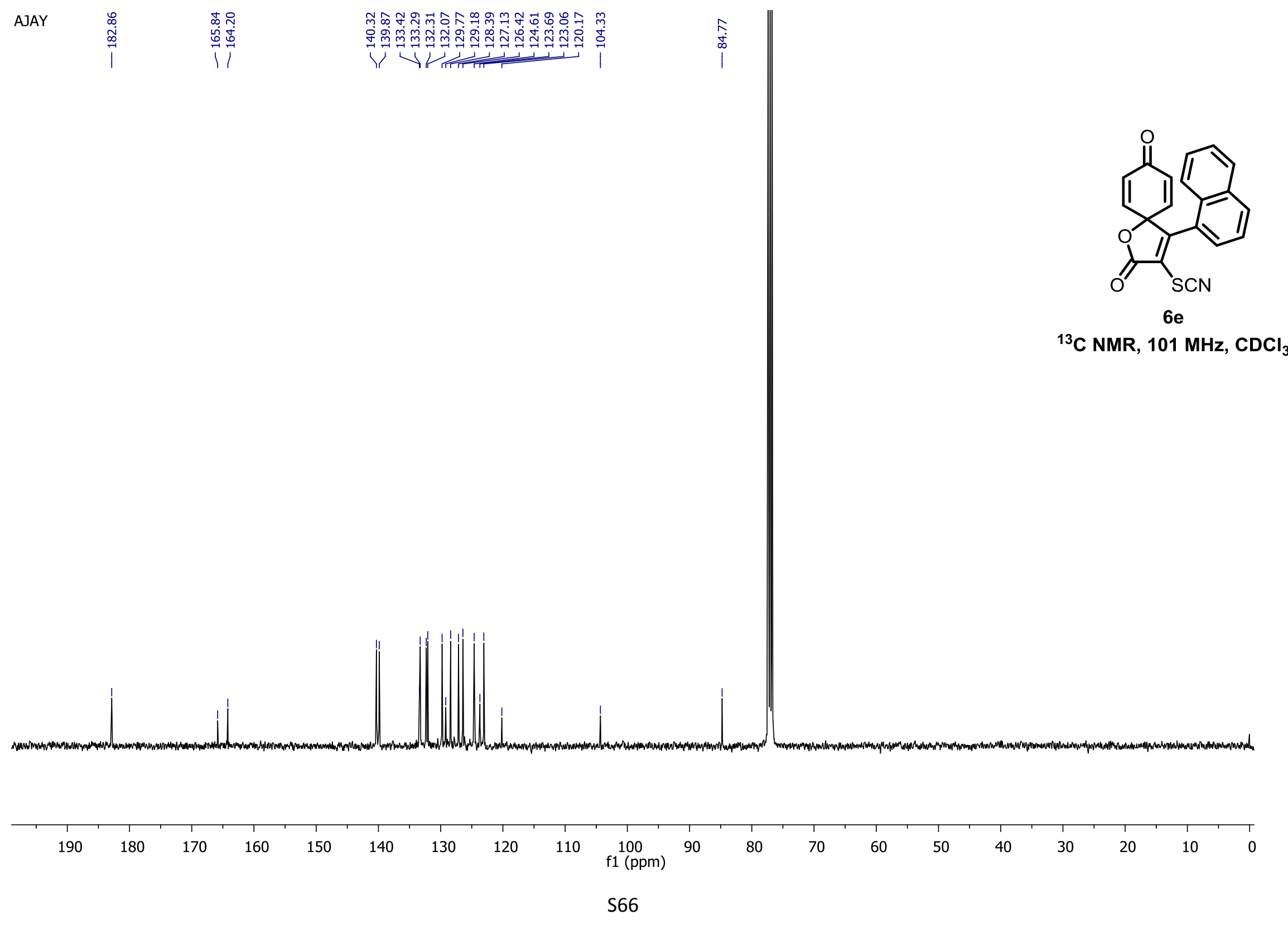




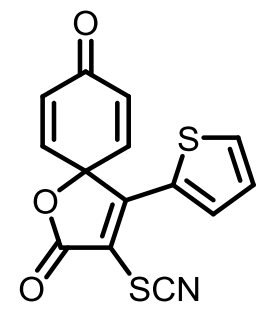

$6 f$

${ }^{1} \mathrm{H}$ NMR, $400 \mathrm{MHz}, \mathrm{CDCl}_{3}$

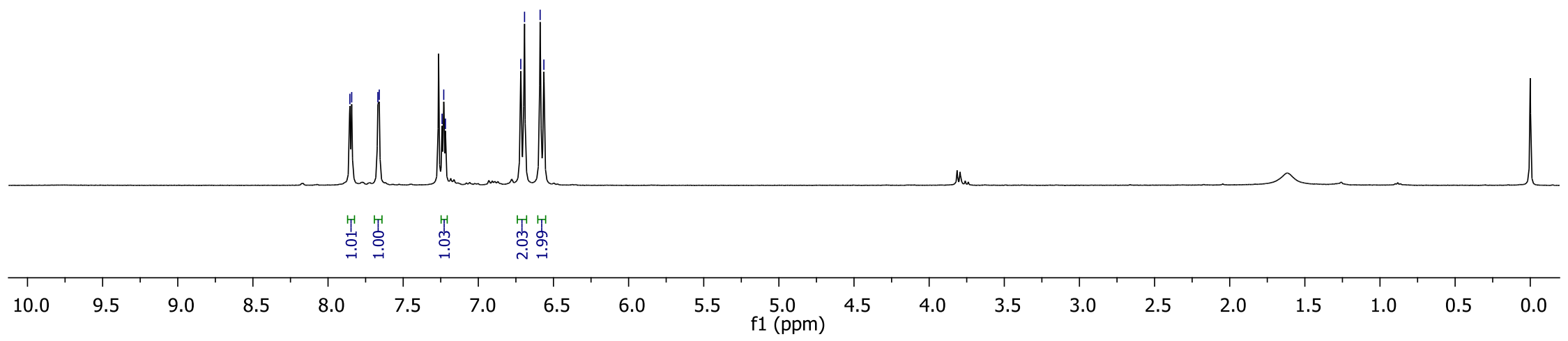




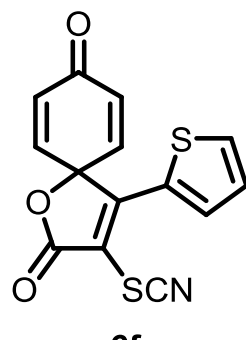

${ }^{13} \mathrm{C}$ NMR, $101 \mathrm{MHz}, \mathrm{CDCl}_{3}$

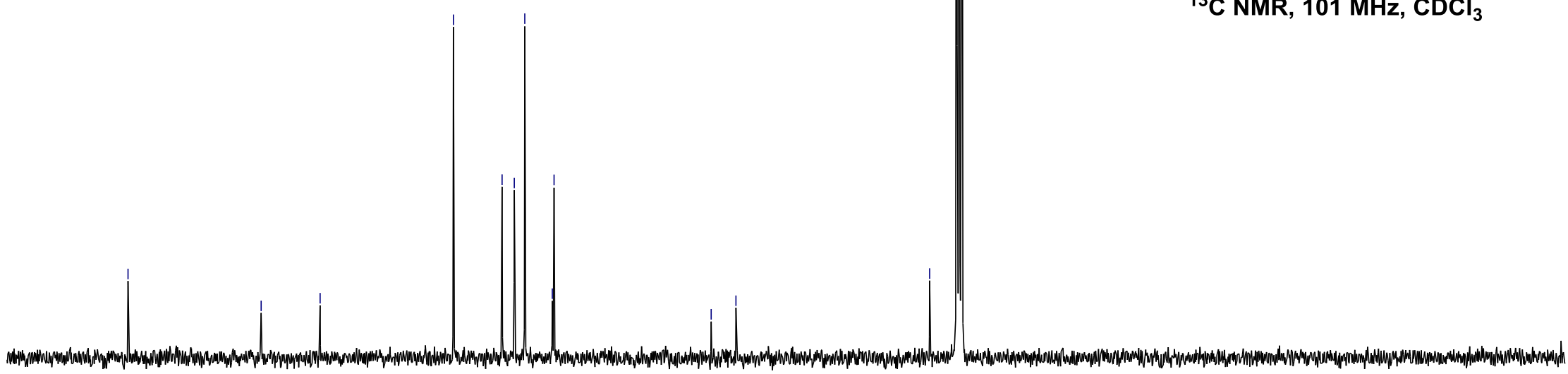

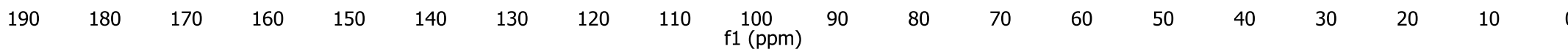




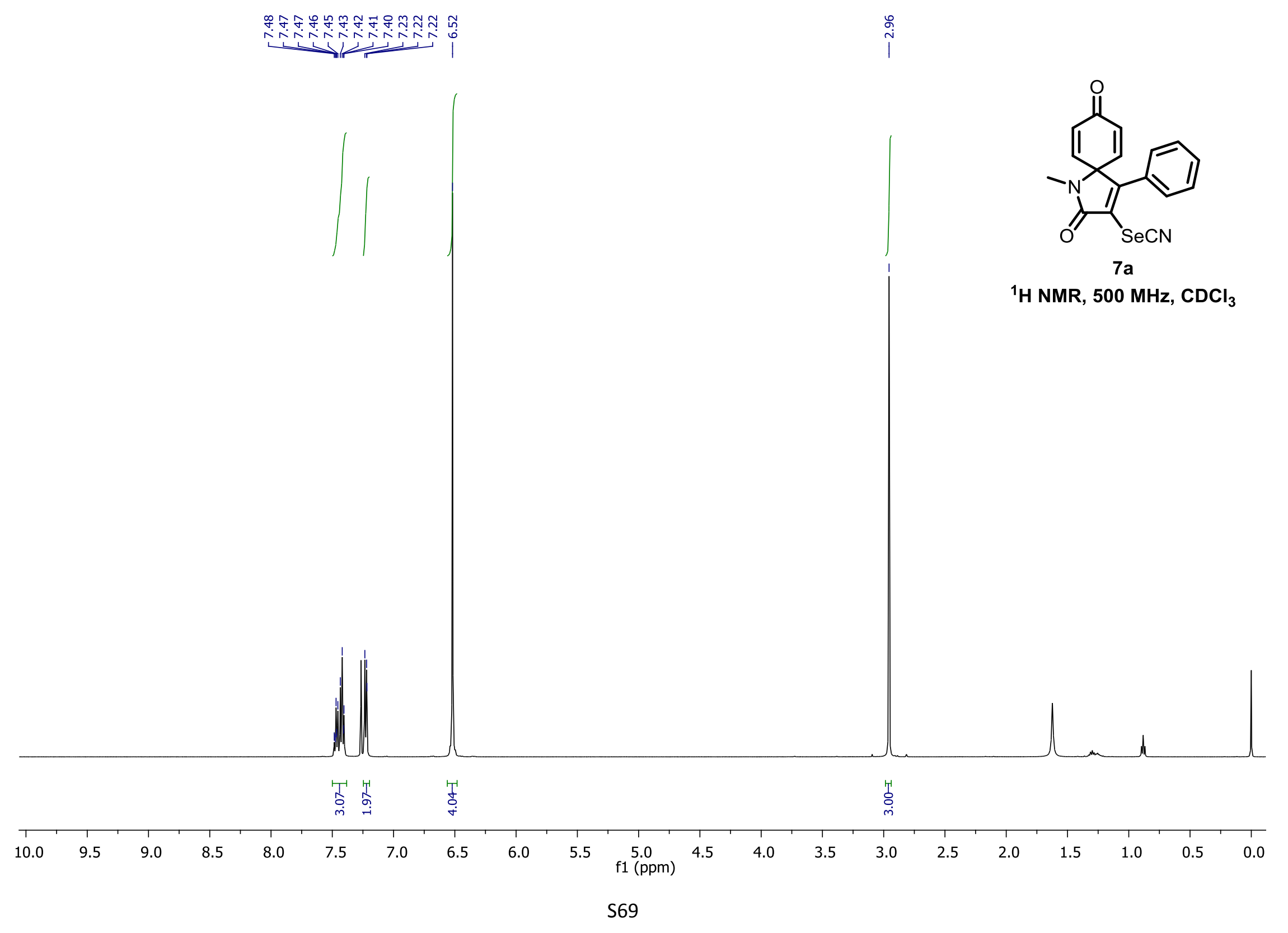




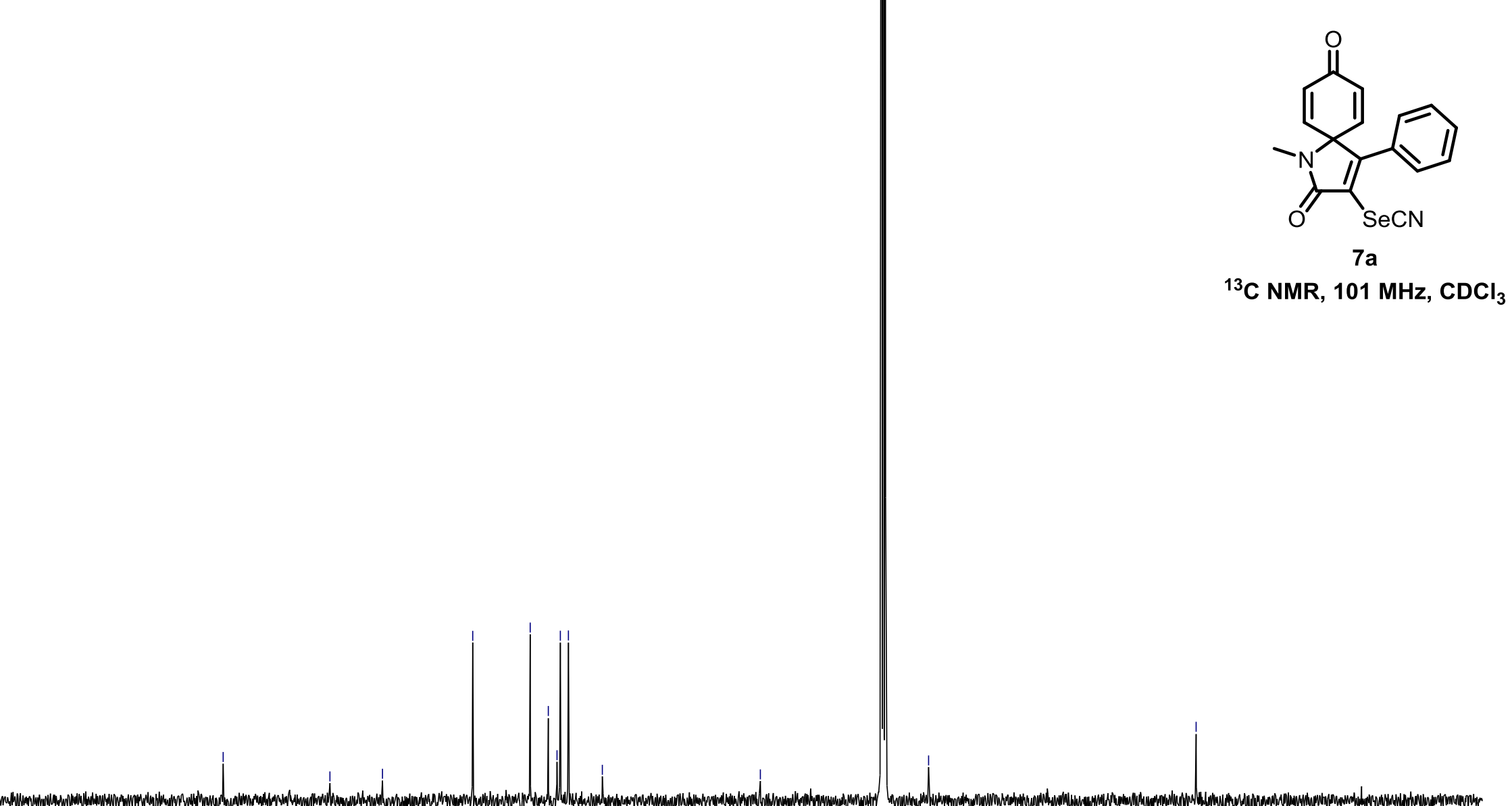

$\begin{array}{llllllllllll}210 & 200 & 190 & 180 & 170 & 160 & 150 & 140 & 130 & 120 & 110 & 100\end{array}$ f1 100 


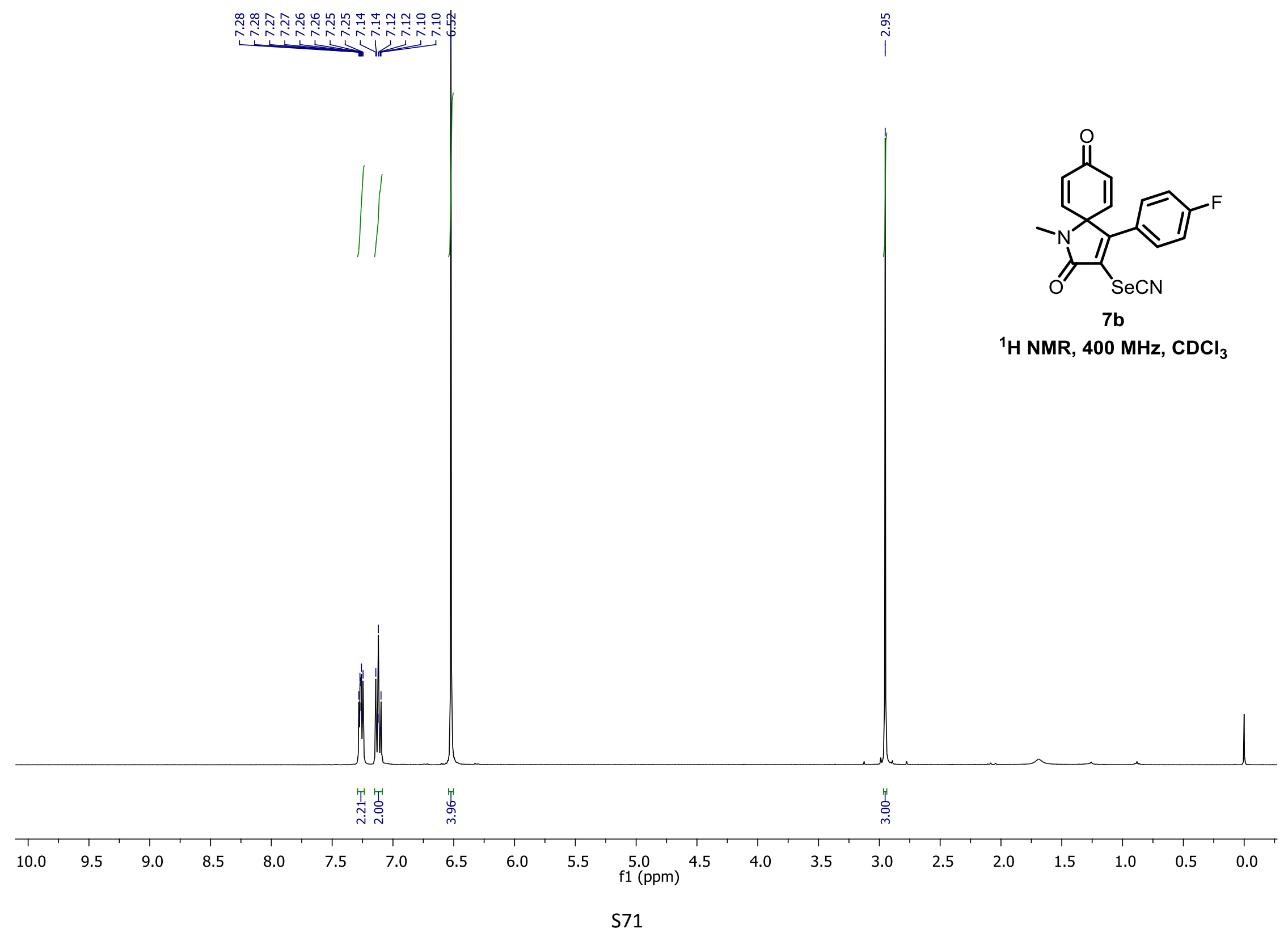



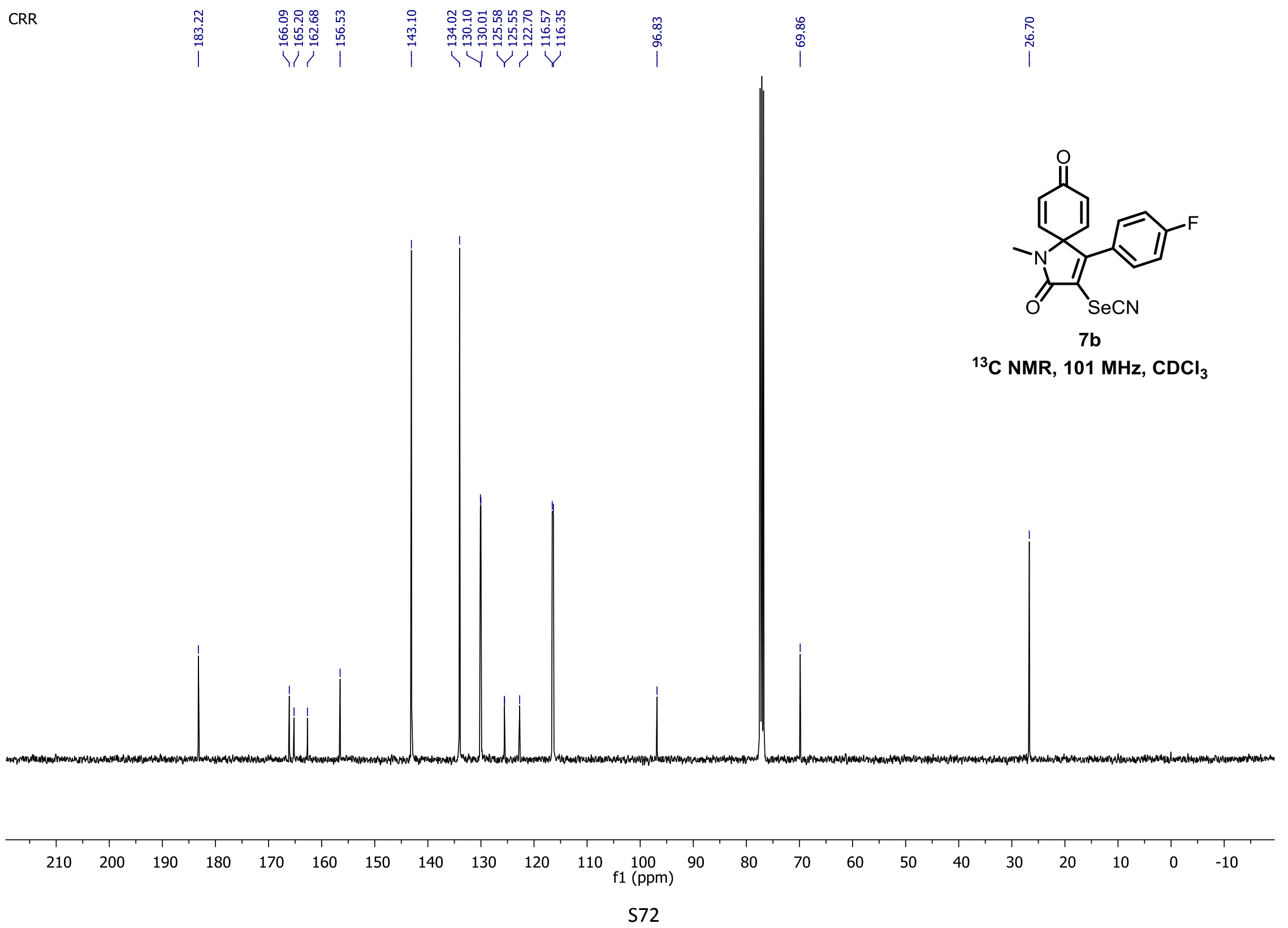


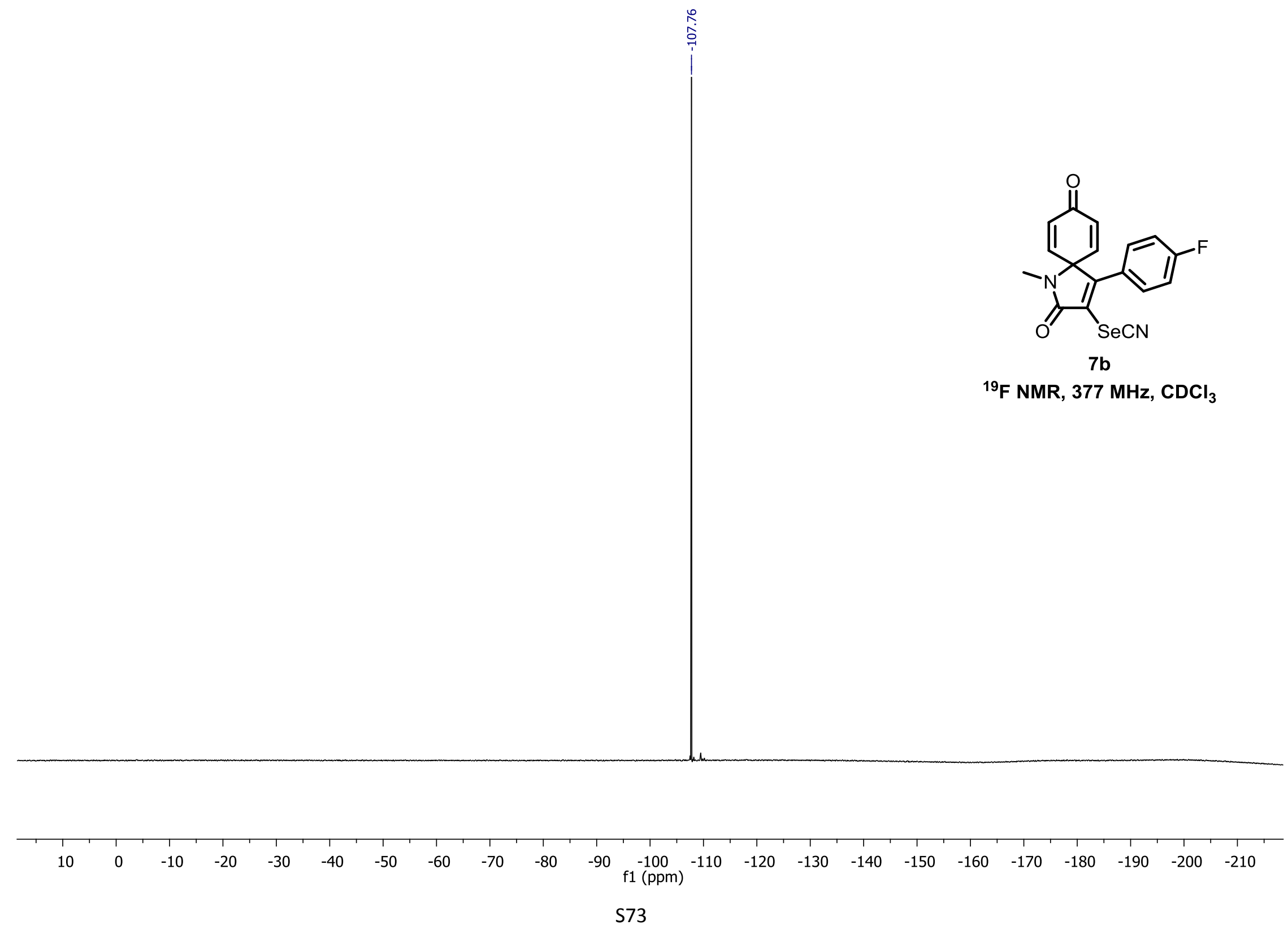




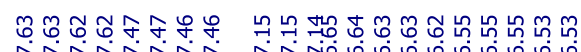

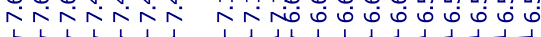
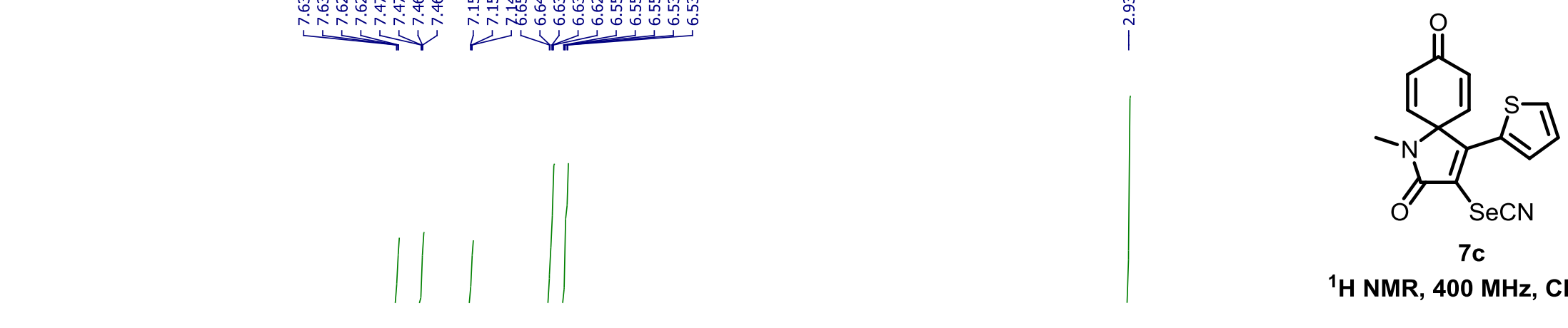

$7 c$

${ }^{1} \mathrm{H}$ NMR, $400 \mathrm{MHz}, \mathrm{CDCl}_{3}$

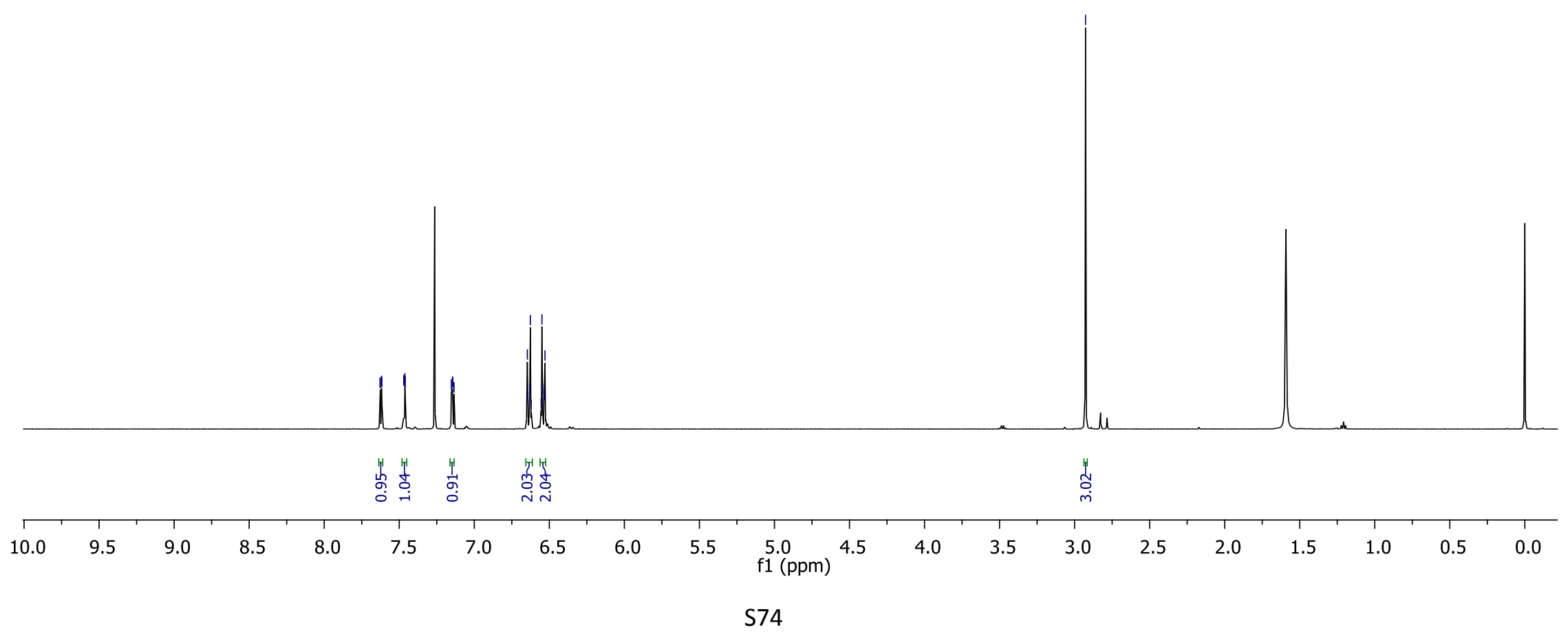




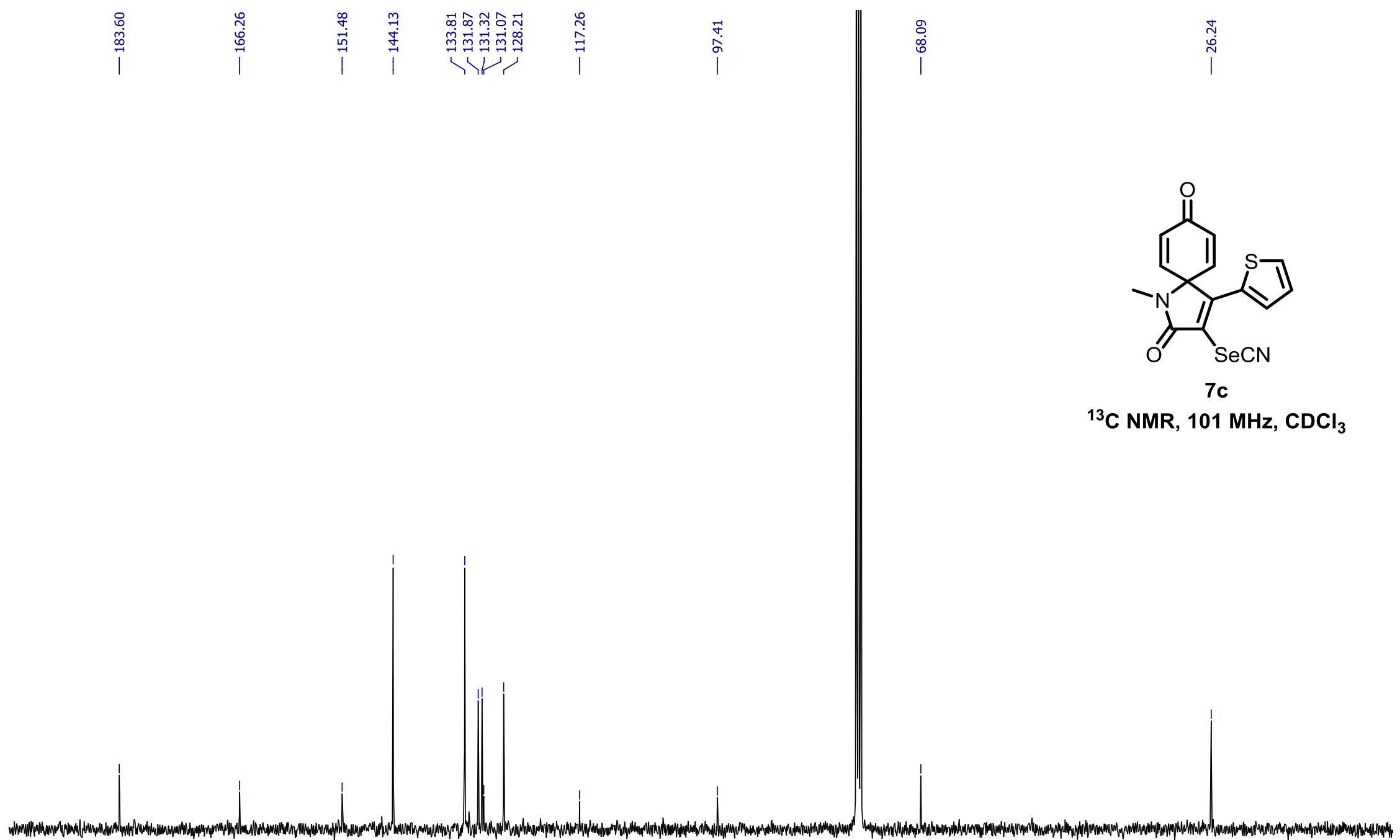

180

160

150

140

130

120

110

f1 100

90

80

70

60

50

40

30

20

10 


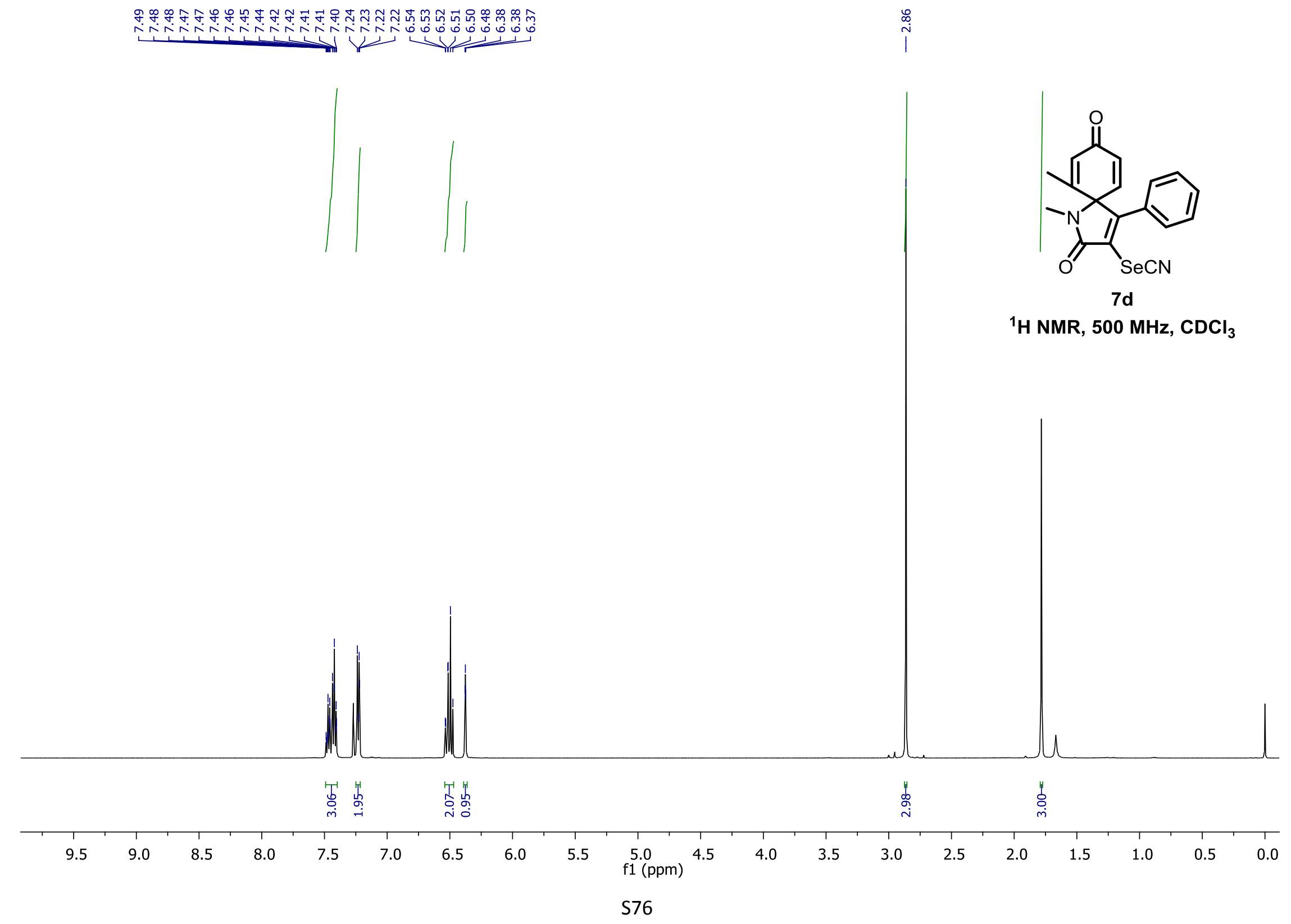



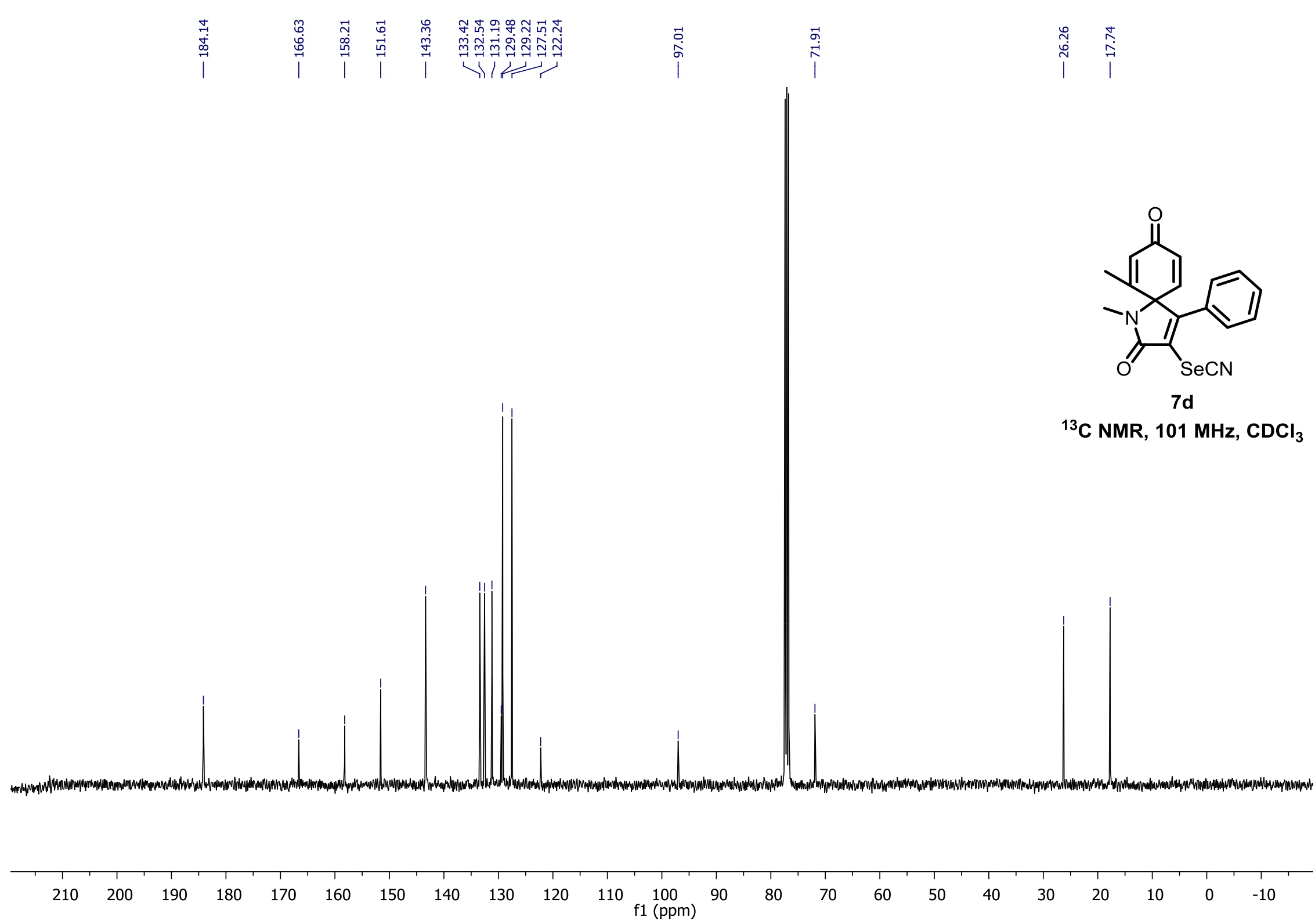

S77 


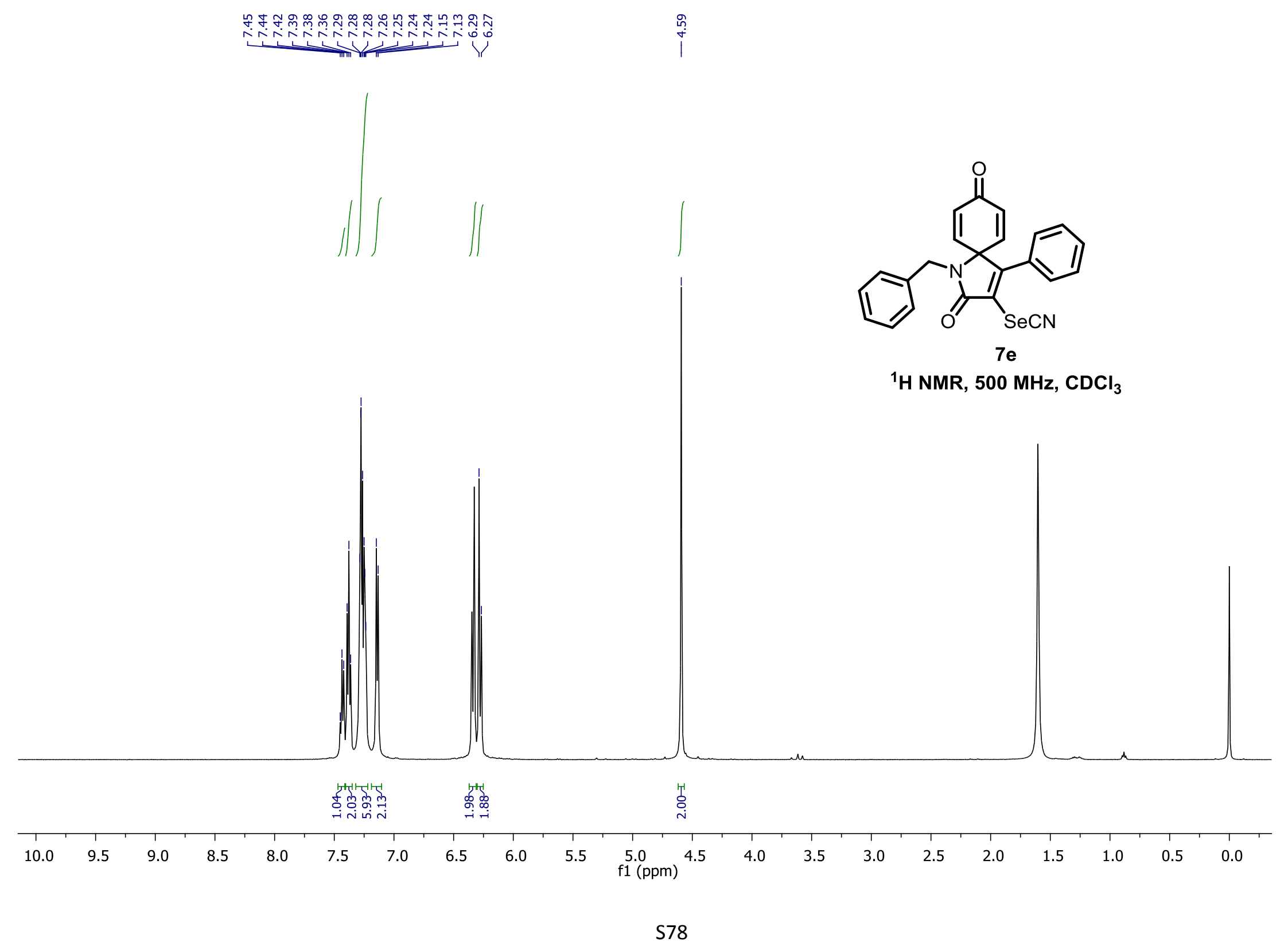


${ }^{13} \mathrm{C}$ NMR, $101 \mathrm{MHz}, \mathrm{CDCl}_{3}$

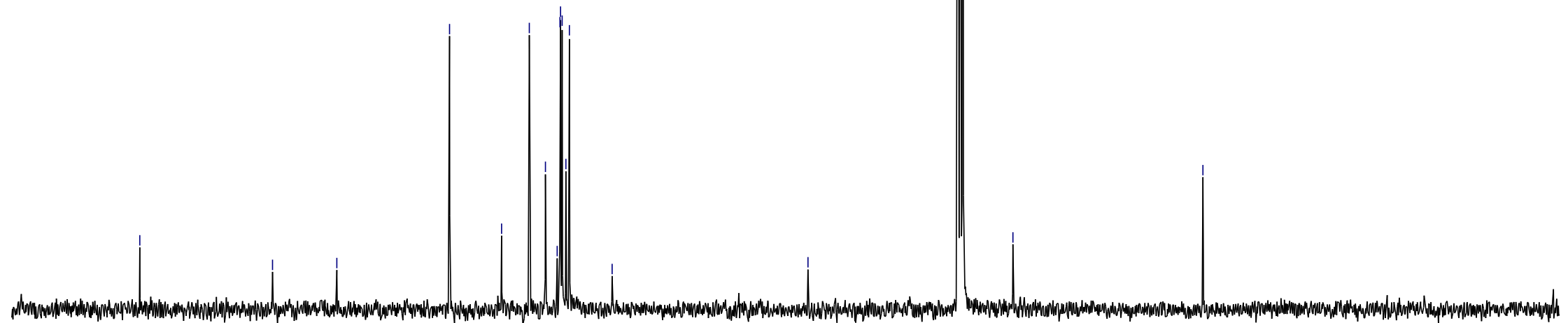




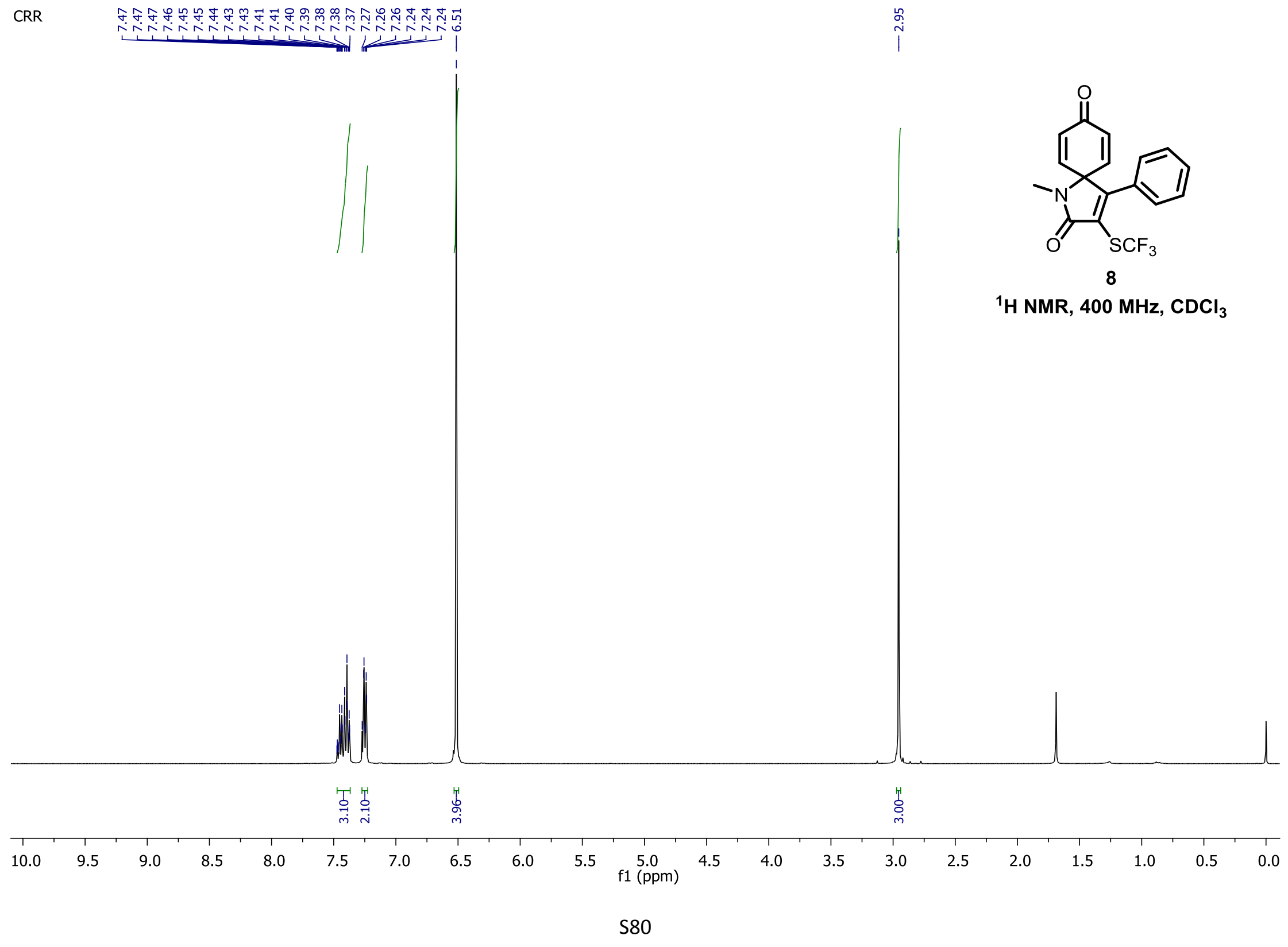




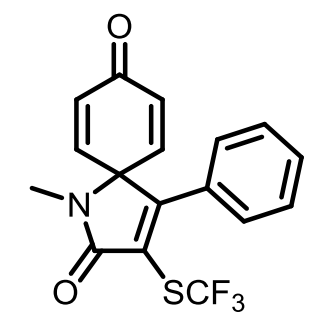

8

${ }^{13} \mathrm{C} \mathrm{NMR,}, 101 \mathrm{MHz}, \mathrm{CDCl}_{3}$

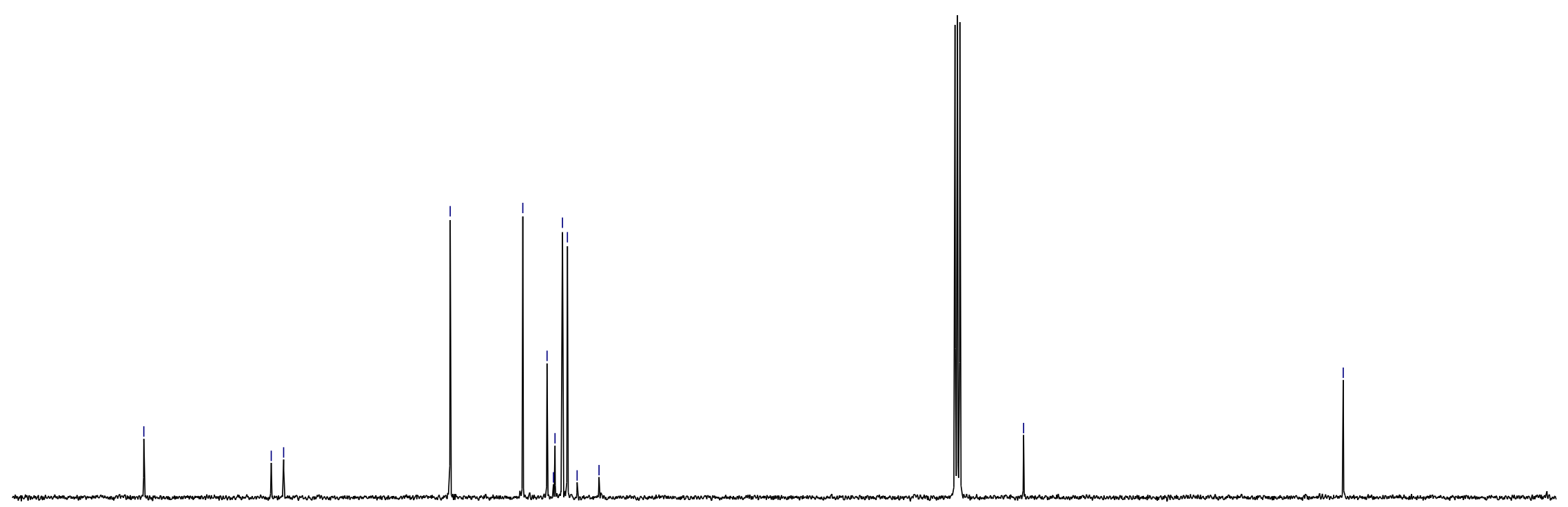




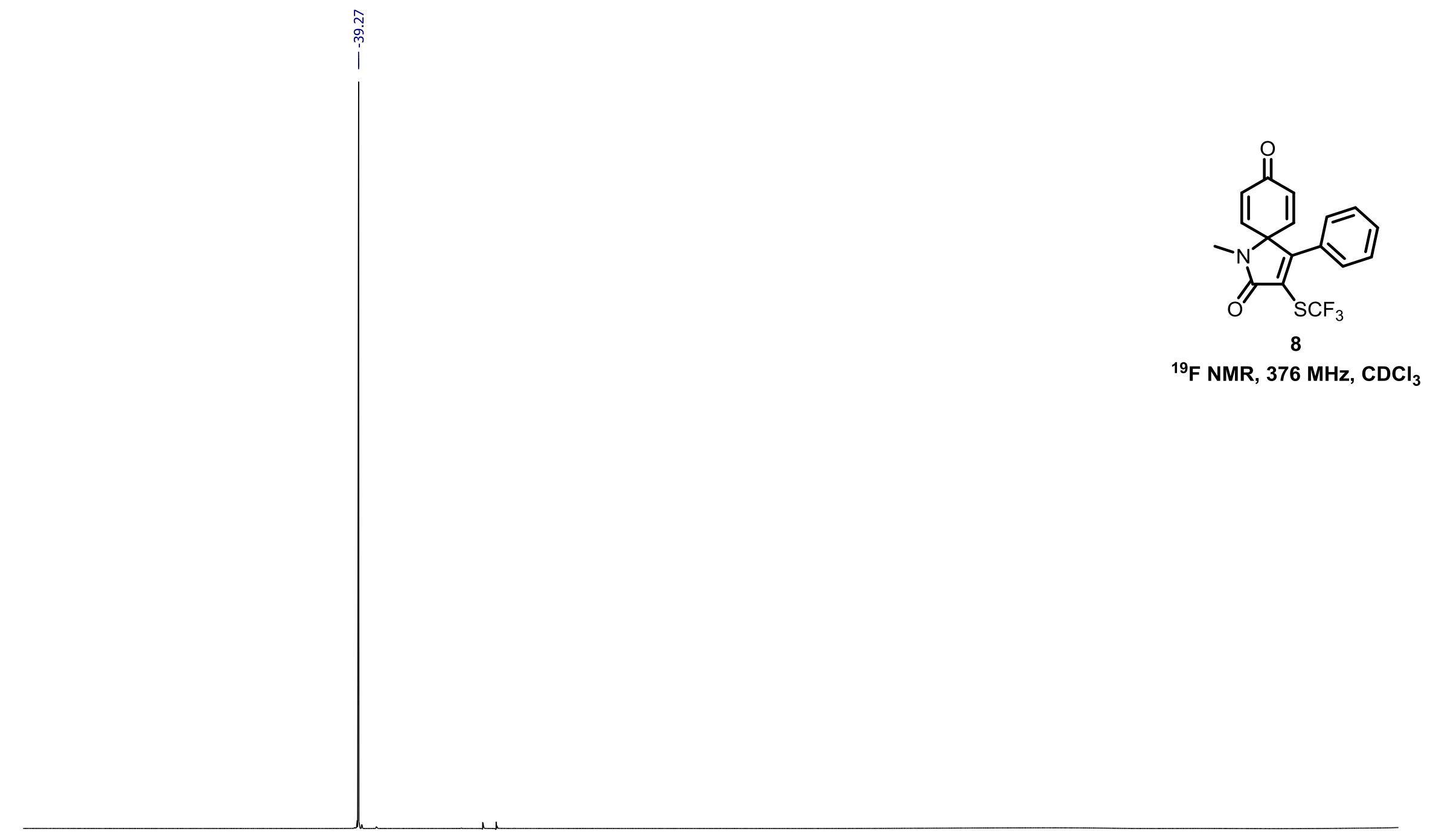

$\begin{array}{llllllllllllllllllllllllllllll}10 & 0 & -10 & -20 & -30 & -40 & -50 & -60 & -70 & -80 & -90 & -100 & -110 & -120 & -130 & -140 & -150 & -160 & -170 & -180 & -190 & -200 & -210 & \end{array}$ S82 


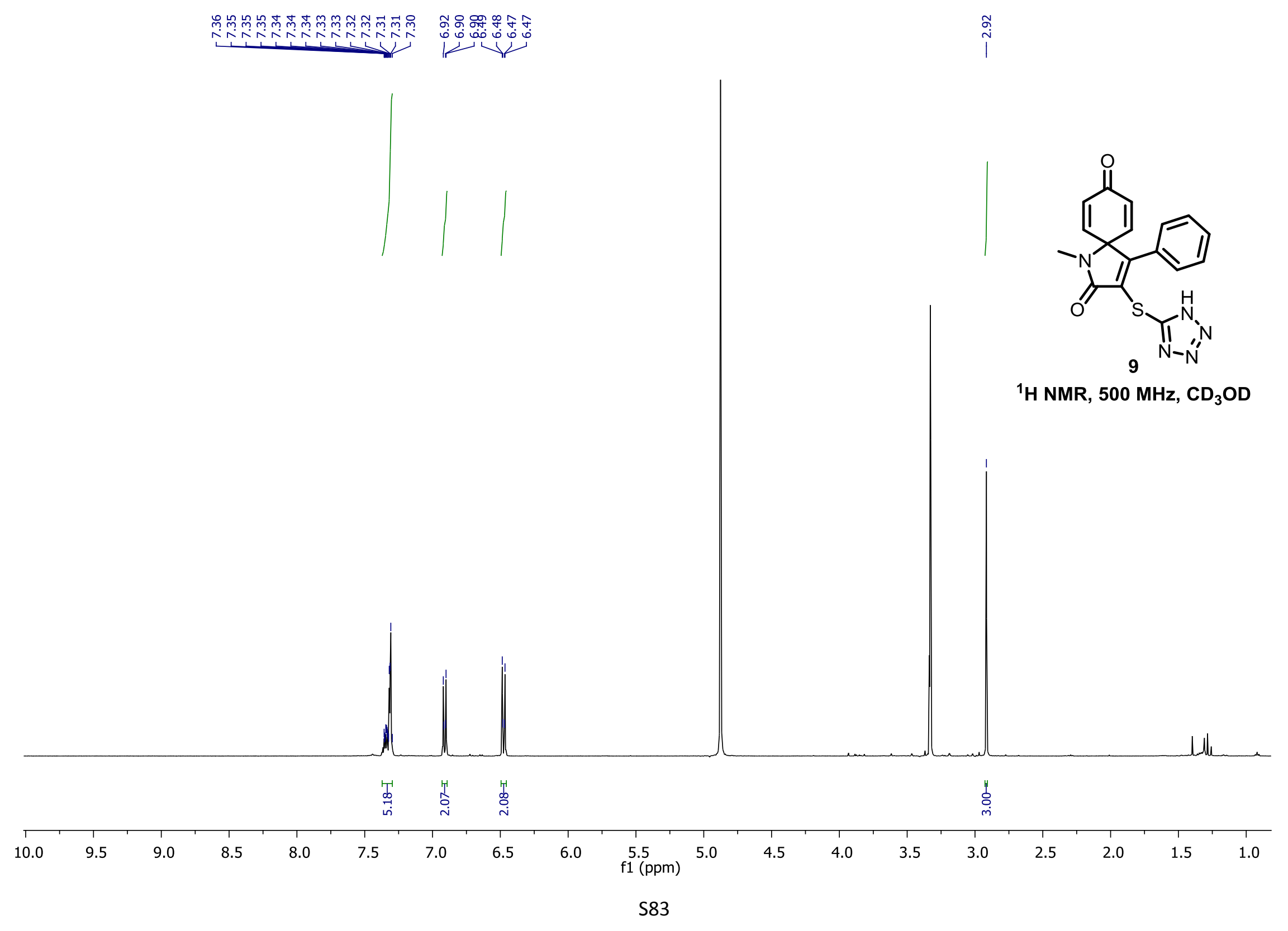




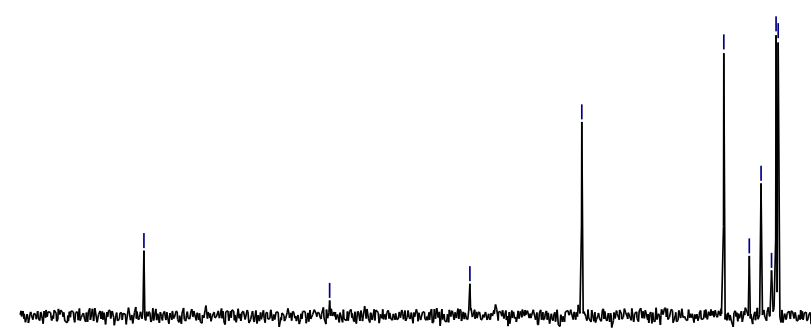




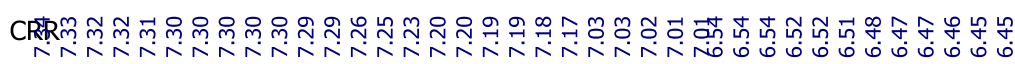

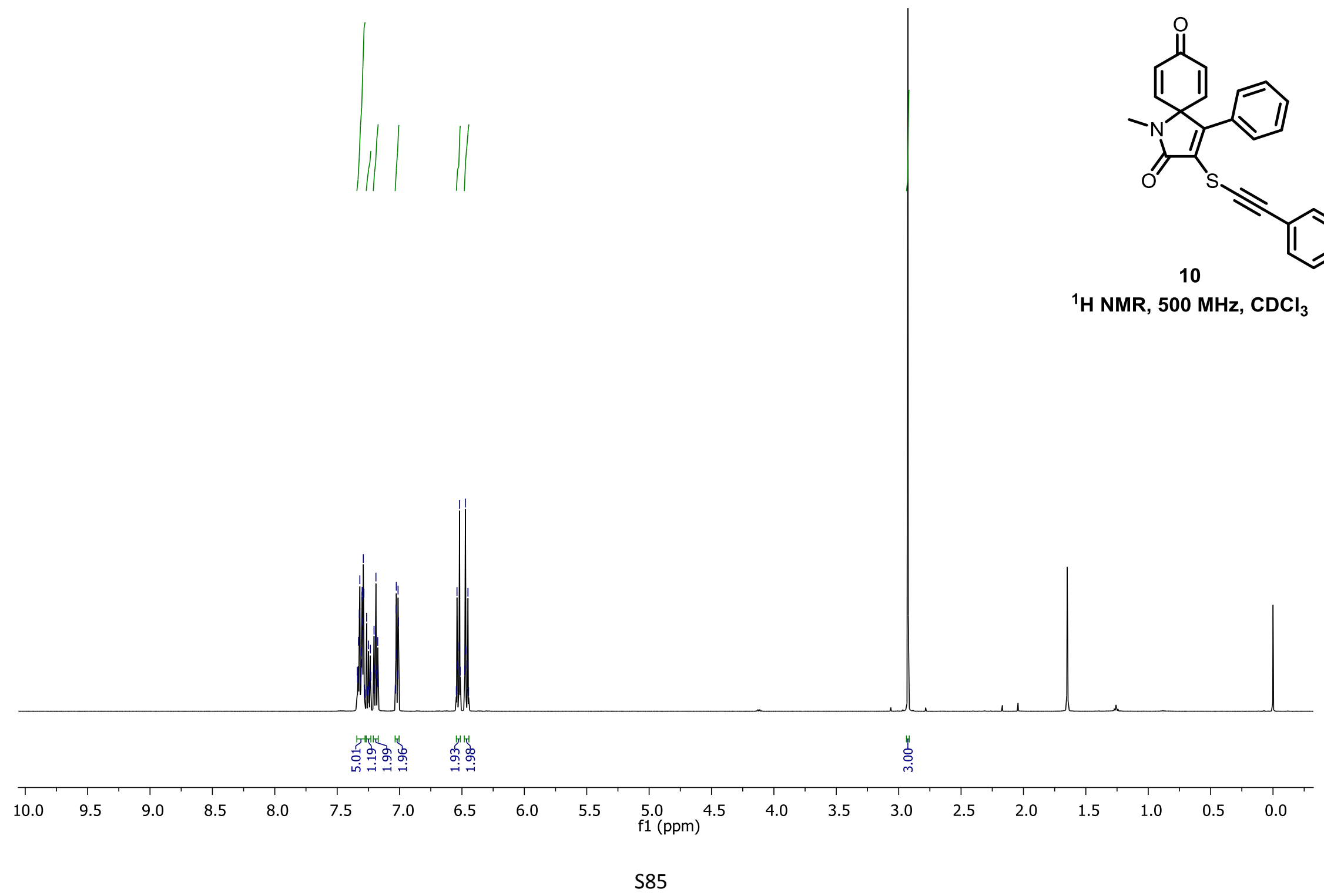




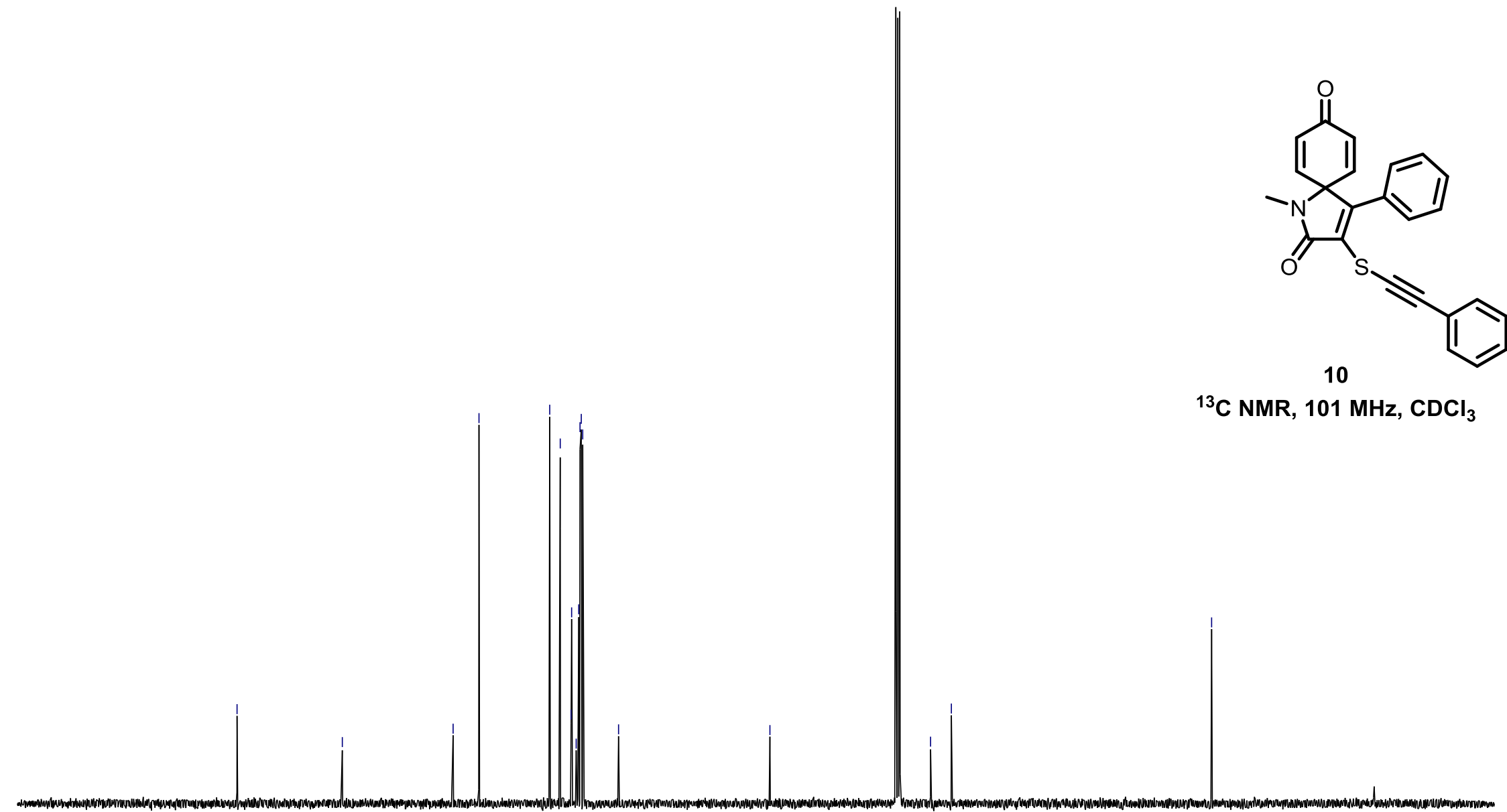

$\begin{array}{llllllllllll}210 & 200 & 190 & 180 & 170 & 160 & 150 & 140 & 130 & 120 & 110 & 100\end{array}$ 

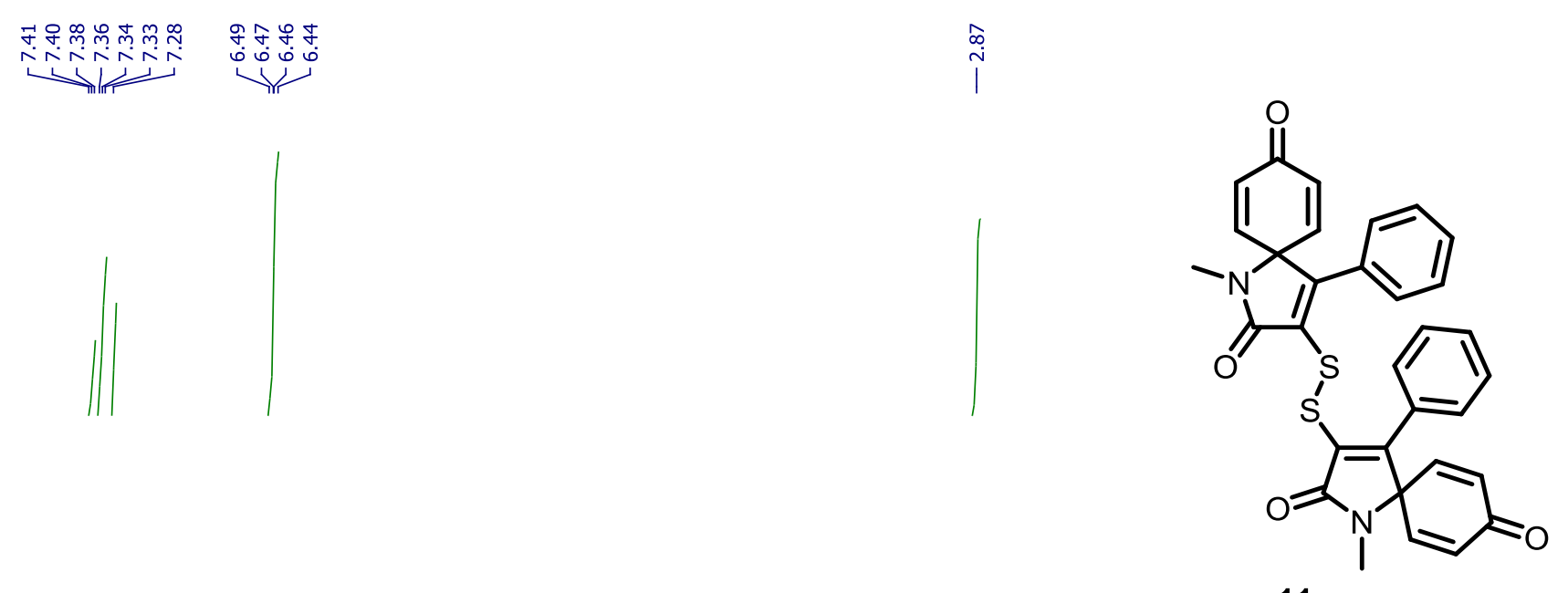

${ }^{1} \mathrm{H}$ NMR, $400 \mathrm{MHz}, \mathrm{CDCl}_{3}$

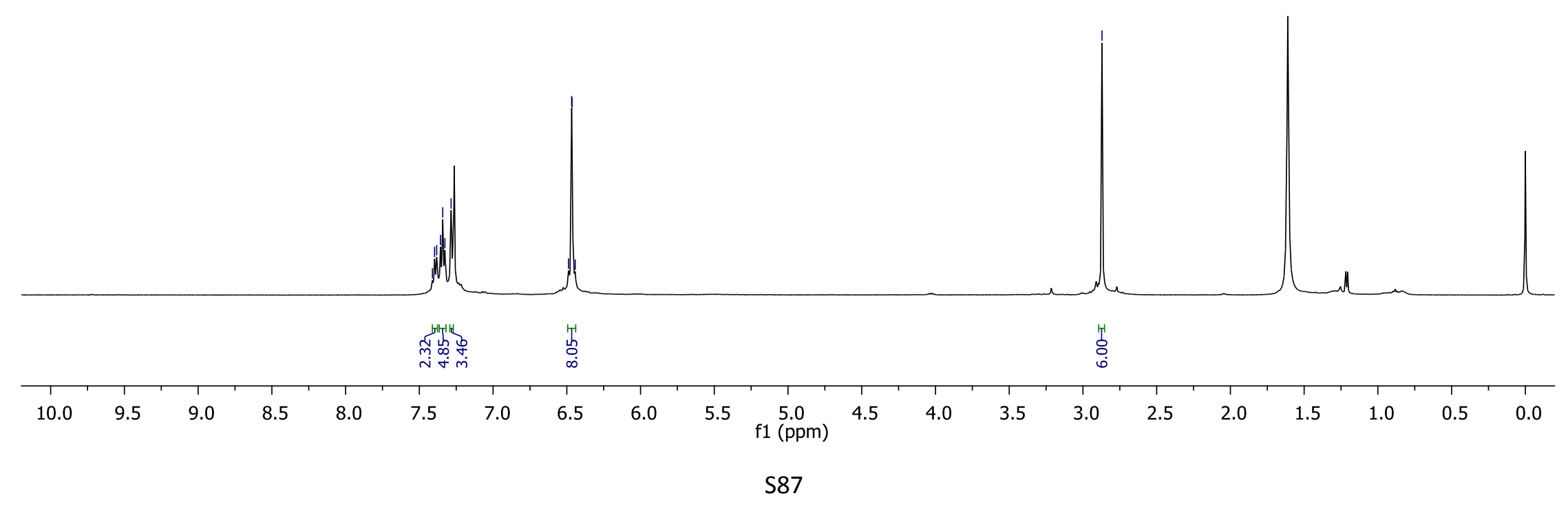




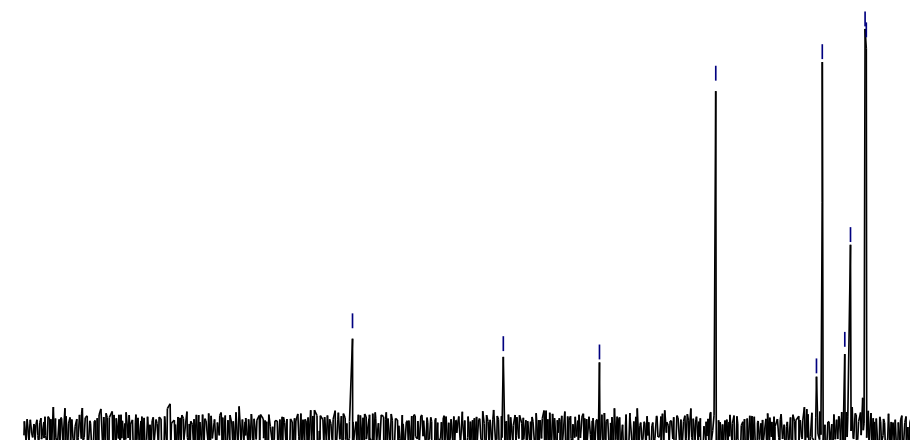

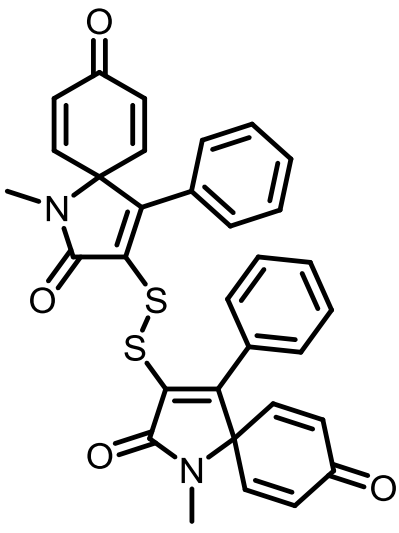

11

${ }^{13} \mathrm{C}$ NMR, $101 \mathrm{MHz}, \mathrm{CDCl}_{3}$ 


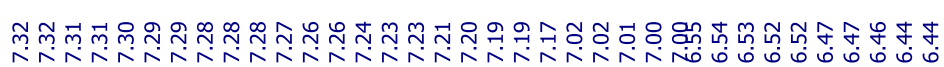
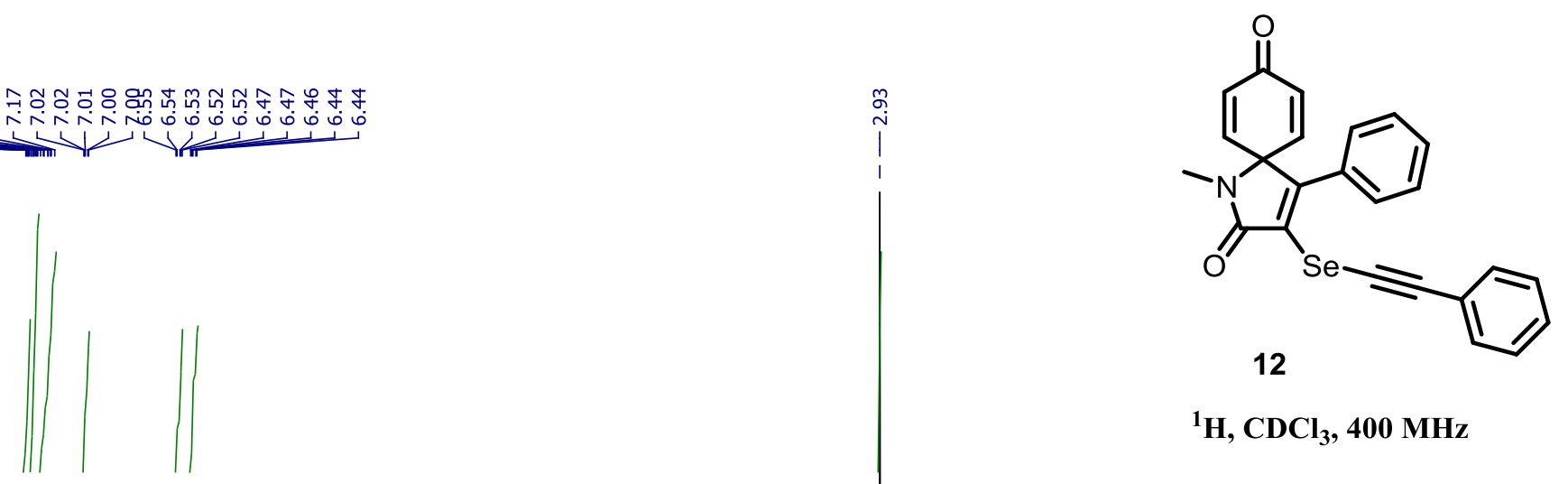

${ }^{1} \mathrm{H}, \mathrm{CDCl}_{3}, 400 \mathrm{MHz}$

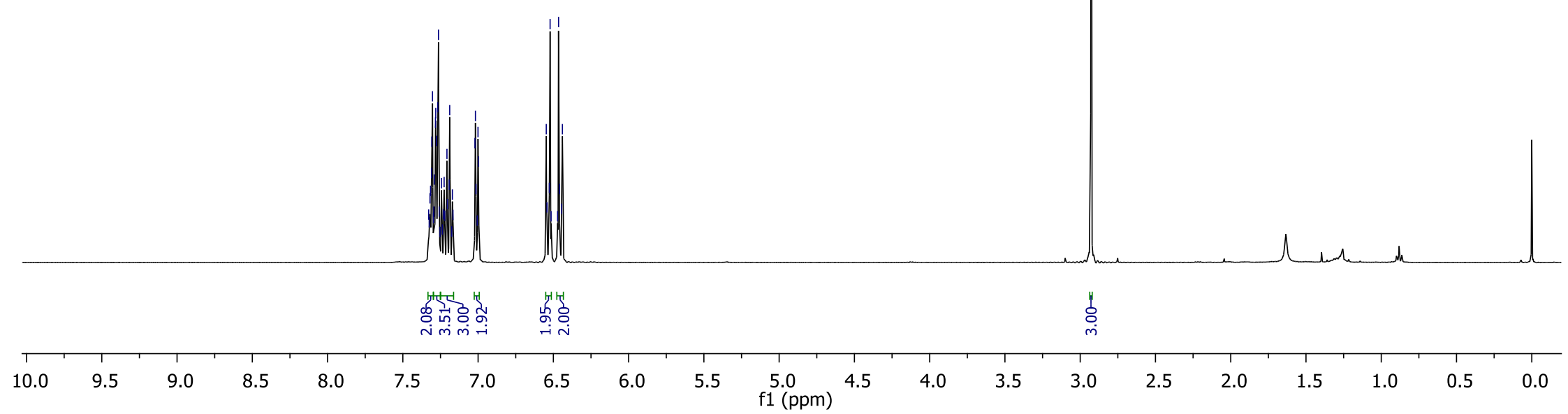




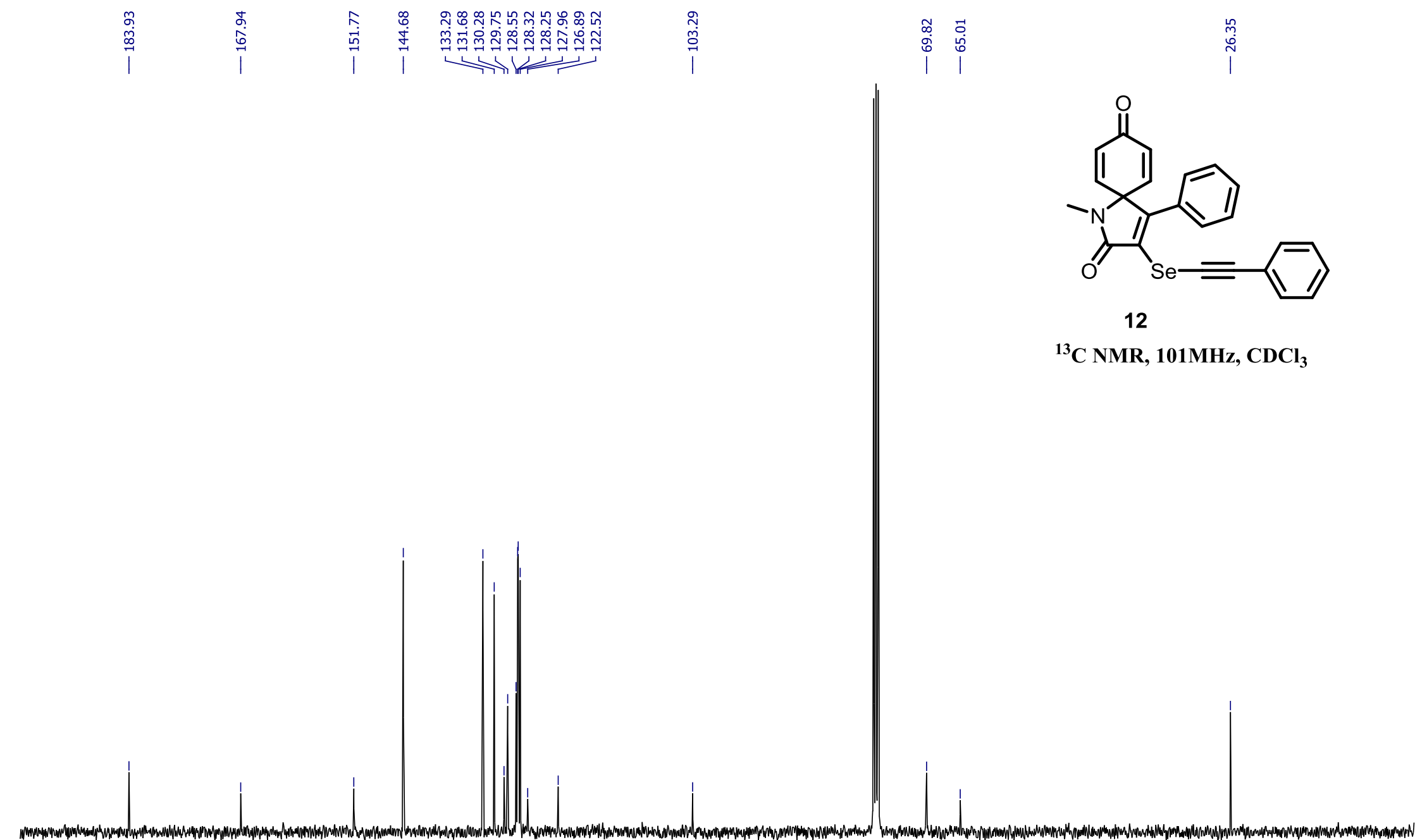

190 